\author{
Universidade de São Paulo \\ Instituto de Física
}

\title{
Estudo estrutural e termodifusivo das partículas de lipoproteína de baixa densidade - LDL
}

\author{
Luciene Oliveira Machado
}

Orientador: Prof. Dr. Antônio Martins Figueiredo Neto

Tese de doutorado apresentada ao Instituto de Física como requisito parcial para a obtenção do título de Doutor em Ciências.

Banca Examinadora:

Prof(a). Dr(a). Antônio Martins Figueiredo Neto (IFUSP)

Prof(a). Dr(a). Marcia Carvalho de Abreu Fantini (IFUSP)

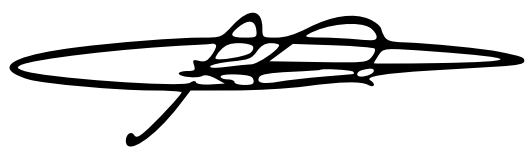

Prof(a). Dr(a). Alessandra Carvalho Goulart (HU USP)

Prof(a). Dr(a). Luiz Juliano Neto (UNIFESP)

Prof(a). Dr(a). Luciana de Oliveira Andrade (UFMG) 


\section{FICHA CATALOGRÁFICA \\ Preparada pelo Serviço de Biblioteca e Informação do Instituto de Física da Universidade de São Paulo}

Machado, Luciene Oliveira

Estudo estrutural e termodifusivo das partículas de lipoproteína de baixa densidade - LDL. São Paulo, 2021.

Tese (Doutorado) - Universidade de São Paulo. Instituto de Física. Depto. de Física experimental.

Orientador(a): Prof. Dr. Antônio Martins Figueiredo Neto

Área de Concentração: Física

Unitermos: 1. Lipoproteína de baixa densidade; 2 . Espalhamento de raios X a baixos ângulos; 3. Varredura-Z; 4. Termodifusão. 


\title{
University of São Paulo \\ Physics Institute
}

\section{Structural and thermodiffusion study of low- density lipoprotein particles - LDL}

\author{
Luciene Oliveira Machado
}

Supervisor: Prof. Dr. Antônio Martins Figueiredo Neto

Thesis submitted to the Physics Institute of the University of São Paulo in partial fulfillment of the requirements for the degree of Doctor of Science.

Examining Committee:

Prof(a). Dr(a). Antônio Martins Figueiredo Neto (IFUSP)

Prof(a). Dr(a). Marcia Carvalho de Abreu Fantini (IFUSP)

Prof(a). Dr(a). Alessandra Carvalho Goulart (HU USP)

Prof(a). Dr(a). Luiz Juliano Neto (UNIFESP)

Prof(a). Dr(a). Luciana de Oliveira Andrade (UFMG) 


\section{Agradecimentos}

Ao Prof. Dr. Antônio Martins Figueiredo Neto, pela oportunidade de integrar seu grupo e pela orientação.

Aos colegas do Grupo de Fluidos Complexos (GFCx).

Às nossas secretárias, Ellen e Juliana, pelo suporte administrativo.

À nossa eficiente e prestativa equipe de técnicos: Arnaldo, Dennys, Fernando e Igino. E ao Tárcis, pelo período em que nos auxiliou.

Ao Dr. André L. Sehnem por toda a ajuda, e por me introduzir ao universo da óptica nãolinear.

Ao Msc. Dennys Reis, pelos ensinamentos sobre SAXS, e por toda a ajuda no decorrer desses anos.

À Dra. Ana Paula de Queiroz Mello (FSP-USP), pelas colaborações e experiências compartilhadas.

Ao Programa de pós-graduação do Instituto de Física (IFUSP) e aos funcionários da secretária de pós-graduação.

À universidade de São Paulo (USP), por sua infraestrutura.

À COLSAN, pelo fornecimento das bolsas de plasma.

Às agências de fomento CNPQ e FAPESP, e ao INCT-FCx, pelo suporte financeiro.

À coordenação de Aperfeiçoamento de Pessoal de Nível Superior (CAPES) - projeto BioMol (no. proc. 23038.004630/2014-35), pela bolsa de estudos (no. proc. 88882.160174/2017-01). Aos amigos e familiares, quer perto ao à distância.

Agradeço a Deus, por esta oportunidade e por todas as experiências vividas nesse período. 


\section{"Trabalha e Confia"}

(Lema do estado do Espírito Santo inspirado em "Trabalha como se tudo dependesse de ti e confia como se tudo dependesse de Deus" - Inácio de Loyola)

"Feliz é quem acha a sabedoria; feliz é aquele que alcança o entendimento".

Provérbios 3:13 


\section{Resumo}

As doenças cardiovasculares estão, atualmente, entre as principais causas de morte em todo o mundo. A aterosclerose é uma dessas doenças cardiovasculares, sendo inflamatória, progressiva e caracterizada pelo acúmulo arterial de lipídios. A relação da lipoproteína de baixa densidade (LDL) com o desenvolvimento da aterosclerose já é conhecido, o que torna esta lipoproteína um importante objeto de estudo. A proposta do presente trabalho foi um estudo estrutural e termodifusivo das partículas de LDL. Foram empregadas no estudo as técnicas de varredura-Z (ZS), espectroscopia UV-vis, espalhamento dinâmico de luz (DLS) e espalhamento de raios X a baixos ângulos (SAXS). Os resultados estruturais indicaram haver alterações na distribuição da densidade eletrônica das partículas de LDL, em função do processo de oxidação induzido por íons $\mathrm{Cu}^{2+}$. Tais alterações, na estrutura da LDL, se mostraram dependentes da evolução temporal da oxidação in vitro. No que se refere à organização lipídica do núcleo da LDL, condição relacionada com a temperatura, os resultados sugeriram que, as alterações estruturais da partícula ocorrem independentemente desta organização. As variações, relacionadas à densidade eletrônica, foram também observadas no estudo in vivo, indicando mudanças na LDL em decorrência da ação de fármacos no organismo. Neste estudo, variações nos raios da partícula também foram observadas. Com relação aos estudos de termodifusão, o modelo de lente térmica generalizado, que permite a determinação do coeficiente Soret $\left(S_{T}\right)$ por meio da técnica de varredura-Z (ZS), aplicada em duas escalas de tempo, foi a abordagem adotada para o estudo das partículas de LDL. Esta se apresenta como uma nova possibilidade no estudo de lipoproteínas plasmáticas. As investigações, baseadas na indução dos fenômenos de lente térmica e lente de matéria em solução de nanopartículas, permitiu a determinação do $S_{T}$ para as partículas de LDL, em condições análogas às fisiológicas, considerando-se força iônica, $\mathrm{pH}$ e temperatura. Um estudo da termodifusão da LDL oxidada in vitro sugeriu uma dependência do $S_{T}$ com o estágio de oxidação da amostra, o que se sugere estar associado a variações de carga superficial da LDL oxidada.

Palavras-chave: lipoproteína de baixa densidade; LDL oxidada; espalhamento de raios X a baixos ângulos; varredura-Z; termodifusão 


\begin{abstract}
Cardiovascular diseases, such as atherosclerosis, are among the main causes of death around the world. Atherosclerosis is a systemic and inflammatory disease characterized by arterial accumulation of lipids. The role of low-density lipoprotein (LDL) in the atherosclerosis development is known and extensively studied. The proposal of this work was a structural and thermodiffusion study of LDL particles. The techniques of Z-scan (ZS), UVVis spectroscopy, dynamic light scattering (DLS) and small angle X-ray scattering (SAXS) were employed. Structural results showed changes in electron density distribution of LDL as a result of oxidative process induced by $\mathrm{Cu}^{2+}$ ions. These structural changes in LDL were dependent of temporal evolution of in vitro oxidation. Our results suggested that structural modification was not inhibited by temperature-dependent lipid arrangement of oxidized LDL core. An in vivo study also indicated changes in electron density distribution of LDL as a result of drugs action, and variations in particle radius were also observed. With regard to thermodiffusion LDL investigation, the generalization of the thermal lens model formalism using Z-scan technique to determine Soret coefficient $\left(S_{T}\right)$ was applied. This represents a new approach to studies of plasma lipoproteins. The investigations, based on thermal and matter lens in nanoparticles solution, allowed the determination of $S_{T}$ from LDL particles under physiological conditions as regards ionic strength, $\mathrm{pH}$ and temperature. The study also suggested a dependence of $S_{T}$ values to in vitro oxidized LDL on their oxidative stage, what can be thought to be associated with changes in surface charge of oxidized LDL.
\end{abstract}

Keywords: low-density lipoprotein; oxidized LDL; small angle X-ray scattering; Z-scan; thermodiffusion 


\section{Lista de Figuras}

Figura 1.1. Resultados mostrando a correlação positiva entre as absorbâncias a $484 \mathrm{~nm}$, relacionados aos conteúdos de antioxidantes nas partículas de LDL, e a amplitude do fenômeno de lente térmica $(\theta)[50]$.

Figura 2.1. Ilustração de um esquema simplificado do arranjo experimental de ZS e do resultado da transmitância normalizada em função da posição da amostra, para um experimento de ZS. Neste caso, o contraste óptico é negativo e o feixe incidente sobre a amostra é desfocalizado.

Figura 2.2. Ilustração das contribuições termoforética e termoelétrica para a termodifusão de nanopartículas dispersas em um meio iônico. A primeira dessas, é relacionada à energia armazenada na dupla camada, enquanto a segunda contribuição, resulta da ação do campo elétrico gerado com a migração dos íons, e que é dado em função do coeficiente Seebeck (S), por $\overrightarrow{\mathrm{E}}=\mathrm{S} \vec{\nabla} T . T$ e $T^{*}$ indicam temperaturas diferentes no meio. Figura adaptada de [58]......32

Figura 3.1 Esquema do arranjo óptico para a realização dos experimentos de ZS.

Figura 4.1. Resultados das análises dos dados de SAXS pelo método IFT, característicos para as partículas de LDL. (A) Curva de intensidade espalhada em função de q e (B) curva da função $p(r)$ para uma amostra de LDL, sem a indução da oxidação.

Figura 4.2. (A) Perfil da curva $p(r)$ para as partículas de LDL, obtida pelo método IFT (programa GNOM). Os números indicam as regiões associadas ao núcleo da partícula (1), aos hidrocarbonetos dos fosfolipídios (2) e às cabeças dos fosfolipídios e à ApoB-100 (3). A seta indica a dimensão máxima dos monômeros que, nesse caso, foi indicado como $245 \AA$. (B) Esquema ilustrativo de uma partícula de LDL indicando seus constituintes, cujas contribuições são associadas às regiões das curvas $p(r)$.

Figura 4.3. Curvas de espalhamento (A) e curvas das funções $p(r)(\mathrm{B})$ para as amostras de LDL nativa e oxidadas, nas condições que combinaram $\mathrm{C}$ e $\mathrm{t}$ de mesmo índice. (C) Esquema dos ensaios de oxidação in vitro da LDL: Cada linha corresponde a uma mesma concentrações de $\mathrm{CuSO}_{4}$ e tempos de reação variados. Cada coluna, a um mesmo tempo de reação e concentração de $\mathrm{CuSO}_{4}$ diferentes. Os quadros indicam as amostras cujos resultados são apresentados em (A) e (B). Em (A), os símbolos correspondem aos dados experimentais e, as linhas contínuas, aos ajustes pelo método IFT

Figura 4.4. A) Curvas de intensidades espalhadas, em função de q, para as análises da LDL oxidada in vitro. Os pontos representam os dados experimentais enquanto as curvas teóricas, para os ajustes pelo método IFT, são representadas pelas linhas. A região indicada por A corresponde aos indicativos de formação de oligômeros da LDL. As regiões indicadas por B sugerem alterações de densidade eletrônica no interior das partículas. B) Os valores de $I(q)$ foram multiplicados por um dado fator, para o deslocamento das curvas, possibilitando uma melhor visualização dos ajustes e do perfil característico dos dados de espalhamento das partículas de LDL. 
Figura 4.5. Curvas $p(r)$ para as análises da LDL oxidada in vitro, geradas pelo ajuste dos dados de espalhamento pelo método IFT. A região indicada por 'A' corresponde aos indicativos de formação de oligômeros da LDL. As regiões indicadas por ' $\mathrm{B}$ ' sugerem alterações de densidade eletrônica nas partículas.

Figura 4.6. (A) Esquema dos ensaios de oxidação e evolução temporal das curvas $I(q)$, indicando alterações estruturais da partícula e do estado oligomérico, nas amostras de LDL oxidada. Os símbolos correspondem aos dados experimentais e, as linhas contínuas, aos ajustes pelo método IFT. B) Os valores de $I(q)$ foram multiplicados por um dado fator, para o deslocamento das curvas, possibilitando uma melhor visualização dos ajustes e do perfil característico dos dados de espalhamento das partículas de LDL.

Figura 4.7. Evolução temporal das curvas $p(r)$, indicando alterações estruturais da partícula e do estado oligomérico, nas amostras de LDL, em decorrência da oxidação.

Figura 4.8. Variação dos valores dos máximos e do mínimo, característicos da $p(r)$ das partículas de LDL, em função do tempo de oxidação. Legenda. máx-1: valor do primeiro máximo da $p(r)$; mín-2: valor do mínimo da $p(r)$; máx-3: valor do segundo máximo da $p(r)$; os números 1, 2 e 3 fazem menção aos valores dos máximos e mínimos indicados na Figura 4.2 .

Figura 4.9. Exemplo de um resultado do processo de desacoplamento. Resultados da aplicação do método GIFT, pelo uso do programa WGIFT, para uma amostra de LDL oxidada. São mostradas as curvas para os fatores de forma $P(q)$ e de estrutura $S(q)$, e os dados experimentais analisados.

Figura 4.10. Resultados para caracterização dos agregados das partículas de LDL. (A) Ajuste das curvas $I(q)_{\text {olig }}$ pelo método IFT, sendo os dados teóricos de intensidades espalhadas representados pelos símbolos e as linhas contínuas, aos ajustes pelo método IFT. (B) Curvas $p(r)$ resultantes dos ajustes pelo IFT. (C) Modelos tridimensionais, obtidos por modelagem $a b$ initio, para os oligômeros formados pelos monômeros de LDL: a) LDL nativa, b) LDL oxidada $t_{1}$, c) LDL oxidada $t_{2}$, d) LDL oxidada $t_{3}$, e) LDL oxidada $t_{4}$

Figura 4.11. A) Evolução das curvas $I(q)$, em função da concentração do agente indutor da oxidação, indicando alterações estruturais e do estado oligomérico nas amostras de LDL. Os símbolos correspondem aos dados experimentais e, as linhas contínuas, aos ajustes pelo método IFT. B) Os valores de $I(q)$ foram multiplicados por um dado fator, para o deslocamento das curvas, possibilitando uma melhor visualização dos ajustes e do perfil característico dos dados de espalhamento das partículas de LDL.

Figura 4.12. Evolução das curvas $p(r)$, em função da concentração do agente indutor da oxidação, indicando alterações estruturais e do estado oligomérico nas amostras de LDL.....58

Figura 4.13. Variação dos valores dos máximos e do mínimo, característicos da $p(r)$ das partículas de LDL, em função da concentração do agente indutor da oxidação. Legenda. máx1: valor do primeiro máximo da $p(r)$; mín-2: valor do mínimo da $p(r)$; máx-3: valor do segundo máximo da $p(r)$; os números 1,2 e 3 fazem menção aos valores dos máximos e mínimos indicados na Figura 4.2. 
Figura 4.14. Resultados para caracterização dos agregados das partículas de LDL. (A) Ajuste das curvas $I(q)_{\text {olig }}$, pelo método IFT, sendo os dados teóricos de intensidades espalhadas representados pelos símbolos e as linhas contínuas, aos ajustes pelo método IFT. (B) Curvas $p(r)$ resultantes dos ajustes pelo IFT. (C) Modelos tridimensionais, obtidos por modelagem $a b$ initio, para os oligômeros formados pelos monômeros de LDL: a) LDL nativa, b) LDL oxidada $\mathrm{C}_{1}$, c) LDL oxidada $\mathrm{C}_{2}$, d) LDL oxidada $\mathrm{C}_{3}$, e) LDL oxidada $\mathrm{C}_{4}$.

Figura 4.15. Resultado do desacoplamento, empregando o método GIFT aos dados de espalhamento de uma amostra de LDL oxidada, mostrando as curvas para os fatores de forma $P(q)$ e os dados experimentais $I(q)$ sobrepostas.

Figura 4.16. Curvas de correlação $C(t)$, resultantes dos experimentos de DLS, para as amostras controle e oxidadas.

Figura 4.17. Redução do conteúdo de antioxidantes na LDL oxidada. Espectros de absorção para a amostra não oxidada (controle) e para as oxidadas, em três tempos de reação diferentes. $\mathrm{O}$ espectro de absorção resultante da análise da amostra oxidada por $7 \mathrm{~h}$ não é mostrado, pois o consumo de antioxidantes carotenoides foi total para esta amostra.

Figura 4.18. Curvas $p(r)$, obtidas com as análises pelo método IFT, para a amostra controle e as amostras oxidadas.

Figura 4.19. Valores de $|\mu|$, obtidos com a modelagem dos dados de SAXS, em função do tempo de oxidação da amostra de LDL.

Figura 4.20. Valores de $|\mu|$, obtidos com a modelagem dos dados de SAXS, em função do tempo de oxidação da amostra de LDL, em comparação com a amostra não oxidada.

Figura 4.21. Resultados estatísticos (Box-plot) para $R$ para as terapias antiplaquetárioestatina, ao início do tratamento $(\mathrm{T}=0)$ e após 6 meses de tratamento $(\mathrm{T}=6)$. Sinvastatina/ezetimida-Ticagrelor (SIMVA/E-TICA), Sinvastatina/ezetimida-Clopidogrel (SIMVA/E-CLOP), Rosuvastatina-Ticagrelor (RSV-TICA), Rosuvastatina-Clopidogrel (RSV-CLOP). (*:diferença significativa; $\mathrm{p}<0,05)$

Figura 4.22. Resultados estatísticos (Box-plot) para $|\mu|$ para as terapias antiplaquetárioestatina, ao início do tratamento $(\mathrm{T}=0)$ e após 6 meses de tratamento $(\mathrm{T}=6)$. Sinvastatina/ezetimida-Ticagrelor (SIMVA/E-TICA), Sinvastatina/ezetimida-Clopidogrel (SIMVA/E-CLOP), Rosuvastatina-Ticagrelor (RSV-TICA), Rosuvastatina-Clopidogrel (RSV-CLOP). (*:diferença significativa; $p<0,05)$

Figura 4.23. Espectros UV-vis para as amostras de LDL nativa, apresentando os valores de extinção em função dos comprimentos de onda, na faixa entre 200 e $800 \mathrm{~nm}$. Em (A) é mostrado o resultado para a amostra 1 e em (B) e o espectro para a amostra 2 .

Figura 4.24. Tratamento dos dados de espectroscopia UV-Vis para as amostras 1(A) e 2 (B). São mostrados os espectros de extinção, ajustes teóricos para a contribuição do espalhamento e espectros de absorção finais. Os espectros em (A) e (B) foram mantidos com a mesma escala. 
Figura 4.25. Espectros de absorção para comprimentos de onda entre 350 e $600 \mathrm{~nm}$, permitindo avaliar os níveis de antioxidantes carotenóides nas amostras de LDL. Os dados foram normalizados pela concentração de proteína nas amostras.

Figura 4.26. (A) Curva de correlação e (B) valores de intensidade relativa, normalizada por número, em função dos valores de diâmetros, para a amostra 1.

Figura 4.27. (A) Curva de correlação e (B) valores de intensidade relativa, normalizada por número, em função dos valores de diâmetros, para a amostra 2.

Figura 4.28. Resultado típico para a dependência temporal da $T_{N}$ em um experimento de LT com uma escolha adequada para o tempo de irradiação da amostra. A posição tomada é uma posição após o foco $(z>0)$. Em destaque, o treco da curva entre os instantes de 40 e $50 \mathrm{~ms}$, mostrando a estabilização da curva.

Figura 4.29. Resultado do experimento de LT para a amostra 1. Os símbolos representam os dados experimentais e as linhas são os ajustes teóricos.

Figura 4.30. Resultado do experimento de LT para a amostra 2. Os símbolos representam os dados experimentais e as linhas são os ajustes teóricos. 79

Figura 4.31. Resultados dos experimentos de LS, mostrando o comportamento termofóbico $\left(S_{T}>0\right)$ observado. A posição experimental foi $\mathrm{z}=7 \mathrm{~mm}$. Os símbolos representam os dados experimentais e as linhas correspondem aos ajustes teóricos.

Figura 4.32. Espectros de absorbância para as amostras de LDL nativa e oxidadas, mostrando a redução nos níveis dos antioxidantes carotenoides com o tempo de oxidação. .84

Figura 4.33. Resultados dos experimentos de LT para as amostras nativa e oxidadas. Os dados experimentais são mostrados pelos símbolos e as linhas correspondem aos ajustes teóricos..85

Figura 4.34. Resultados dos experimentos de LS para as duas amostras oxidadas. Os dados experimentais são mostrados pelos símbolos e as linhas correspondem aos ajustes teóricos..86

Figura 4.35. Dependência de $A_{c}$ (A) e do $S_{T}$ (B) com o tempo de oxidação, para os ensaio de oxidação in vitro da LDL. Nos dados para os quais as barras de incertezas não são visíveis, estas foram menores que o símbolo representativo do parâmetro. 


\section{Lista de Tabelas}

Tabela 3.1 - Reagentes e fornecedores.

Tabela 4.1. Valores de tempos e razões molares empregados nos ensaios de oxidação da LDL.

Tabela 4.2. Valores de densidade eletrônica para as moléculas que compõem as partículas de LDL (retirado de Muller et al, 1978 [79]). Valor determinado para a água: $334 \mathrm{e} / \mathrm{nm}^{3}$.

Tabela 4.3. Valores de raio hidrodinâmico médio $\left(R_{H}\right)$ para a amostra controle e as amostras oxidadas.

Tabela 4.4. Valores de raio médio $(R)$ retornados pela modelagem dos dados de SAXS para a amostra controle e as amostras oxidadas. As incertezas foram retornadas pela modelagem dos dados.

Tabela 4.5. Valores de tempo de reação e $|\mu|$, em relação ao fenômeno da cinética da oxidação. As incertezas foram retornadas pela modelagem dos dados.

Tabela 4.6. Valores das absorbâncias a $484 \mathrm{~nm}$, extraídos dos dados dos espectros de absorção e após normalização pela concentração das amostras ( $A_{484 \mathrm{~nm}}$ e $A_{c}$, respectivamente), para as amostras 1 e 2 .

Tabela 4.7. Comparação entre raios médios, determinados pelas análises de DLS, e os valores esperados. ${ }^{*}$ Valores esperados, com base na literatura

Tabela 4.8. Valores de $A_{484 n m}$ e $\theta_{L T}$, para as amostras 1 e 2 . Os valores de $A_{484 n m}$ e $\theta_{L T}$ não foram corrigidos por $\mathrm{c}$, representando exatamente a concentração das amostras empregadas nos ensaios realizados

Tabela 4.9. Valores de $\mathrm{S}_{\mathrm{T}}$ determinados e os parâmetros experimentais ou ajustados.

Tabela 4.10. Valores das absorbâncias a $484 \mathrm{~nm}\left(A_{484 \mathrm{~nm}}\right.$ e $\left.A_{c}\right)$ e de $S_{T}$, para as amostras 1 e 2 .

Tabela 4.11. Valores das absorbâncias a $484 \mathrm{~nm}$, para as amostras de LDL nativa e oxidadas durante dois tempos de reação distintos. Os valores mostram a redução dos níveis de antioxidantes em função da oxidação.

Tabela 4.12. Valores de $\mathrm{S}_{\mathrm{T}}$, parâmetros experimentais e ajustados, para os dois estudos termodifusivos. 


\section{Sumário}

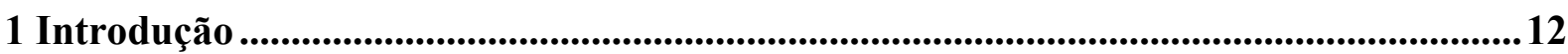

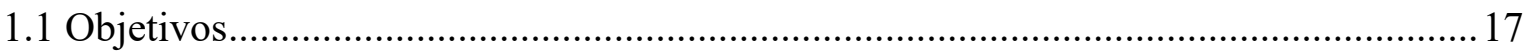

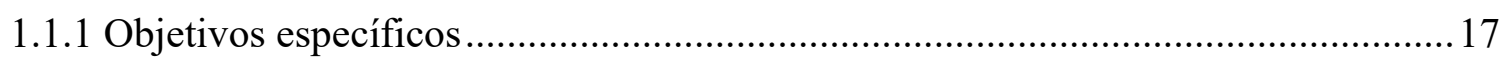

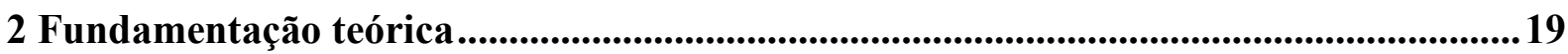

2.1 Espalhamento de raios X a baixos ângulos (SAXS).................................................... 19

2.1.1 Método da transformada de Fourier indireta (IFT) ...........................................20

2.1.2 Modelagem dos dados de intensidades espalhadas em função de q........................21

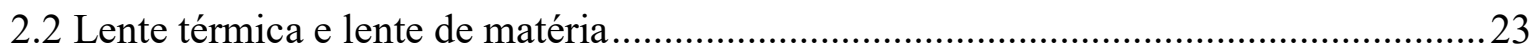

2.2.1 A técnica de varredura-Z (ZS) e o modelo da lente térmica (LT)..........................24

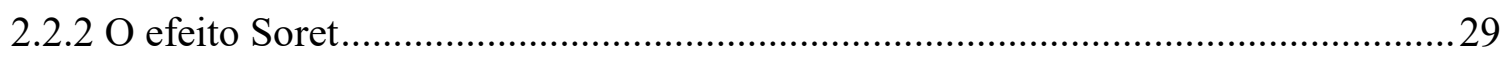

2.2.3 Origem do efeito Soret em nanopartículas carregadas ........................................ 31

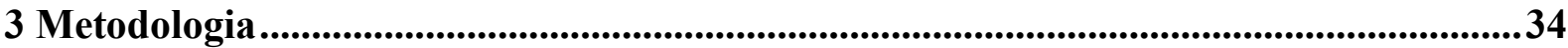

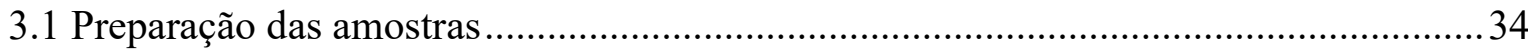

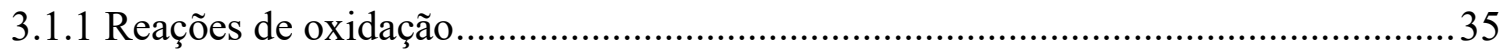

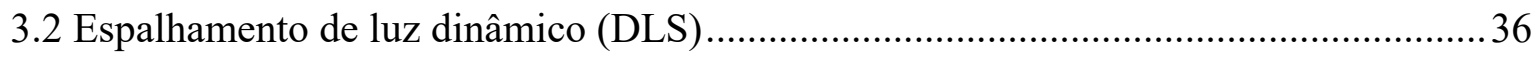

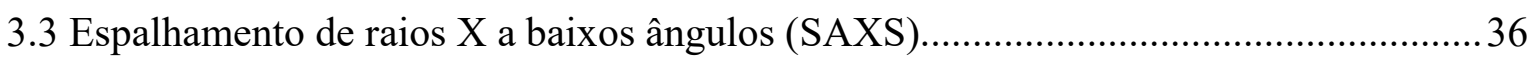

3.3.1 Coleta, integração e tratamento dos dados .............................................................. 36

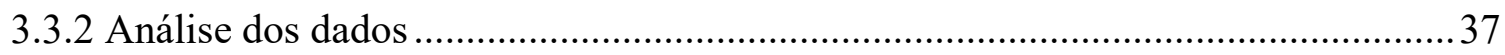

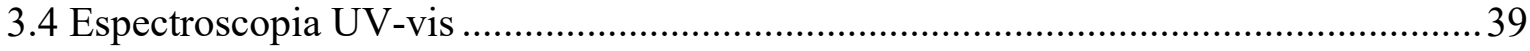

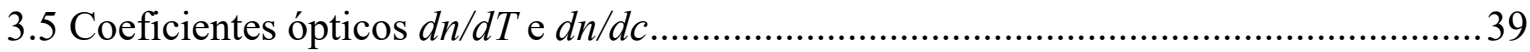

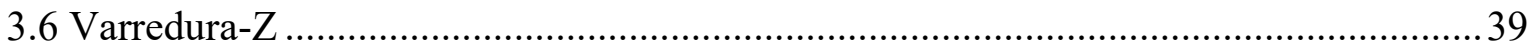

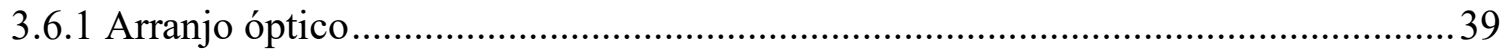

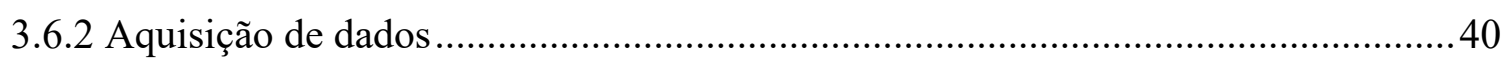

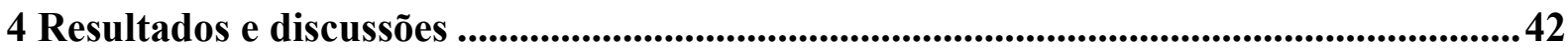

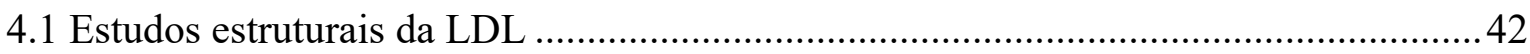

4.1.1 Avaliação dos efeitos do tempo de reação e da concentração do agente oxidante na

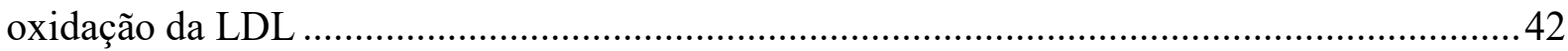

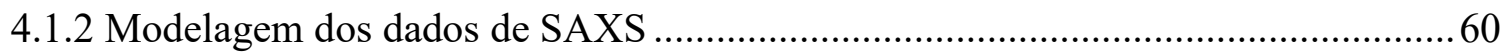

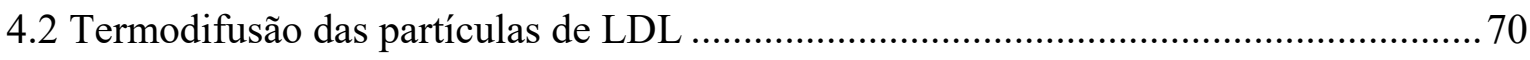

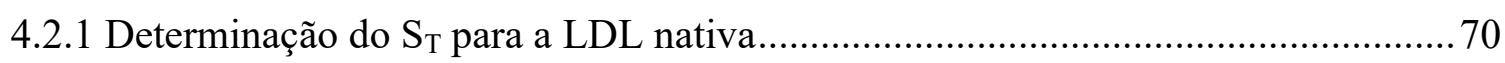


4.4.2 $\mathrm{S}_{\mathrm{T}}$ para a LDL oxidada in vitro: Influência dos níveis de oxidação da LDL 84

5 Conclusões e Perspectivas

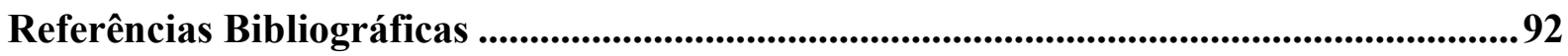

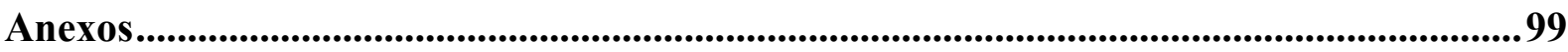




\section{Introdução}

As doenças cardiovasculares estão entre as principais causas de morte em todo o mundo $[1,2,3]$. A aterosclerose é uma doença cardiovascular, que contribui para esse elevado número de mortes, acarretando também internações e estados de morbidez. Trata-se de uma doença inflamatória e progressiva cuja manifestação se dá com a deposição de lipídios, dentre eles o colesterol, nas paredes internas das artérias do indivíduo, ocasionando o surgimento das chamadas placas ateroscleróticas, podendo levar à redução da luz desses vasos sanguíneos e consequente comprometimento da irrigação de tecidos [4]. A elevação das taxas de colesterol no sangue é um dos fatores de risco para o surgimento e progressão da aterosclerose $[5,6]$.

O colesterol, essencial para os organismos animais, é um esterol constituinte das membranas celulares e é o precursor dos ácidos biliares, da vitamina $\mathrm{D}$ e dos hormônios esteroides [7, 8]. Os lipídios, tais como o colesterol, são insolúveis em água e, por esta razão, seu transporte no organismo só é possível pela ligação a lipoproteínas plasmáticas [8]. O transporte de colesterol para tecidos periféricos é realizado por uma classe de lipoproteínas plasmáticas, denominadas lipoproteínas de baixa densidade (LDL, do Inglês Low Density Lipoprotein), e já é sabido que elevadas taxas de colesterol associado à LDL (LDL-C) contribuem para o desenvolvimento da aterosclerose $[6,9]$. Além da relação entre as alterações das taxas lipídicas no plasma de indivíduos e o acometimento pela aterosclerose, já foi demonstrado que o processo de oxidação da LDL é também um fator que contribui para o surgimento e progressão da doença $[7,10,11,12]$. Por esta razão, a chamada LDL oxidada (LDLox) é descrita como uma forma aterogênica desta lipoproteína.

As partículas de LDL são formadas por uma região central apolar, constituída por trigliceróis e ésteres de colesterol, ao redor da qual se distribui uma monocamada de fosfolipídios, colesterol livre e uma apolipoproteína $[8,13]$. As partículas de LDL apresentam um diâmetro médio de $22 \mathrm{~nm}$, compreendendo uma faixa de 18 a $25 \mathrm{~nm}[14,15]$, e densidades entre 1,006 e 1,063 g/mL. Diferentemente de outras classes de lipoproteínas, a LDL apresenta apenas uma apolipoproteína por partícula, a ApoB-100, distribuída ao redor da LDL [16]. A LDL é associada ao transporte do colesterol para os tecidos periféricos, cujas células possuem receptores de superfície capazes do reconhecimento da ApoB-100, os denominados receptores de LDL (LDLr). Tais receptores mediam a captação do colesterol nas células [8]. 
Como já foi mencionado, uma das hipóteses que se ocupa da explicação da atuação aterogênica da LDL, considera alterações decorrentes de processos oxidativos. Embora o mecanismo de oxidação da LDL, em organismos vivos, não seja em seu todo elucidado, sabese que este envolve a peroxidação lipídica [17, 18], afetando a porção de lipídios da LDL. Os produtos da peroxidação lipídica, por sua vez, podem se ligar a resíduos da ApoB-100, conduzindo à modificações dessa apolipoproteína. Sabe-se que tais modificações da ApoB100 estão associadas ao desenvolvimento da aterosclerose, por mecanismos relacionados ao não reconhecimento da LDL por partes dos receptores celulares LDLr [19-24]. Outro mecanismo associado à atuação da LDL, no desenvolvimento da doença aterosclerótica, é a captação, por macrófagos, de formas modificadas desta lipoproteína, dando origem às chamadas células espumosas [25]. As alterações na superfície das partículas de LDL, como resultado de sua oxidação, podem também afetar suas interações interpartículas, levando à formação de oligômeros, usualmente referidos como agregados [26]. A oligomerização da LDL, ou agregação, também tem sido apontada como um fator que contribui para o desenvolvimento das placas ateroscleróticas, provavelmente devido à captação destes agregados pelos macrófagos [27].

Visando a uma melhor compreensão de como se dão os processos oxidativos que dão origem a LDL oxidada, bem como a relação desses com a atuação aterogênica desta partícula, muitos estudos empregam a oxidação in vitro, a fim de induzir um processo controlado. Embora estudos in vitro nem sempre mimetizem os fenômenos que ocorrem in vivo, alguns estudos já mostraram que a LDL oxidada in vitro apresenta características comuns às da LDL obtida do organismo humano. Hoff e O'Neil investigaram semelhanças estruturais e funcionais compartilhadas pela LDL oxidada in vitro (LDLox) e pela LDL extraída de placas ateroscleróticas (LDL-A) [28]. Ambas (LDLox e LDL-A) se mostraram diferentes da LDL nativa, ou não modificada, em aspectos como o aumento da mobilidade eletroforética. Os resultados do trabalho sugeriram ser a oxidação a modificação predominante das LDLs presentes na lesão aterosclerótica. No referido trabalho, a LDLox foi originada pela reação com íons cobre, por 8-18h, a $20^{\circ} \mathrm{C}$. Se ocupando do mesmo tema, Esterbauer et al. [29] citam as características apresentadas por partículas de LDL retiradas das paredes arteriais, das quais destacamos o aumento da mobilidade eletroforética e o aumento da tendência à formação de agregados.

Embora já tenha sido constatada, a atuação aterogênica da LDL oxidada ainda não é totalmente compreendida. Técnicas e métodos físicos, empregados na caracterização de 
materiais, tais como espalhamento de raios X a baixos ângulos (SAXS, do Inglês Small Angle $X$-ray Scattering) e a técnica de varredura Z (ZS, do Inglês Z-Scan), são ferramentas que podem contribuir para elucidar questões referentes a esse tema, permitindo, por exemplo, propor relações entre as alterações funcionais e as mudanças estruturais ou moleculares dessa lipoproteína.

Conhecida a estreita relação entre estrutura e funcionalidade, apresentada por diversas biomoléculas e biopartículas, o estudo estrutural da LDL vem sendo um campo de frequente estudo. Já foram reportados estudos empregando as técnicas de dicroísmo circular, ressonância magnética nuclear, espectroscopia de infravermelho e microscopia eletrônica, entre outras, no estudo dessas partículas [30, 31]. Embora já se tenham estudos estruturais de lipoproteínas desde os anos 70, estes ainda se fazem úteis, uma vez que há questões que permanecem não elucidadas. Além disso, o desenvolvimento e o aprimoramento das técnicas de caracterização, ou mesmo dos métodos de análise de dados experimentais com estas obtidos, e a combinação de diferentes técnicas, têm conduzido a novas abordagens para estes estudos. Um exemplo está nos estudos da organização da porção de colesterol do núcleo da LDL, investigado por diferentes autores [14, 32-34], e para os quais o desenvolvimento da técnica de cryo-microscopia teve importante contribuição [33, 34]. Tais trabalhos tratam de uma faixa de temperatura de transição de fase. Acima desta temperatura de transição, a estratificação do colesterol, caracterizada por uma fase líquido-cristalina a temperaturas mais baixas, se torna desordenada. Embora ainda não haja uma definição quanto ao papel fisiológico desta transição, ou mesmo se algo análogo a esta ocorre in vivo, já foi estudado o papel desta organização lipídica do núcleo na resistência da LDL à oxidação [34, 35].

Além da compreensão de aspectos relacionados à estrutura da LDL, um maior entendimento de sua dinâmica no organismo, também pode contribuir para o conhecimento sobre a atuação aterogênica desta lipoproteína. À formação e crescimento das placas ateroscleróticas também é associada a infiltração da LDL nas paredes arteriais. Compreender o mecanismo de acumulação, a isto relacionado, pode contribuir para esclarecer o processo envolvido na aterosclerose. Nesse contexto, a migração da LDL no interior das paredes arteriais vem sendo um tema de estudo [36, 37, 38]. Em um estudo teórico da migração da LDL nas artérias, sob hipertermia, Chung e Vafai investigaram a contribuição do efeito Soret no transporte da LDL no interior desses vasos [38].

O efeito Soret, também chamado de termodifusão, é o fenômeno de difusão de partículas em solução, induzido por um gradiente de temperatura. O coeficiente Soret é o 
parâmetro usualmente considerado para descrever esse efeito em soluções de nanopartículas. No estudo de Chung e Vafai, por ausência de um valor experimental, um valor positivo típico de coeficiente Soret $\left(S_{T}=0,01 \mathrm{~K}^{-1}\right)$ foi adotado para as simulações. Um valor inferior $\left(S_{T}=\right.$ $0,005 \mathrm{~K}^{-1}$ ) também foi empregado, considerando uma possível redução dos valores do $S_{T}$, como consequência da grande dimensão das partículas de LDL [38]. Os autores concluíram ser o efeito Soret, nas condições investigadas, uma contribuição relevante para a migração da LDL no interior dos vasos.

O conhecimento de que gradientes de temperatura, estabelecidos em soluções, podem conduzir à migração de partículas ou íons nelas dispersos, base do efeito Soret, já é bem estabelecido. No entanto, a descrição deste fenômeno, em função das grandezas físicas que compõem os sistemas nos quais este é observado, ainda não é de todo descrita. Em fluidos complexos, o efeito Soret é dependente de diferentes mecanismos ou parâmetros [39, 40], o que impossibilita, ou torna difícil, uma predição teórica do comportamento termodifusivo nesses meios. Com base nisso, uma determinação experimental pode ser entendida como uma alternativa mais adequada, se comparada a uma abordagem teórica. No entanto, para a LDL, ainda não há na literatura um valor experimental de $S_{T}$, sendo os estudos, como o acima mencionado, baseados em predições teóricas para este parâmetro.

O Grupo de Fluidos Complexos (GFCx-IFUSP), grupo junto ao qual a presente tese foi desenvolvida, tem como um dos seus temas de estudo a caracterização de lipoproteínas, sobretudo investigando a funcionalidade da LDL, por aplicação de técnicas ópticas. O GFCxIFUSP tem suas atividades voltadas ao estudo de nanopartículas, por aplicação de técnicas de espalhamento e de técnicas de óptica não-linear. Os estudos relacionando o risco de desenvolvimento da aterosclerose com a forma oxidada da LDL, e não apenas com sua quantidade no plasma humano, conduziu nosso grupo de pesquisa a uma busca por uma abordagem física para esse tema. Os primeiros estudos apresentaram a aplicação da técnica de ZS, com estudos baseados na indução da formação da lente térmica, na caracterização das respostas ópticas da LDL nativa e oxidada in vitro, caracterizando uma abordagem inovadora para o tema, por não serem, até então, reportados estudos empregando óptica não-linear ao estudo de lipoproteínas [41-44]. Posteriormente, a técnica de ZS, também foi combinada a técnicas de espalhamento para avaliar as alterações estruturais, provocadas pela oxidação [45] ou glicação da LDL [46].

Os estudos de óptica não-linear, em alguns casos combinadas aos de espalhamento, vêm sendo, mais recentemente, aplicados aos estudos in vivo, nos quais as alterações das 
partículas de LDL investigadas, são decorrentes de processos do organismo e não induzidos em ambiente extracorpóreo, como nos estudos in vitro [47-49]. Um estudo recente investigou a ocorrência de alterações estruturais e ópticas na LDL em decorrência da ação farmacológica, empregada no tratamento de pacientes após um episódio de infarto do miocárdio. Foram avaliados os efeitos de terapias combinadas antiplaquetário-estatinas nas partículas de LDL. Um dos principais resultados desse trabalho foi apresentar uma relação entre os dados ópticos, indicando uma correlação entre os valores de absorbância a 484 nm, relacionados aos conteúdos de antioxidantes nas partículas de LDL, e a amplitude do fenômeno de lente térmica. Para todos os casos, ou seja, grupos de terapias, uma correlação positiva foi encontrada. A Figura 1.1 mostra esses resultados. Do ponto de vista estrutural, alterações da distribuição de densidade eletrônica na LDL, bem como variações nos raios das partículas, em decorrência do tratamento, foram as alterações perceptíveis [50].
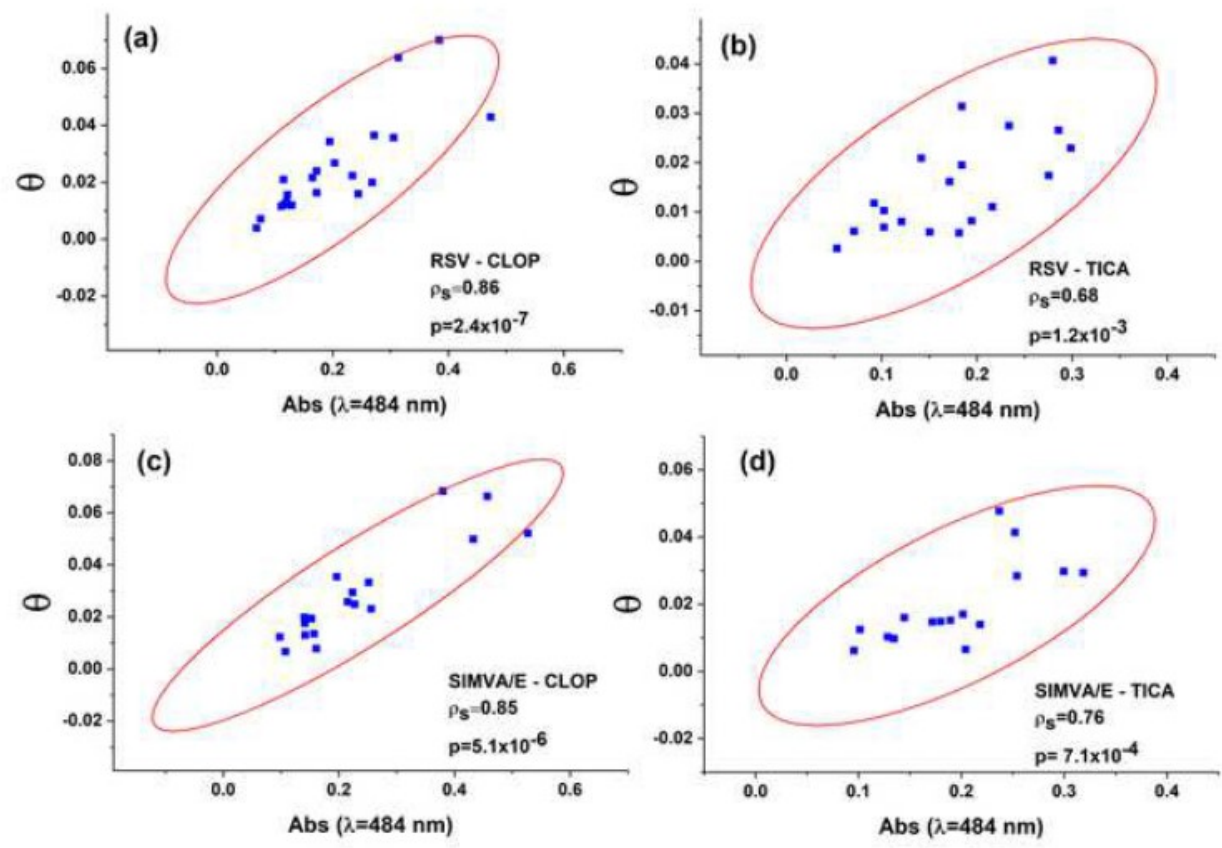

(retirado de [50])

Figura 1.1. Resultados mostrando a correlação positiva entre as absorbâncias a 484 nm, relacionados aos conteúdos de antioxidantes nas partículas de LDL, e a amplitude do fenômeno de lente térmica $(\theta)$ [50].

No contexto atual, o estudo da LDL pode compreender duas importantes abordagens, a compreensão de mecanismos relacionados com o desenvolvimento da aterosclerose e o 
estabelecimento de metodologias que possibilitem o avanço destes estudos. É nesse sentido que o presente trabalho espera contribuir.

Com relação à estrutura da LDL e suas modificações, em trabalhos empregando a técnica de SAXS, por exemplo, alterações do perfil de densidade eletrônica são reportadas. A maior parte desses estudos se baseia em resultados das curvas $p(r)$ ou curvas de distribuição de densidade eletrônica. Propor novas abordagens de análises, e melhores interpretações dos resultados por estas fornecidos, é um dos desafios no estudo da LDL. Já para os estudos da dinâmica de migração da partícula de LDL, como o de Chung e Vafai citado anteriormente, há ainda a escassez de resultados experimentais. A abordagem experimental se faz útil, nesses casos, dada a dificuldade de previsões teóricas de vários aspectos. Estudos ópticos, como os que empregam a técnica de ZS, podem contribuir para tais abordagens. Diante dessas considerações, a proposta do presente trabalho foi um estudo estrutural e temodifusivo da LDL.

\subsection{Objetivos}

Do ponto de vista estrutural, o objetivo do trabalho foi a investigação das alterações, de densidade eletrônica e de estado oligomérico, nas partículas de LDL, induzidos pelo processo de oxidação in vitro. Também foi proposto um exemplo de aplicação, das investigações das alterações estruturais da LDL, a um estudo in vivo. Já o estudo do comportamento termodifusivo da LDL, teve por objetivo descrever esse comportamento para tais partículas, bem como a determinação de um valor experimental de $S_{T}$ para a LDL.

\subsubsection{Objetivos específicos}

- Avaliar a influência da concentração do agente oxidante e do tempo de reação, na oxidação in vitro da LDL, por meio do monitoramento de alterações estruturais.

- Correlacionar os eventos do processo oxidativo, que afetam as moléculas constituintes da LDL e são descritos na literatura, com as alterações estruturais observadas.

- Avaliar o papel da organização lipídica, do núcleo da LDL, na resistência desta partícula à oxidação, por meio do estudo das alterações estruturais da LDL oxidada in vitro e a uma temperatura de $37^{\circ} \mathrm{C}$. 
- Apresentar um exemplo de aplicação do modelo, e do que foi estudado in vitro, a um estudo in vivo, investigando modificações na partícula de LDL como resultado de um tratamento farmacológico.

- Determinar o comportamento termodifusivo da LDL e determinar um valor experimental de coeficiente Soret $\left(S_{T}\right)$.

- Investigar se o comportamento termodifusivo pode ser afetado pelo estado oxidativo da LDL, descrevendo o comportamento do $S_{T}$ em função do nível de oxidação da partícula. 


\section{Fundamentação teórica}

Neste capítulo será apresentada uma fundamentação teórica, relacionada às principais técnicas ou fenômenos físicos envolvidos nos estudos que compõem o trabalho, visando ao bom entendimento da metodologia adotada, bem como de aspectos relacionados à discussão dos resultados.

\subsection{Espalhamento de raios $X$ a baixos ângulos (SAXS)}

Uma técnica de grande utilidade para a caracterização de sistemas em solução e cujo uso tem sido crescente, é o espalhamento de raios X a baixos ângulos (SAXS). Devido à sua resolução, esta técnica não fornece informações a nível atômico, mas possui ampla aplicação na obtenção de informações como forma, tamanho, grau de ordenamento e interação entre partículas dispersas em um dado meio. O arranjo de um experimento de SAXS compreende um feixe de raios $\mathrm{X}$, monocromático e colimado, incidindo sobre a amostra em análise. Da interação dos raios $\mathrm{X}$ com a matéria resulta o espalhamento desses. As intensidades dos raios espalhados, registradas por um detector, fornecem os dados bidimensionais do experimento.

A intensidade dos raios $X$ espalhados é uma função do ângulo de espalhamento $(2 \theta) \mathrm{e}$, portanto, o perfil de espalhamento pode ser expresso como uma função do vetor de transferência de momento $(\vec{q})$, cujo módulo é definido em termos do ângulo de espalhamento, como $q=\frac{4 \pi \operatorname{sen} \theta}{\lambda}$, onde $\lambda$ é o comprimento de onda da radiação incidente [51]. A integração dos dados bidimensionais fornece as curvas das intensidades espalhadas em função dos valores de $q, I(q)$.

Sendo o fenômeno de espalhamento de raios $\mathrm{X}$ resultante da interação desses com os elétrons constituintes da matéria, a intensidade espalhada $I(q)$, grandeza mensurável em um experimento de SAXS, está relacionada à densidade eletrônica do objeto espalhador. Desse modo, para uma partícula fixa no espaço, temos [51, 52]

$$
I(\vec{q})=f(\vec{q}) \cdot f(\vec{q})^{*}
$$

sendo $f(\vec{q})$ a amplitude de espalhamento, dada pela transformada de Fourier da densidade eletrônica $(\rho)$ da partícula espalhadora [51, 52]: 


$$
f(\vec{q})=\frac{1}{4 \pi} \int_{v} \rho(\vec{r}) e^{-i \vec{q} \cdot \vec{r}} d \vec{r} .
$$

Para a condição de uma partícula que não esteja fixa no espaço, condição experimental real, é necessário considerar uma situação média, em relação a todas as possíveis orientações que a partícula assuma no espaço. Uma operação possível para tal, no espaço recíproco, é realizar uma média sobre o ângulo sólido $\Omega: I(q)\left\langle f(\vec{q})^{2}\right\rangle_{\Omega}$, chegando-se a [51]

$$
I(q)=4 \pi \int_{0}^{\infty} p(r) \frac{\operatorname{sen}(q r)}{q r} d r
$$

A função $p(r)$, definida na equação 2.3 , é chamada função de distribuição de pares de distância, dada por [50]

$$
p(r)=\frac{r^{2}}{2 \pi^{2}} \int_{0}^{\infty} q^{2} I(q) \frac{\operatorname{sen}(q r)}{q r} d q
$$

sendo $r$ a distância entre dois elementos de volume, no interior da partícula.

Dada a intensidade espalhada para uma partícula aleatóriamente orientada (equação 2.3), pode-se escrever esta grandeza para um conjunto de n partículas, também de orientações aleatórias, como [51]

$$
I(q)=n P(q) S(q)
$$

sendo $P(q)=\left\langle f(\vec{q})^{2}\right\rangle$ o fator de forma e $S(q)=\langle S(\vec{q})\rangle$ o fator de estrutura do sistema. O fator de forma é um parâmetro relacionado às informações das partículas constituintes da amostra, enquanto o fator de estrutura fornece informações das interações entre essas partículas como, por exemplo, interações que resultem na formação de oligômeros.

As informações contidas nos dados de espalhamento, adquiridos em um experimento de SAXS, podem ser acessadas por meio dos métodos de análise, como o método da transformada de Fourier indireta ou a modelagem dos dados, que serão descritos em seguida.

\subsubsection{Método da transformada de Fourier indireta (IFT)}

Como já foi visto, a função $p(r)$ pode ser obtida através da transformada inversa de Fourier da intensidade espalhada $I(q)$. No entanto, a determinação direta da $p(r)$, por meio da equação 2.4 , possui limitações intrínsecas. Isso porque esta determinação envolve uma 
integração até infinito, enquanto os dados experimentais compõem um intervalo finito. Uma alternativa, que permite contornar tal limitação, é a aplicação de métodos de análise nos quais a obtenção da $p(r)$ se dá de forma indireta, como no método da transformada de Fourier indireta (IFT).

Nesse método, a transformada inversa de Fourier das intensidades espalhadas fornece a função $p(r)$. A $p(r)$ pode se entendida como um histograma dos pares de distâncias $(r)$, isto é, distâncias entre dois elementos de volume, no interior da partícula espalhadora. A partir da $p(r)$ pode-se, portanto, obter indicativos como a máxima dimensão das partículas que compõem uma amostra, ou a forma dessas.

\subsubsection{Modelagem dos dados de intensidades espalhadas em função de $q$}

O método de IFT é, em geral, empregado para etapas iniciais de análise, para obter informações gerais sobre um determinado sistema em estudo, tais como estado oligomérico, ou noções sobre forma e dimensão das partículas. Além da aplicação deste método, que possibilita análises envolvendo a curva $p(r)$, etapas de modelagem dos dados de SAXS se fazem úteis, em especial, no estudo de partículas formadas por múltiplos componentes, como a LDL [33]. A aplicação de modelos, que também se utilizam das informações das intensidades espalhadas, permite obter parâmetros estruturais, tais como espessura de camadas moleculares, anisotropia, organização e distribuição de componentes. Por esta razão, a modelagem dos dados de SAXS é, em geral, uma análise mais informativa do que interpretações diretas das curvas de intensidades espalhadas ou das curvas $p(r)$. Tais modelos podem ser desenvolvidos com base em informações fornecidas pela aplicação de outras técnicas que, por exemplo, apresentem uma maior resolução quando comparadas ao SAXS, ou por técnicas de imagem, como a microscopia.

Conforme definido acima, as intensidades espalhadas, em um experimento de SAXS, são função da densidade eletrônica do objeto espalhador. No entanto, para partículas dispersas em um dado meio, o contraste de espalhamento $(\Delta \rho)$ é uma definição necessária. O contraste de espalhamento corresponde à diferença entre as densidades eletrônicas da partícula em estudo $\left(\rho_{\text {part }}\right)$ e do meio no qual esta se dispersa $\left(\rho_{\text {meio }}\right)$, logo $\Delta \rho=\rho_{\text {part }}-\rho_{\text {meio }}$. Nota-se que a detecção da intensidade espalhada, nos experimentos de SAXS, só é possível se o $\Delta \rho$ for diferente de zero. Para um sistema monodisperso, $I(q)$ será dependente de $\Delta \rho$, de acordo com a definição [51] 


$$
I(q)=N \Delta \rho^{2} V^{2} P(q),
$$

onde $V$ e $P(q)$ são o volume e fator de forma das partículas, respectivamente.

A fim de investigar alterações na estrutura da LDL, decorrentes da já mencionada transição de fase do colesterol constituinte do núcleo da partícula, Maric et al [33] propuseram um modelo para a análise dos dados de SAXS. Tal modelo foi baseado em dados de cryomicroscopia [34], que mostraram que, a baixas temperaturas, a LDL apresenta a forma de um elipsoide de revolução oblato, forma induzida pelas camadas do colesterol estratificado. Para temperaturas acima das da faixa de transição de fase do colesterol, devido à perda da estratificação deste, a partícula adquire a forma esférica [34].

Os autores do modelo propuseram ser esta uma abordagem de análise útil no monitoramento de mudanças estruturais da LDL, quando esta é submetida a condições como processos oxidativos, variações de temperatura ou outros agentes externos [33]. Esta abordagem de análise foi implementada em nosso grupo, para o estudo da glicação da LDL [46]. Para este caso, a temperatura considerada foi $37^{\circ} \mathrm{C}$, temperatura na qual a LDL é descrita como uma partícula esférica [33]. Sendo assim, essa implementação do modelo [46] utiliza o fator de forma para uma esfera, de raio $R$, dado por [51],

$$
P(q)=\frac{3[\operatorname{sen}(q R)-q R \cos (q R)]}{(q R)^{3}} .
$$

Sendo a LDL uma partícula de organização micelar, do tipo núcleo-camada, a intensidade espalhada pode ser escrita em termos da contribuição de cada uma dessas regiões. Tais contribuições, para a intensidade de espalhamento teórica $\left(I_{\text {Teor }}\right)$, são dadas por:

$$
P_{\text {Mod }}=\left[\Delta \rho_{c} V_{t} P_{t}(q)-\left(\Delta \rho_{c}-\Delta \rho_{n}\right) V_{n} P_{n}(q)\right]^{2},
$$

onde $\Delta \rho_{n}=\rho_{\text {núcleo }}-\rho_{\text {meio }}$ e $\Delta \rho_{c}=\rho_{\text {camada }}-\rho_{\text {meio }}$ são os contrastes de densidade eletrônica para o núcleo e a monocamada da LDL, respectivamente. Sendo $\rho$ a densidade eletrônica de cada um dos meios, indicados pelos respectivos índices. Ao contraste de espalhamento da monocamada é atribuído valor unitário $\left(\Delta \rho_{c}=1\right)$, e o contraste do núcleo $\left(\Delta \rho_{n}\right)$ é ajustado em relação ao primeiro. Dessa forma, o parâmetro, retornado pela modelagem, é o contraste de espalhamento relativo $(\mu)$, dado por $\mu=\Delta \rho_{n} / \Delta \rho_{c}$. 
As contribuições de volume da partícula, para a intensidade espalhada, são dadas por $V_{t}=\frac{4 \pi}{3} R^{3}$ e $V_{n}=\frac{4 \pi}{3}\left(R-D_{c}\right)^{3}$, onde $V_{t}$ é o volume total da partícula de raio $R$ e $V_{n}$ é o volume do núcleo da partícula, sendo $D_{c}$ a espessura da camada externa da LDL. Já as contribuições referentes aos fatores de forma, são dadas em termos do fator de forma total da partícula $P_{t}(q)$ e da contribuição referente ao núcleo $P_{n}(q)$ :

$$
P_{t}(q)=\frac{3[\operatorname{sen}(q R)-q R \cos (q R)]}{(q R)^{3}}
$$

e

$$
P_{n}(q)=\frac{3\left\{\operatorname{sen}\left[q\left(R-D_{c}\right)\right]-q\left(R-D_{C}\right) \cos \left[q\left(R-D_{C}\right)\right]\right\}}{\left[q\left(R-D_{C}\right)\right]^{3}} .
$$

Até aqui, foram descritas as contribuições do núcleo e da camada, no entanto, a LDL possui ainda a ApoB-100. A fim de incluir a presença da proteína na modelagem de dados, e considerar possíveis quebras de simetria relacionadas à presença desta, um termo de flutuação para cadeias flexíveis é incluído neste modelo. Para tal, foi empregado um fator de forma para cadeias gaussianas. Este termo $\left(P_{F l u t}\right)$ é então, dado por [33],

$$
P_{\text {Flut }}=\frac{2\left(e^{-x}-1+x\right)}{x^{2}}
$$

sendo $x=q^{2} R_{g}{ }^{2}$, onde $R_{g}$ é o raio de giro das cadeias flexíveis. A intensidade de espalhamento teórica total pode, então, ser escrita como:

$$
I_{\text {Teor }}=S_{1} P_{\text {Mod }}+S_{2} P_{\text {Flut }}+\text { back, }
$$

onde $S_{1}$ e $S_{2}$ são fatores de escala e back é um fator de fundo.

\subsection{Lente térmica e lente de matéria}

A termodifusão, também chamada de efeito Soret, é um fenômeno físico de transporte de massa, originado pela migração de espécies químicas, como íons e partículas, em resposta a um gradiente de temperatura. Tais gradientes de temperatura são originados pela 
distribuição não homogênea de calor em soluções, o que resulta na formação de regiões de maior ou de menor temperatura. Adotaremos chama-lás de regiões quentes ou frias do meio. As partículas podem apresentar uma migração preferencial para uma dessas regiões, o que descreve seus comportamentos termodifusivos. É definido como comportamento termofílico a migração direcionada às regiões quentes, enquanto o transporte para regiões frias caracteriza o comportamento termofóbico. Para uma análise quantitativa do fenômeno termodifusivo, o coeficiente Soret $\left(S_{T}\right)$ pode ser determinado.

O modelo de lente térmica generalizado, empregando a técnica de varredura-Z, é um das abordagens que permite a determinação do coeficiente Soret. Desenvolvido por Alves et al [38], trata-se de uma abordagem na qual os fenômenos de difusão de calor e de massa podem ser individualmente analisados, fornecendo os parâmetros para a determinação do $S_{T}$, como será descrito adiante.

\subsubsection{A técnica de varredura-Z (ZS) e o modelo da lente térmica (LT)}

A varredura-Z é uma técnica que permite o estudo de efeitos ópticos não-lineares, decorrentes da interação da luz com o meio em estudo [53]. Em um experimento de ZS, um feixe laser, de perfil gaussiano, incide sobre uma lente convergente, componente do arranjo experimental, promovendo a formação da cintura do feixe, caracterizada por ser a posição na qual o feixe apresenta seu raio mínimo $\left(w_{0}\right)$. A amostra é posicionada após a lente, de modo que esta seja iluminada pelo feixe focalizado. A incidência do feixe sobre a amostra se faz com esta em deslocamento, sobre o eixo de propagação da luz, definido como eixo z. A intensidade transmitida pela amostra $\left(I_{c f}\right)$ é captada por um detector, após passar por uma íris $[53,54]$. Essa intensidade transmitida, ou transmitância, é o dado de importância em um experimento de ZS, sendo medida como uma função do tempo e da posição da amostra, ao longo do eixo $z$. Os dados de transmitância podem ser normalizados pelo valor de transmitância no instante inicial de aquisição sendo, portanto, usual o termo transmitância normalizada $\left(T_{N}\right)$.

A absorção da luz por um meio, em um processo que não envolva radiação, conduz à conversão da luz absorvida em calor. No caso de um experimento de ZS, este aquecimento não é homogêneo. A região na qual ocorre a incidência do laser se torna mais aquecida, em relação às regiões não irradiadas da amostra. Desse modo, ocorre um gradiente de temperatura e, consequentemente, um gradiente de índice de refração é formado no interior da amostra. O 
índice de refração do meio é, portanto, função da temperatura, sendo a relação entre essas grandezas dada por [54]

$$
n(r, t)=n_{0}+\left(\frac{d n}{d T}\right) \Delta T(r, t)
$$

onde $\Delta n=n-n_{0}$ é a variação no índice de refração, proveniente de um incremento de temperatura $\Delta T$. O termo $d n / d T$ é denominado coeficiente termo-óptico [53]. Devido a essa variação de índice de refração, os raios de luz incidentes em diferentes regiões da amostra, são transmitidos com diferenças de fase entre si. Como resultado dessa defasagem, ocorre o comportamento de lente da amostra, podendo ser convergente ou divergente. $\mathrm{O}$ comportamento de lente convergente ocorre quando o coeficiente termo-óptico do meio é positivo $(d n / d T>0)$, resultando na focalização do feixe. Nos meios nos quais este coeficiente é negativo $(d n / d T<0)$, a amostra apresenta um comportamento de lente divergente, acarretando a desfocalização do feixe.

As intensidades dos efeitos de focalização e desfocalização são proporcionais à intensidade do feixe laser incidente sobre a amostra. Logo, quando a amostra se encontra em posições $Z$ próximas à região da cintura do feixe, esses efeitos são máximos. Para posições muito distantes do foco, esses efeitos se tornam desprezíveis, conduzindo a valores de $T_{N}$ próximos de 1. Disto decorre o perfil pico-vale, característico das curvas de transmitância normalizada em função da posição $z$, adquiridas em um experimento de ZS. Um esquema simplificado de uma varredura-Z e a formação da curva característica de $T_{N}$, em função da posição da amostra, são mostrados na Figura 2.1. A figura ilustra o deslocamento da amostra, de uma posição anterior ao foco $(z<0)$ até uma posição posterior ao foco $(z>0)$, e as correspondentes contribuições de pico e vale, para o caso de uma amostra com contraste termo-óptico negativo $(d n / d T<0)$.

No caso de uma amostra que possua $d n / d T>0$, e posicionada na região anterior a região focal $(z<0)$ da lente componente do arranjo, o aumento de temperatura conduz ao aumento do índice de refração na região irradiada e a focalização do feixe ocorre, com a amostra descrevendo um comportamento de lente convergente. Disto resulta a diminuição da intensidade detectada em função do tempo. Ao passar pela região do foco, o feixe incidente não sofrerá desvio. Já para as regiões após o foco $(z>0)$ a intensidade registrada apresenta um perfil temporal de crescimento. Para um meio de não linearidade negativa, $d n / d T<0$, o comportamento é o inverso do descrito (Figura 2.1). 
A
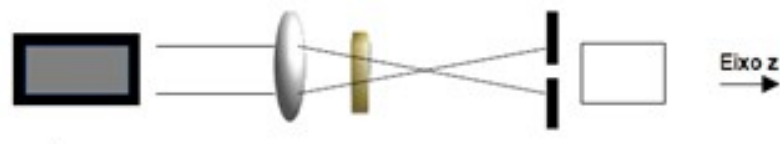

Laser

Lente Amostra

Detoctor

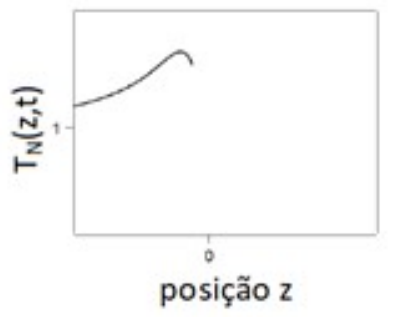

B
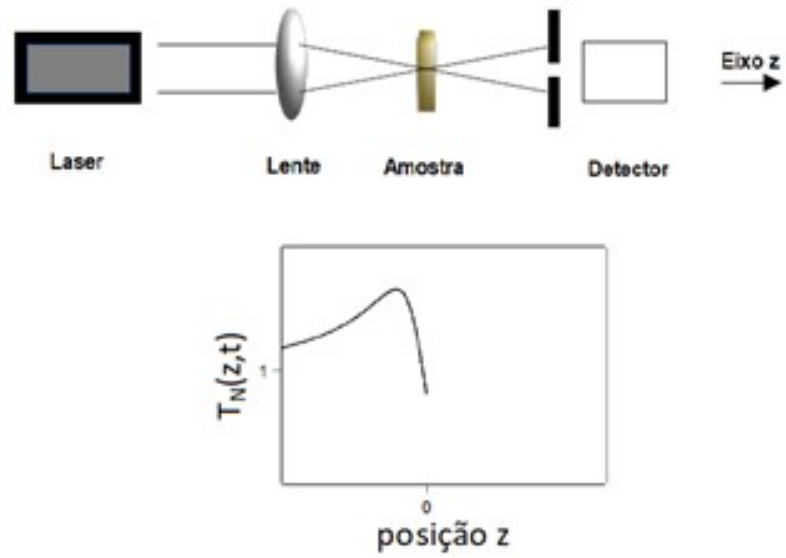

C
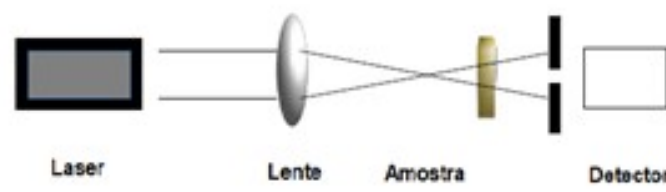

$\stackrel{\text { Eixoz }}{\longrightarrow}$

Laser

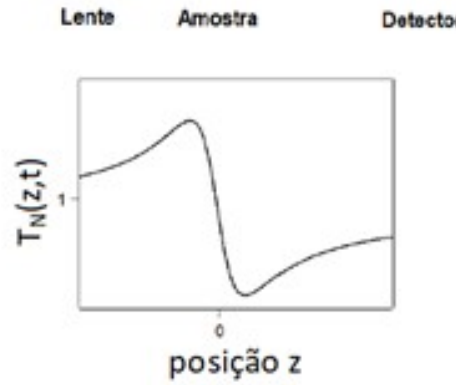

Figura 2.1. Ilustração de um esquema simplificado do arranjo experimental de ZS e do resultado da transmitância normalizada em função da posição da amostra, para um experimento de ZS. Neste caso, o contraste óptico é negativo e o feixe incidente sobre a amostra é desfocalizado.

Um dos modelos que descreve os efeitos de focalização e desfocalização, decorrentes do aquecimento de um meio por incidência de um feixe gaussiano, é o modelo de lente térmica (LT). Nesta abordagem, é considerado que a distribuição de calor ocorre em duas 
dimensões e com transmissão na direção radial, perpendicular à direção de propagação do feixe. A equação de calor (equação 2.14) pode ser usada para descrever a situação [39, 55],

$$
\frac{\partial \Delta T(r, t)}{\partial t}=D_{L T} \nabla^{2} \Delta T(r, t)+\frac{q(r)}{\rho c_{p}}
$$

onde a difusividade térmica $D_{L T}$ do meio é dada em função de sua condutividade térmica $\left(k_{T}\right)$, da densidade $(\rho)$ e do calor específico $\left(c_{p}\right)[56,57]$ :

$$
D_{L T}=\frac{k_{T}}{\rho c_{p}}
$$

Na equação 2.14, $q(r)$ é o calor proveniente de um feixe lazer de raio $w$ e potência $P$, dado por

$$
q(r)=\frac{2 \alpha P}{\pi w^{2}} e^{-2 r^{2} / w^{2}}
$$

sendo $\alpha$ o coeficiente de absorção óptica e $r$ a distância do centro do feixe a um ponto no plano de difusão de calor. $\mathrm{O}$ raio $w$ é definido em função do raio correspondente ao da cintura do feixe $\left(w_{0}\right)$, como $w^{2}=w_{0}{ }^{2}\left[1+\left(z / z_{0}\right)^{2}\right]$, onde $z_{0}=\frac{\pi w_{0}{ }^{2}}{\lambda}$ é o parâmetro de Rayleigh. A solução para a equação do calor (equação 2.14), em $r \rightarrow 0$, uma aproximação válida uma vez que a intensidade $\left(I_{c f}\right)$ é medida no centro do feixe, fornece o gradiente de temperatura $(\Delta T)$ $[56,57]$, que conduz à variação de índice de refração expressa na equação 2.13. Esse gradiente de temperatura é dado por

$$
\Delta T(r, t)=\frac{0,06 \alpha P}{\pi k_{T}}\left[\ln \left(1+\frac{2 t}{t_{L T}}\right)-2\left(\frac{r}{w}\right)^{2} \frac{2 t}{2 t+t_{L T}}\right]
$$

sendo $t_{\mathrm{LT}}$ o tempo característico para os efeitos térmicos:

$$
t_{\mathrm{LT}}=\frac{w^{2} \rho c_{p}}{4 k_{T}}
$$

que pode também ser escrito em função da difusividade térmica do meio $\left(D_{\mathrm{LT}}\right)$, ficando

$$
t_{\mathrm{LT}}=\frac{w^{2}}{4 D_{\mathrm{LT}}}
$$


Ainda em relação à equação $2.17, t$ é o tempo experimental. A constante, no primeiro termo, resulta da solução da equação de calor (equação 2.14) [53, 58] sendo, portanto, independente das condições experimentais adotadas.

Como já foi mencionado, na descrição do experimento de ZS, do gradiente de índice de refração resulta o comportamento de lente da solução de partículas. Neste caso, o comportamento de lente térmica ocorre, já que o tempo de irradiação $\left(t_{L T}\right)$ está na escala de efeitos térmicos. O inverso da distância focal da lente térmica formada $\left(1 / f_{L T}\right)$ é dependente do gradiente de índice de refração $n(r, t)$. Esta dependência é dada por [39, 57],

$$
\frac{1}{f_{L T}}=-l\left(\frac{d n}{d T}\right) \frac{d^{2} \Delta T(r, t)}{d r^{2}}=-l\left(\frac{d n}{d T}\right) \frac{0.24 \alpha P}{k_{T} \lambda} \frac{1}{\left(1+\gamma^{2}\right) z_{0}} \frac{2 t}{2 t+t_{L T}}
$$

onde

$$
\theta_{L T}=-\frac{0.24 \alpha P l}{k_{T} \lambda}\left(\frac{d n}{d T}\right)
$$

é a amplitude da lente térmica, $z_{0}$ é o parâmetro de Rayleigh e $\gamma=z / z_{0}$ é a posição relativa da amostra $[39,57]$. Logo, $f_{L T}$ pode ser escrita em função de $\theta_{L T}$ :

$$
\frac{1}{f_{L T}}=\theta_{L T} \frac{1}{\left(1+\gamma^{2}\right) z_{0}} \frac{2 t}{2 t+t_{L T}} .
$$

Os fenômenos de focalização ou desfocalização do feixe, conduzem à variações na intensidade detectada $\left(I_{c f}\right)$, logo, ocorrem variações da transmitância normalizada. Considerando a descrição acima, o modelo de lente térmica, baseado na aproximação parabólica da lente térmica, permite escrever $T_{N}$ como uma função do tempo de irradiação $(t)$ e da posição da amostra (z), como mostra a equação 2.23 [57]. Nesse caso, a transmitância normalizada é definida como $T_{N}(z, t)=T_{N}(z, t) / T_{N}(z, 0)$.

$$
T_{N}^{-1}(z, t)=1-2 \gamma \frac{2 \theta_{L T} t}{\left(1+\gamma^{2}\right) 2 t+t_{L T}}+\left(1+\gamma^{2}\right)\left[\frac{2 \theta_{L T} t}{\left(1+\gamma^{2}\right) 2 t+t_{L T}}\right]^{2}
$$




\subsubsection{O efeito Soret}

Como descrito na seção anterior, $t_{L T}$ é o tempo característico para efeitos térmicos. Experimentos realizados nesta escala temporal, da ordem de dezenas de milissegundos, permitem o estudo da difusão de calor em um dado meio. Para uma escala de tempo da ordem de $10^{3}$ vezes maior, escala de dezenas de segundos, o fenômeno de migração de massa pode ser observado. Tal migração, resultado da não homogeneidade da temperatura na amostra irradiada e consequente movimentação dos constituintes do meio para regiões quentes ou frias, acarreta um gradiente de concentração. O fenômeno de difusão das espécies, sob o efeito de um gradiente de temperatura, como já foi mencionado, é chamado de termodifusão ou efeito Soret $[55,58]$. Nesse regime, o comportamento de lente, observado para a amostra, é chamado de lente de matéria ou lente Soret. Para um sistema em termodifusão, o fluxo de massa total $\left(\overrightarrow{J_{M}}\right)$ pode ser escrito considerando as contribuições dos gradientes de temperatura $(\vec{\nabla} T)$ e de massa, também chamado de gradiente de concentração $(\vec{\nabla} c)$ [55],

$$
\overrightarrow{J_{M}}=-D_{M} \vec{\nabla} c-c(1-c) D_{T} \vec{\nabla} T
$$

onde $D_{M}$ é o coeficiente de difusão de massa, $D_{\mathrm{T}}$ é o coeficiente de difusão térmica e $c$ é a concentração de partículas. Quando o estado estacionário, em relação à migração de massa, se estabelece, as transferências de temperatura e de matéria passam a apresentar um acoplamento. Nesta condição, se dá a definição do coeficiente Soret [55],

$$
S_{T}=\frac{D_{T}}{D_{M}}=\frac{1}{c(1-c)}\left|\frac{\vec{\nabla} c}{\vec{\nabla} T}\right|
$$

O coeficiente Soret $\left(S_{T}\right)$, dado em $\mathrm{K}^{-1}$, é o parâmetro usualmente empregado para expressar o comportamento termodifusivo de partículas em solução. Coeficientes termodifusivos positivos $\left(S_{T}>0\right)$ são definidos para migrações termofóbicas, enquanto coeficientes negativos $\left(S_{T}<0\right)$ são associados a comportamentos termofílicos [55].

Para determinar a distribuição de massa $\partial \Delta c(r, t) / \partial t$, responsável pela lente Soret, a equação para o fluxo total de massa no sistema $\left(\overrightarrow{J_{M}}\right)$ (equação 2.24 ) pode ser aplicada na equação de continuidade [55]:

$$
\frac{\partial \Delta c(r, t)}{\partial t}=-\nabla \cdot \overrightarrow{J_{M}}=-D_{M} \nabla^{2} \Delta c+c(1-c) D_{T} \nabla^{2} \Delta T(\mathrm{r}, \mathrm{t}) .
$$


Empregando a definição para o coeficiente Soret (equação 2.25), a equação a ser resolvida, para determinar a distribuição de massa, se torna [55, 59]:

$$
\frac{\partial \Delta c(r, t)}{\partial t}=-\nabla \cdot \overrightarrow{J_{M}}=-D_{M} \nabla^{2} \Delta c+c(1-c) S_{T} D_{M} \nabla^{2} \Delta T(\mathrm{r}, \mathrm{t})
$$

Considerando as equações 2.14 e 2.15, e a condição de estado estacionário $\partial \Delta T(r, t) / \partial t=0$, temos $\nabla^{2} \Delta T(\mathrm{r}, \mathrm{t})=-\frac{q(r)}{k_{T}}$, onde $q(r)$ foi definido na equação 2.16 , a solução para a equação 2.27 é [55. 59]

$$
\Delta c(r, t)=\frac{0,06 \alpha P c S_{T}}{\pi k_{T}}\left[\ln \left(1+\frac{2 t}{t_{L S}}\right)-2\left(\frac{r}{w}\right)^{2} \frac{2 t}{2 t+t_{L S}}\right]^{2}
$$

Assim como na lente térmica, o inverso da distância focal da lente Soret $\left(1 / f_{L S}\right)$ é dependente do gradiente de índice de refração $n(r, t)$ [39]:

$$
\frac{1}{f_{L S}}=-l\left(\frac{d n}{d c}\right) \frac{d^{2} \Delta c(r, t)}{d r^{2}}=-l\left(\frac{d n}{d c}\right) \frac{-0.24 \alpha P c S_{T}}{k_{T} \lambda} \frac{1}{\left(1+\gamma^{2}\right) z_{0}} \frac{2 t}{2 t+t_{L S}}
$$

onde

$$
\theta_{L S}=\frac{0.24 c S_{T} \alpha P l}{\lambda k_{T}}\left(\frac{d n}{d c}\right)
$$

é a amplitude da lente Soret $[39,60]$, podendo $f_{L S}$ ser reescrita como

$$
\frac{1}{f_{L S}}=\theta_{L S} \frac{1}{\left(1+\gamma^{2}\right) z_{0}} \frac{2 t}{2 t+t_{L S}}
$$

Comparando-se as equações 2.21 e 2.30 , nota-se que a amplitude da lente Soret pode ser escrita em função da amplitude da lente térmica [39]. A amplitude $\theta_{L S}$ e o coeficiente Soret $\left(S_{T}\right)$ estão, portanto, relacionados entre si, como mostra a equação 2.32 [57]:

$$
\theta_{L S}=\theta_{L T} c S_{T}\left(\frac{d n}{d T}\right)^{-1}\left(\frac{d n}{d c}\right)
$$


onde $c$ é a concentração da amostra. O coeficiente óptico $d n / d c$ corresponde à variação do índice de refração em função da concentração.

Na lente Soret, a transmitância normalizada $\left(T_{N}\right)$ como função do tempo de irradiação e da posição da amostra, é dada por [57]

$$
T_{N}^{-1}(z, t)=1-2 \gamma \frac{2 \theta_{L S} t}{\left(1+\gamma^{2}\right) 2 t+t_{L S}}+\left(1+\gamma^{2}\right)\left[\frac{2 \theta_{L S} t}{\left(1+\gamma^{2}\right) 2 t+t_{L S}}\right]^{2}
$$

Note-se que, adotando uma normalização coerente, que permita considerar apenas a contribuição do fenômeno de termodifusão, $T_{N}(z)=T(z, t) / T\left(z, t_{\mathrm{LT}}\right)$, uma equação análoga à equação 2.23 pode ser escrita, para o caso da difusão de partículas.

\subsubsection{Origem do efeito Soret em nanopartículas carregadas}

\section{Efeito da dupla camada elétrica}

Uma das primeiras teorias que descreveu o efeito Soret, em partículas carregadas, foi proposta por Ruckenstein, descrevendo o fenômeno termodifusivo como resultante de um gradiente de tensão interfacial [61]. De acordo com essa teoria, partículas carregadas, sob o efeito de um gradiente térmico, adquirem uma velocidade de migração termoforética $\left(v_{T}\right)$ devido a um gradiente de tensão interfacial. Esta velocidade é dada por,

$$
v_{T}=\frac{-l}{\eta} \frac{d \gamma}{d z}=\frac{-l}{\eta} \frac{d \gamma}{d T} \frac{d T}{d z}
$$

onde $l$ é o comprimento característico de partículas carregadas $\left(l=k^{-1}\right.$, inverso do comprimento de Debye), $\eta$ é a viscosidade do fluido e $\gamma$ é a tensão interfacial. A tensão interfacial $\gamma$ pode ser definida em termos da energia da dupla camada elétrica,

$$
\gamma=-\int_{0}^{\zeta} \sigma(\psi) d \psi
$$

sendo $\zeta$ o potential zeta, indicando que o limite da integração é o plano de cisalhamento, $\sigma$ e $\psi$ são a carga superficial e o potencial da partícula, respectivamente. A equação 2.35 mostra a 
dependência da tensão interfacial com a energia armazenada na dupla camada elétrica das partículas, enquanto a equação 2.34 relaciona a tensão interfacial à velocidade termoforética.

\section{Efeito de sais}

Do mesmo modo que as partículas, os íons, provenientes da dissociação dos sais em solução, podem migrar por ação de um gradiente térmico, dando origem a um campo elétrico. Neste caso, dá-se o nome de campo termoelétrico. Este fenômeno é chamado de efeito Seebeck e decorre do efeito Soret intrínseco dos íons. A contribuição do efeito Seebeck, na termodifusão de partículas carregadas, foi considerado por Eslahian et al [62]. Uma expressão global para o $S_{T}$, que considera tanto os efeitos do movimento de íons como do movimento de partículas, foi proposta $[62,63]$ :

$$
S_{T}=\frac{\epsilon}{\eta T M}\left[\frac{\zeta^{2}}{12}(1+\tau+\alpha)-\zeta S T\right]
$$

onde $\epsilon$ é a permeabilidade dielétrica da solução, $\eta$ é sua viscosidade, $D_{M}$ é o coeficiente de difusão de massa, $\tau$ corresponde a um parâmetro relacionado à permeabilidade da água e S é o coeficiente de Seebeck $[62,63]$.

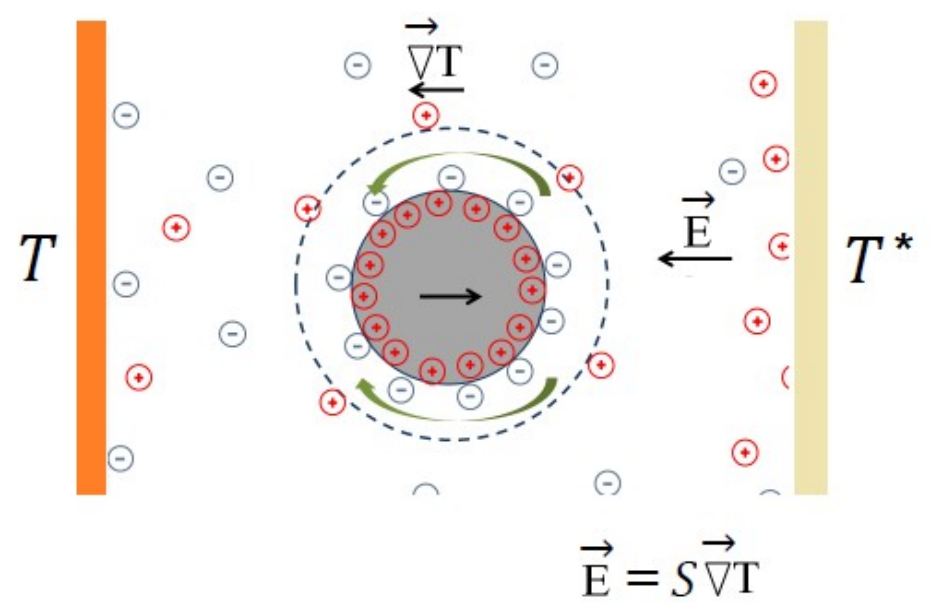

Figura 2.2. Ilustração das contribuições termoforética e termoelétrica para a termodifusão de nanopartículas dispersas em um meio iônico. A primeira dessas é relacionada à energia armazenada na dupla camada, enquanto a segunda contribuição resulta da ação do campo elétrico, gerado com a migração dos íons, e que é dado em função do coeficiente Seebeck (S), por $\overrightarrow{\mathrm{E}}=\mathrm{S} \vec{\nabla} T . T$ e $T^{*}$ indicam temperaturas diferentes no meio. Figura adaptada de [58]. 
Muitos autores consideram a contribuição dos efeitos termoelétricos ou dos efeitos termoforéticos, de modo separado, na termodifusão de nanopartículas carregadas. No entanto, os dois podem contribuir para a migração de nanopartículas carregadas, quando dispersas em meios iônicos [40,58], como ilustra a Figura 2.2. 


\section{Metodologia}

\section{Materiais}

As bolsas de plasma foram obtidas por doação da Associação Beneficente de Coleta de Sangue (COLSAN). Os reagentes utilizados no presente trabalho, e seus respectivos fornecedores, são listados na Tabela 3.1.

Tabela 3.1 - Reagentes e fornecedores.

\begin{tabular}{ll}
\hline \hline Reagente & Fornecedor \\
\hline Ácido bicinchonínico - kit quantificação de proteínas $(\mathrm{BCA})$ & Pierce \\
Ácido etilenodiaminotetraacético, solução (EDTA) & Invitrogen \\
Brometo de potássio $(\mathrm{KBr})$ & Sigma-Aldrich \\
Cloreto de sódio $(\mathrm{NaCl})$ & Sigma-Aldrich \\
Fosfato de sódio dibásico $\left(\mathrm{Na}_{2} \mathrm{HPO}_{4}\right)$ & Sigma-Aldrich \\
Sulfato de Cobre $\left(\mathrm{CuSO}_{4}\right)$ & Sigma-Aldrich \\
Hidroxitolueno Butilado $(\mathrm{BHT})$ & Sigma-Aldrich \\
Fluoreto de fenilmetilsulfonil $(\mathrm{PMSF})$ & Sigma-Aldrich \\
Aprotinina & Sigma-Aldrich \\
Benzamidina & Sigma-Aldrich \\
Filtros & Milipore \\
\hline
\end{tabular}

\subsection{Preparação das amostras}

Inicialmente, foram adicionados ao plasma os inibidores de protease Fluoreto de fenilmetilsulfonil (PMSF, $5 \mu \mathrm{M})$, Aprotinina $(10 \mu \mathrm{g} / \mathrm{mL})$ e Benzamidina $(10 \mu \mathrm{M})$ e o antioxidante Hidroxitolueno Butilado (BHT, $100 \mu \mathrm{M})$ [64]. As amostras de LDL foram obtidas por ultracentrifugação sequencial [65]. Neste procedimento, o plasma foi ultracentrifugado para retirada da lipoproteína de muito baixa densidade, a VLDL, cuja densidade é de $1,006 \mathrm{~g} / \mathrm{mL}$. Após a ultracentrifugação, o sobrenadante contendo a VLDL, foi recolhido e descartado. A densidade do infranadante foi ajustada ao limite superior da densidade da lipoproteína de baixa densidade (LDL - 1,063 g/mL), pela adição de brometo de potássio $(\mathrm{KBr})$. Esse conteúdo foi ultracentrifugado e o sobrenadante, contendo a LDL, 
recolhido. As ultracentrifugações foram realizadas utilizando-se um rotor $75 \mathrm{Ti}$ (Hitachi Centrifuge), em ultracentrífuga Hitachi Centrifuge, a $40000 \mathrm{rpm} \mathrm{e} 4^{\circ} \mathrm{C}$ [46]. A duração de cada ultracentrifugação foi de 20 horas. Após a separação, as amostras de LDL foram dialisadas em solução fosfato-salina $\left(\mathrm{NaCl} 150\right.$ mM, $\mathrm{Na}_{2} \mathrm{HPO}_{4} 10$ mM, pH 7,4) com ou sem EDTA (10 mM). As diálises foram realizadas visando a retirada de $\mathrm{KBr}$ e, quando desejado, a introdução do EDTA, agente de preservação das amostras contra o processo de oxidação natural. A eficiência da diálise foi avaliada pelas medidas da condutividade elétrica e do $\mathrm{pH}$ das amostras, tendo como referência a solução de diálise, garantindo-se assim que as amostras estivessem em condições análogas às fisiológicas, no que se refere à força iônica e ao pH . Às amostras de LDL foram adicionados os inibidores de protease Fluoreto de fenilmetilsulfonil (PMSF, $5 \mu \mathrm{M})$, Aprotinina $(10 \mu \mathrm{g} / \mathrm{mL})$ e Benzamidina $(10 \mu \mathrm{M})$. Após a preparação, as amostras foram filtradas em filtros de $0,22 \mu \mathrm{m}[66,67]$. As concentrações de proteínas das amostras de LDL foram determinadas pelo método colorimétrico que emprega o ácido bicinchonínico, utilizando o kit comercial BCA, seguindo as instruções do fabricante e a albumina foi utilizada como padrão. As absorbâncias foram lidas a um comprimento de onda de $562 \mathrm{~nm}$, em um espectrofotômetro de placas (microplate reader $800 \mathrm{TS}$, da BioTek).

As amostras foram utilizadas, no máximo, uma semana após a preparação [33, 68, 69]. Por esta razão, diferentes processos de separação foram realizados no decorrer do trabalho.

Para os estudos estruturais da LDL in vivo as etapas de coleta das amostras de plasma e separação da LDL foram realizadas por colaboradores. A metodologia é descrita na referencia [50].

\subsubsection{Reações de oxidação}

As reações de oxidação da LDL foram realizadas em diferentes condições, de acordo com o objetivo do estudo no qual foram empregadas. Em todos os casos, a oxidação foi induzida por íons $\mathrm{Cu}^{2+}$, por meio da adição de solução de $\mathrm{CuSO}_{4}$. As reações foram realizadas sem agitação, ao abrigo de luz, e foram interrompidas pela adição de EDTA a $1 \mathrm{mM}$ de concentração final nas amostras [68]. Os tempos de reação, temperatura e concentração de $\mathrm{CuSO}_{4}$ foram parâmetros variados. As condições, referentes a estes parâmetros, serão descritas para cada caso, junto à apresentação dos resultados.

Em alguns casos, além das amostras oxidadas, foi preparada uma amostra controle. A amostra controle corresponde à LDL com adição de cobre, mas contendo EDTA previamente. Desse modo, garante-se uma amostra não oxidada, porém com os mesmos constituintes que 
as amostras oxidadas. As concentrações de $\mathrm{CuSO}_{4}$ e EDTA, portanto, foram mantidas as mesmas da amostra oxidada, com a qual se desejou comparar a controle.

Todas as amostras oxidadas foram utilizadas, no máximo, uma semana após a preparação.

\subsection{Espalhamento de luz dinâmico (DLS)}

O espalhamento de luz dinâmico (DLS, do inglês Dynamic Light Scattering) foi empregado para a determinação do raio hidrodinâmico $\left(R_{H}\right)$ das partículas de LDL. Os dados de DLS foram adquiridos no equipamento 90Plus Particle Size Analyzer (Brookhaven), composto por um laser com comprimento de onda de $657 \mathrm{~nm}$ e um detector a um ângulo fixo de $90^{\circ}$. Para cada amostra, foram realizadas 5 exposições de $3 \mathrm{~min}$, à $37^{\circ} \mathrm{C}$. O software $\mathrm{BIC}$ Dynamic Light Scattering (Brookhaven) foi empregado para os ajustes dos dados experimentais das curvas de correlação $C(t)$, pelo método NNLS (Mínimos quadrados não negativos). A análise dos dados relaciona o coeficiente de difusão das partículas (D), dado determinado em um experimento de DLS, com o raio hidrodinâmico $\left(R_{H}\right)$ das mesmas, pela relação de Stokes-Einstein, dada por [70]:

$$
\mathrm{D}=\frac{\mathrm{k}_{\mathrm{B}} \mathrm{T}}{6 \pi \eta \mathrm{R}_{\mathrm{H}}}
$$

sendo $\mathrm{k}_{\mathrm{B}}$ a constante de Boltzmann, $\mathrm{T}$ a temperatura da solução, $\eta$ a viscosidade do solvente [70].

Os resultados, dos ajustes dos dados experimentais, foram empregados nos cálculos dos raios médios, para cada uma das amostras analisadas. Para o cálculo de raio médio, foi considerada a contribuição de cada valor de raio para a intensidade total detectada.

\subsection{Espalhamento de raios X a baixos ângulos (SAXS)}

\subsubsection{Coleta, integração e tratamento dos dados}

Os dados de SAXS foram coletados no Laboratório Nacional de Luz Sincrotron (LNLS) ou no equipamento pertencente ao GFCx - IFUSP. No primeiro caso, os dados foram coletados na Linha SAXS 1 - Laboratório Nacional de Luz Sincrotron, a um comprimento 
de onda de 1,48 Å. A distância entre a amostra e o detector foi de 3,0 metros, fornecendo um intervalo, para os valores de $q$, de 0,004 a $0,15 \AA^{-1}$. As amostras foram acondicionadas em porta-amostras com janelas de mica e as medidas realizadas em vácuo e temperatura ambiente $\left(22,0^{\circ} \mathrm{C}\right)$. As curvas de SAXS foram geradas, a partir dos dados coletados, pela integração das intensidades registradas, utilizando uma rotina disponível no LNLS. Os dados foram normalizados para escala absoluta e os erros estimados com o programa SUPERSAXS (Oliveira JCP and Pedersen JS, não publicado). Em nosso laboratório, os dados de SAXS foram coletados em um equipamento Xeuss 2.0 (Xenocs SAS ${ }^{2}$ ), com uma fonte de raios X de $\mathrm{Cu}(\lambda=1,54 \AA)$ e um detector Dectris Pilatus ${ }^{\mathrm{TM}} 300 \mathrm{k}$. As distâncias entre a amostra e detector foram de 1,2 ou 2,5 metros. Estas configurações forneceram os intervalos de $q$ de

$0,009<q<0,326 \AA^{-1}$ e $0,004<q<0,157 \AA^{-1}$, respectivamente. As amostras foram acondicionadas em porta-amostras caseiros e as medidas realizadas em vácuo e temperatura controlada $\left(37,0 \pm 0,1^{\circ} \mathrm{C}\right)$. O tempo total das medidas foi de $3 \mathrm{~h}$ para cada amostra.

Os primeiros experimentos de SAXS foram realizados no LNLS, devido às configurações, que possibilitaram os intervalos de $q$ desejados. Posteriormente a isso, foi adquirido um novo equipamento de SAXS, pelo GFCx, possibilitando a coleta de dados, em uma faixa ampla de valores de $q$, em nosso laboratório.

A configuração adotada, para cada estudo, será mencionada junto aos resultados.

\subsubsection{Análise dos dados}

\section{Análises pelo método da transformada de Fourier indireta (IFT)}

As análises pelo método da transformada de Fourier indireta (IFT) foram realizadas com o programa GNOM [71]. Para tais, as amostras foram consideradas como sistemas monodispersos. As análises forneceram os ajustes teóricos dos dados experimentais e as curvas $p(r)$. Os valores máximos de $r$ foram fornecidos ao programa.

\section{Análises pelo método da generalização da transformada de Fourier inversa (GIFT)}

Para os casos nos quais foi caracterizado apenas um dos componentes do sistema, os oligômeros da LDL, as análises de dados de SAXS envolveram o desacoplamento entre o fator de forma $P(q)$ e o fator de estrutura $S(q)$. Nesses casos, para a intensidade espalhada 
definida na equação 2.5 , temos $\mathrm{P}(q)=I(q)_{\text {mon }}$ e $S(q)=I(q)_{\text {olig }}$, sendo $I(q)_{\text {mon }}$ a intensidade espalhada pelas partículas de LDL e $I(q)_{\text {olig }}$ a contribuição de seus oligômeros. O método da generalização da transformada de Fourier inversa (GIFT), inicialmente proposto por Glatter $[72,73]$ é um dos métodos que permite este desacoplamento. No presente trabalho, este foi o método empregado, por meio do programa WGIFT [74]. Foi empregado o modelo que considera a expressão de Guinier para descrever o comportamento de partículas oligoméricas globulares, sendo o fator de estrutura, nesse caso, dado por $[53,75]$ :

$$
S(q)=1+S_{c}^{\text {olig }} e^{-\left(q^{2} R_{G}^{\text {olig }}{ }^{2}\right) / 3},
$$

onde $R_{G}^{\text {olig }}$ é o raio de giro dos oligômeros e $S_{c}^{\text {olig }}$ um fator de escala, relacionado à fração não monomérica presente no sistema [53, 75].

\section{Modelagem $A b$ initio}

A modelagem ab initio foi aplicada ao estudo de caracterização dos oligômeros da LDL, fornecendo uma sugestão da forma tridimensional destes. Para a modelagem ab initio, foi utilizado o programa DAMMIN [76], que se utiliza da abordagem dummy atom model, ou modelagem com átomos fictícios. Foi considerado que os agregados da LDL são formados por partículas isoladas $[27,75]$ e utilizado o modo expert do programa, que permite a escolha de um valor de raio para os dummy atoms. Para este foi escolhido um valor semelhante ao raio médio das partículas de LDL.

Os dados de entrada foram os dados teóricos das intensidades espalhadas, resultantes da extrapolação para valores extremamente pequenos de $q$, resultantes das análises com o método GIFT. Estas intensidades teóricas correspondem a informações dos agregados apenas, sem a contribuição da LDL monomérica [75].

\section{Modelagem dos dados de intensidade espalhadas - $I(q)$}

Considerando a resolução da técnica de SAXS, a modelagem dos dados envolveu parâmetros globais das partículas de LDL. Os dados experimentais, de intensidades espalhadas em função dos valores de $q, I(q)$, foram modelados retornando o raio total da partícula $(R)$ e seus contrastes relativos de densidade eletrônica $(\mu)$. O modelo empregado foi o descrito na seção 2.1.2. 


\subsection{Espectroscopia UV-vis}

Os coeficientes de absorção $(\alpha)$ foram determinados a partir da absorbância $(A)$ das amostras no comprimento de onda de $532 \mathrm{~nm}$. A absorbância de um meio é dada por $A=$ $-\ln \left(\mathrm{I} / \mathrm{I}_{0}\right)$, sendo $\mathrm{I}$ e $\mathrm{I}_{0}$, respectivamente, as intensidades transmitida e incidente sobre a amostra. A razão entre essas intensidades pode ser escrita em função de $\alpha$ e do caminho óptico $(l)$ percorrido pela luz, como $\mathrm{I} / \mathrm{I}_{0}=e^{-\alpha l}$. Logo, o coeficiente de absorção pode ser determinado pela relação,

$$
\alpha=A \frac{\ln 10}{l}
$$

Os valores de $A$ foram obtidos dos espectros de absorção. Tais espectros correspondem aos dados de extinção, descontando-se a contribuição de espalhamento. Para tal, foi considerada a contribuição do espalhamento Rayleigh, cuja intensidade é inversamente proporcional à quarta potência do comprimento de onda $\left(\lambda^{-4}\right)[77,78]$. Os dados de extinção foram adquiridos em um arranjo de espectroscopia de ultravioleta visível (UV-VIS) (USB4000, da Ocean Optics). As amostras foram analisadas em cubetas de quartzo com caminho óptico de $1 \mathrm{~cm}$. A temperatura foi controlada $\left(37^{\circ} \mathrm{C}\right)$ e o intervalo de comprimentos de onda foi de 200 a $800 \mathrm{~nm}$.

\subsection{Coeficientes ópticos $d n / d T$ e $d n / d c$}

A dependência linear do índice de refração com a temperatura e com a concentração das amostras, foram exploradas para a determinação dos coeficientes ópticos $d n / d T e d n / d c$, respectivamente. Os índices de refração foram medidos em um refratômetro (ATAGO500i).

\subsection{Varredura-Z}

\subsubsection{Arranjo óptico}

Os experimentos ópticos foram realizados em um arranjo composto por um laser $\mathrm{CW}$, com perfil gaussiano, e comprimento de onda de $\lambda=532 \mathrm{~nm}$ (Verdi V-10, Coherent). A parte inicial do arranjo é composta por duas lentes convergentes no intervalo das quais um shutter é posicionado. A primeira das lentes (L1) promove a focalização do feixe para o sutther, 
possibilitando o controle dos intervalos de tempo de irradiação das amostras. Após a passagem pelo shutter, o feixe é novamente focalizado, pela segunda lente (L2), para a lente principal do arranjo (L3). Esta lente principal fará com que o feixe seja focalizado na região de deslocamento da amostra sendo, portanto, a componente do arranjo experimental que promove a formação da cintura do feixe, na qual o raio do feixe é mínimo $\left(w_{0}\right)$, e que permite a incidência de diferentes intensidades sobre a amostra, quando está é deslocada ao longo do eixo z. O deslocamento da amostra é realizado por um microdeslocador, controlado pelo programa de aquisição de dados, e sobre o qual um porta-amostra é inserido. A intensidade transmitida pela amostra é captada por um fotodetector, posicionado no campo distante.

Nesse arranjo, a íris é posicionada a uma distância de cerca de 1 metro da região de deslocamento da amostra. O fotodetector possui conexão com um osciloscópio que registra as intensidades ao longo do tempo. O sinal do osciloscópio é registrado pelo programa de aquisição dos dados. A Figura 3.1 mostra um esquema do arranjo óptico utilizado, disponível no GFCx.

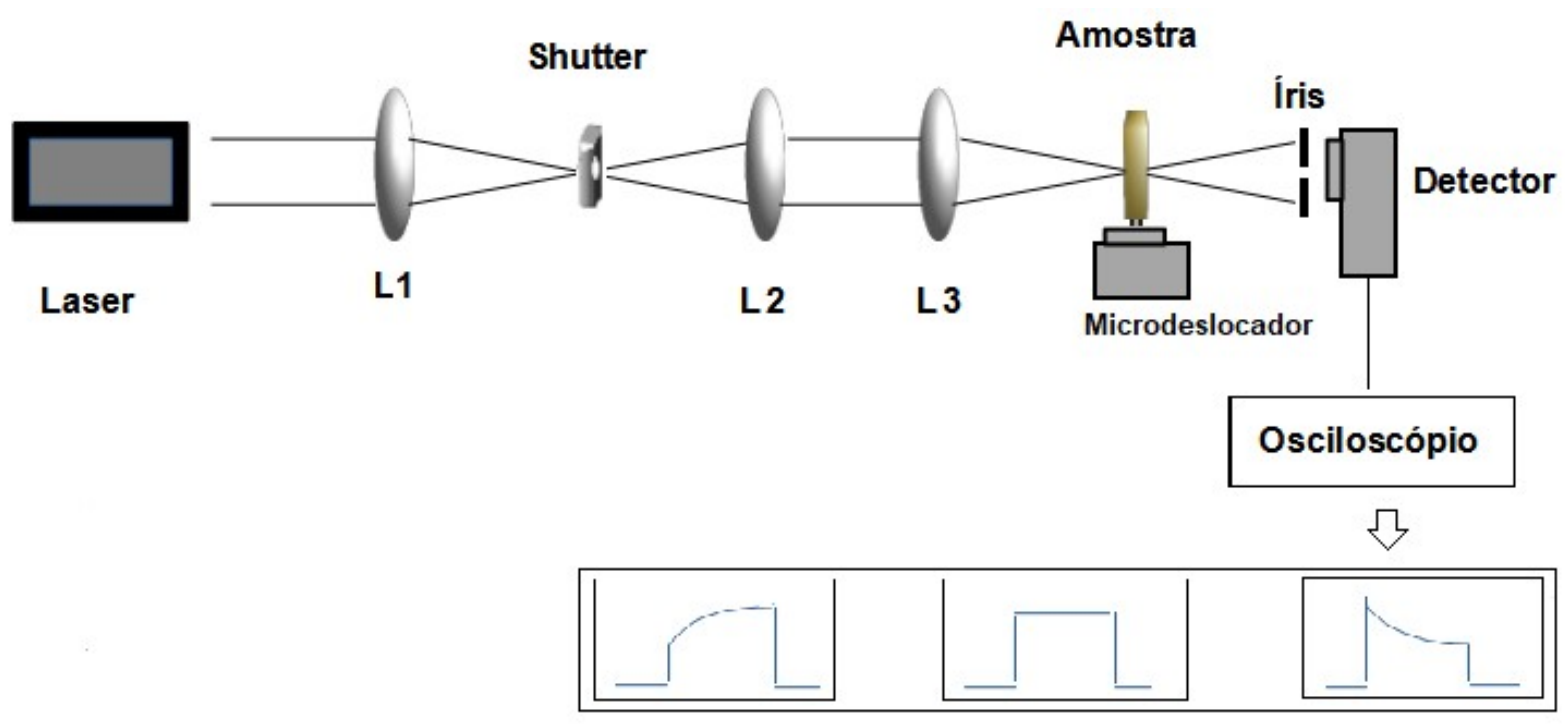

Figura 3.1 Esquema do arranjo óptico para a realização dos experimentos de ZS.

\subsubsection{Aquisição de dados}

O programa zscan_shutter, desenvolvido no GFCX-IFUSP, foi o programa de aquisição empregado. Para a execução do experimento, são fornecidas ao programa as 
configurações, sendo essas, informações de intervalo de tempos, posições de deslocamento da amostra, número de aquisições e de posições. Os dados adquiridos correspondem às intensidades transmitidas, em função do tempo, para cada posição experimental $z$, isto é, $T(z, t)$, para um $z$ fixo.

As amostras foram analisadas em cubetas de quartzo com caminho óptico de $200 \mu \mathrm{m}$ (Hellma Q170-700). Todos os experimentos foram realizados à temperatura de $(37,0 \pm 0,1)$ ${ }^{\circ} \mathrm{C}$ e a potência do laser foi de $(0,10 \pm 0,01) \mathrm{W}$.

Para induzir a lente térmica, a incidência do laser sobre as amostras foi modulada para pulsos quadrados de 50 milissegundos. A varredura foi realizada em 60 posições, ao longo do eixo $z$, sendo 10-12 o número de aquisições em cada posição. A passagem do laser, e sua interrupção, foram controladas pelo shutter. Para a obtenção dos dados de intensidade transmitida em função da posição, os dados foram normalizados, pelo instante inicial do pulso registrado, resultando em $T_{N}(z)=T(z, t) / T(z, 0)$. Os dados experimentais, $T_{N} \mathrm{x} z$, foram ajustados segundo o modelo de LT (equação 2.23), fornecendo os valores para a amplitude da lente térmica $\left(\theta_{L T}\right)$.

Nos experimentos de lente Soret, a duração dos pulsos foi ajustada para 50 segundos, com 120 segundos de intervalo, permitindo o resfriamento da amostra e evitando um efeito térmico acumulativo. O controle da passagem do laser também foi realizado via shutter. As amostras foram mantidas fixas, em posições positivas em torno da posição de máxima desfocalização do feixe, ou seja, posição na qual a resposta para a lente térmica é máxima em torno de $z=\sqrt{2} z_{0}$ [58], sendo $z_{0}$ o parâmetro de Rayleigh, definido no capítulo de fundamentação teórica. O número de aquisições variou entre 10 e 12, para cada posição $Z$. A definição das posições para a realização dos experimentos de lente Soret, se deu com base nos resultados de lente térmica, obtidos na primeira etapa do experimento. Os dados experimentais foram ajustados pela equação 2.33, retornando a amplitude da lente Soret $\left(\theta_{L S}\right)$. Neste caso, foram ajustados os dados de $T(z, t)$ em uma posição $z$ fixa, ajustando-se, portanto, os dados de evolução temporal da intensidade medida. As amplitudes das lentes térmica e Soret $\left(\theta_{L T}\right.$ e $\theta_{L S}$, respectivamente) foram introduzidas na equação 2.32, para a determinação do $S_{T}$. 


\section{Resultados e discussões}

Neste capítulo serão apresentados os resultados do trabalho, divididos em estudos estruturais da oxidação da LDL e estudos da termodifusão da LDL.

\subsection{Estudos estruturais da LDL}

\subsubsection{Avaliação dos efeitos do tempo de reação e da concentração do agente oxidante na oxidação da LDL}

Essa etapa foi realizada a fim de avaliar a influência dos fatores concentração de agente oxidante e tempo de reação, na oxidação in vitro da LDL. Para tal, amostras de LDL, oxidadas em diferentes condições, tiveram suas alterações estruturais investigadas por meio da técnica de SAXS. As amostras foram obtidas por reações empregando diferentes concentrações de $\mathrm{CuSO}_{4}\left(\mathrm{C}_{M}\right)$ e diferentes tempos de reação $\left(t_{R}\right)$. Embora seja conhecido que estes fatores são influentes na indução da oxidação da LDL, será aqui apresentada uma abordagem estrutural.

A tabela 4.1 mostra os valores adotados para as concentrações molares de $\mathrm{CuSO}_{4}$, no meio reacional, e os tempos de reação adotados para cada condição. Todas as reações foram a $25{ }^{\circ} \mathrm{C}$. Os dados de SAXS foram coletados no LNLS - linha SAXS1 —, com as configurações e condições descritas no item 3.3.1. As análises dos dados foram realizadas pelo método IFT.

Tabela 4.1. Valores de tempos e razões molares empregados nos ensaios de oxidação da LDL.

\begin{tabular}{cc}
\hline Concentração de $\mathrm{CuSO}_{4}\left(\mathrm{C}_{\mathrm{M}}\right)$ & Tempos de reação $\left(\mathrm{t}_{\mathrm{R}}\right)$ \\
\hline $\mathrm{C}_{1}=35 \mu \mathrm{M}$ & $\mathrm{t}_{1}=1 \mathrm{~h} 20 \mathrm{~min}$ \\
$\mathrm{C}_{2}=50 \mu \mathrm{M}$ & $\mathrm{t}_{2}=2 \mathrm{~h} 20 \mathrm{~min}$ \\
$\mathrm{C}_{3}=90 \mu \mathrm{M}$ & $\mathrm{t}_{3}=3 \mathrm{~h} 40 \mathrm{~min}$ \\
$\mathrm{C}_{4}=160 \mu \mathrm{M}$ & $\mathrm{t}_{4}=6 \mathrm{~h} 45 \mathrm{~min}$ \\
\hline
\end{tabular}

Para a LDL nativa, como apresentado na Figura 4.1, foi possível verificar resultados coerentes com a literatura $[45,73,76]$, mostrando que a metodologia empregada na obtenção das amostras permite reproduzir tais resultados. 

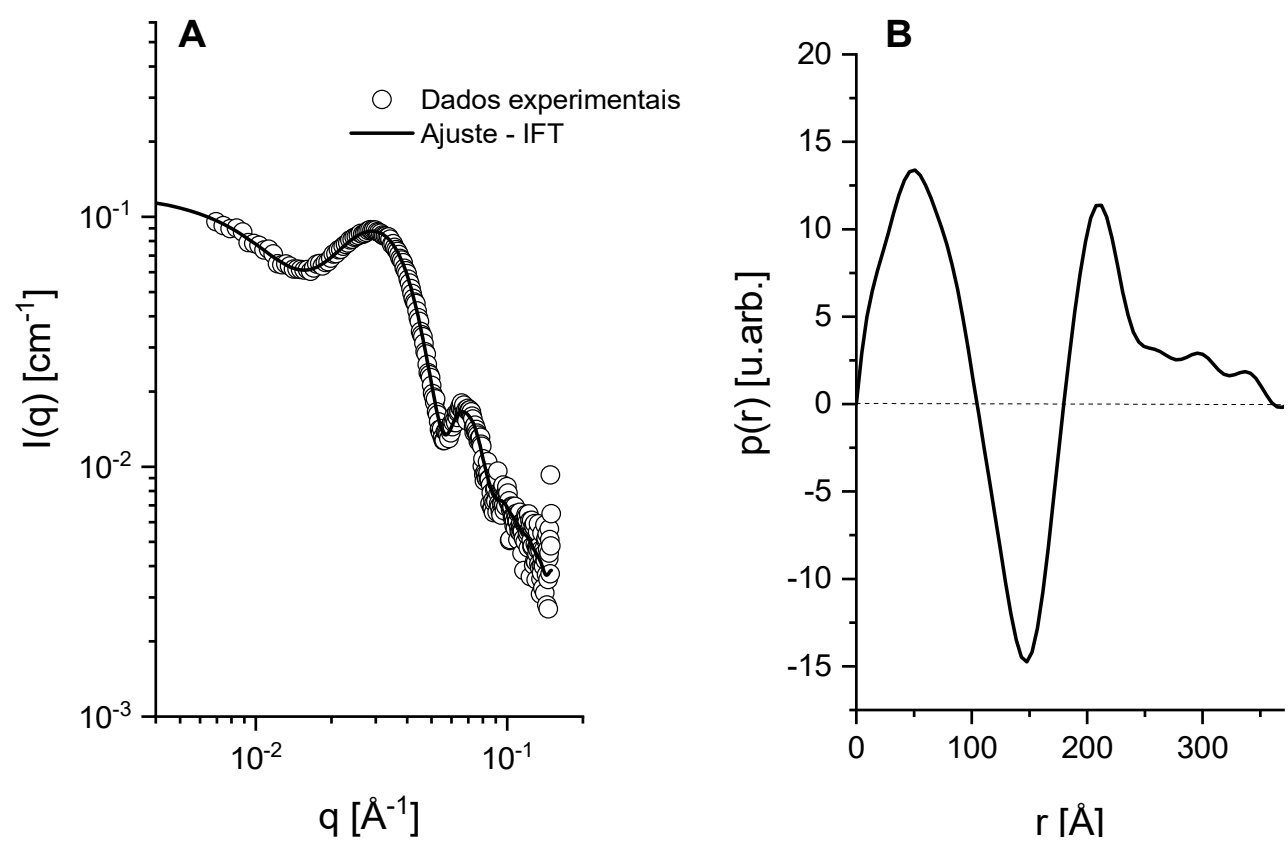

Figura 4.1. Resultados das análises dos dados de SAXS pelo método IFT, característicos para as partículas de LDL. (A) Curva de intensidade espalhada em função de $q$ e (B) curva da função $p(r)$ para uma amostra de LDL, sem a indução da oxidação. Em (A) os pontos representam os dados experimentais enquanto as curvas teóricas, para os ajustes pelo método IFT, são representadas pelas linhas.

A LDL é uma partícula composta por diferentes constituintes, cada um desses apresentando uma densidade eletrônica. Na Tabela 4.2 são apresentados os valores de densidade eletrônica dos diferentes componentes da LDL, e o valor que determinamos para a densidade eletrônica da água, para comparação. Esses valores mostram, portanto, que a constituição da LDL acarreta diferenças de densidade eletrônica, em regiões distintas da partícula, e que seus constituintes terão diferentes contrastes de espalhamento $(\Delta \rho)$. Além disso, cada um desses componentes fornece uma contribuição para o contraste de densidade eletrônica global do núcleo e da monocamada da LDL. As diferenças de densidade eletrônica, na partícula de LDL, fazem com que a curva de intensidades espalhadas, apresente dois máximos característicos, para o intervalo de valores de q em questão (Figura 4.1A). Tal característica, a variação de densidade eletrônica na partícula de LDL, também é indicada na curva $p(r)$ (Figura 4.1B), sobre a qual comentaremos mais detalhadamente em seguida. 
Tabela 4.2. Valores de densidade eletrônica para as moléculas que compõem as partículas de LDL (retirado de Muller et al, 1978 [79]). Valor determinado para a água: $334 \mathrm{e} / \mathrm{nm}^{3}$.

\begin{tabular}{cc}
\hline Componente & $\rho\left(\mathrm{e} / \mathrm{nm}^{3}\right)$ \\
\hline Proteína & 447 \\
Fosfolipídios & 340 \\
Colesterol & 347 \\
Colesterol esterificado & 309 \\
Triglicerídios & 309 \\
\hline
\end{tabular}

A função $p(r)$ já foi definida na seção 2.1, acrescentaremos aqui apenas alguns aspectos relacionados à interpretação dos resultados obtidos. Dado que a $p(r)$ corresponde a um histograma dos pares de distâncias $(r)$, que ocorrem no interior da partícula espalhadora, cada ponto em sua abscissa corresponde a um valor de par de distâncias $r$, enquanto os valores em sua ordenada representam a frequência de ocorrência de cada um desses valores de $r$. A origem da curva é em zero, uma vez que nenhum par de distância pode assumir o valor nulo. A extremidade final da curva também é nula, pois nenhum par de distâncias pode assumir um valor $r$ superior à dimensão máxima da partícula espalhadora. Logo, a $p(r)$ pode indicar alterações estruturais relacionadas à dimensão das partículas. Além disso, a distribuição das distâncias é normalizada pelo produto dos contrastes de espalhamento $(\Delta \rho)$, das regiões nas quais se encontram as extremidades do segmento $r$ [80]. Sendo assim, para partículas com regiões de diferentes densidades eletrônicas, que acarretem contrastes de espalhamento de sinal contrário $(\Delta \rho>0$ e $\Delta \rho<0)$, ocorrem regiões negativas na $p(r)$. Esse perfil é característico de partículas multicamadas como, por exemplo, as do tipo núcleocamada [51]. Desse modo, a $p(r)$ pode indicar alterações da distribuição da densidade eletrônica que ocorrem neste tipo de partículas.

Para a curva $p(r)$, obtida com a análise dos dados de espalhamento de uma amostra da LDL nativa (Figura 4.1B), nota-se um perfil característico de partículas núcleo-camada, esféricas, compostas por essas duas regiões dispostas de forma concêntrica, e apresentando contrastes de espalhamento de sinais contrários $(\Delta \rho>0$ e $\Delta \rho<0)$ [51].

Além disso, a curva $p(r)$, relacionada às partículas de LDL, apresenta três regiões características. A primeira destas, uma região positiva que se estende de valores de $r$ de 0 a aproximadamente $75 \AA$, tem sua contribuição associada aos ésteres de colesterol e triglicérides, constituintes do núcleo da partícula [80,81]. Os hidrocarbonetos que compõem 
as caudas dos fosfolipídios, constituintes da monocamada da partícula, são relacionados com a região negativa da $p(r)$, um mínimo na proximidade $140 \AA[80,81]$. Uma segunda região positiva, caracterizada por um máximo na região de $200 \AA$, tem associação com a cabeça dos fosfolipídios e com a apolipoproteína, ambos localizados na camada externa da LDL [80, 81]. A Figura 4.2 mostra, de modo global, essas três regiões. A curva apresentada é a $p(r)$ obtida para uma amostra de LDL nativa.

A

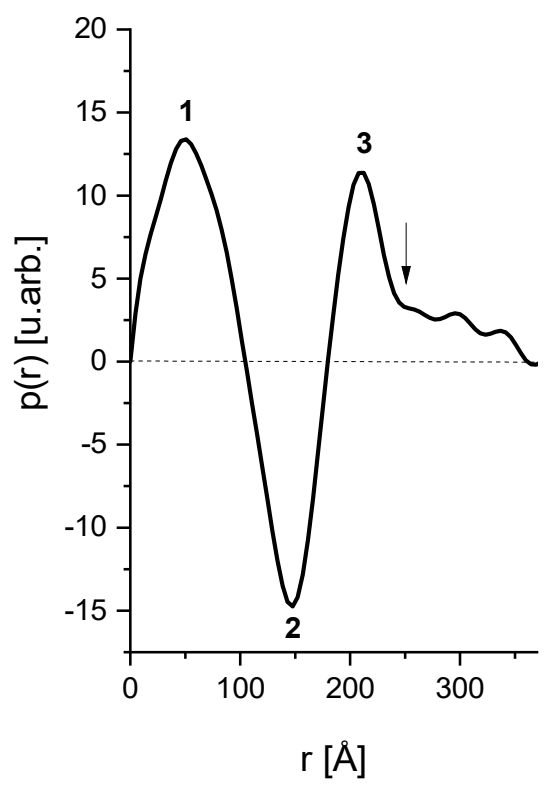

B

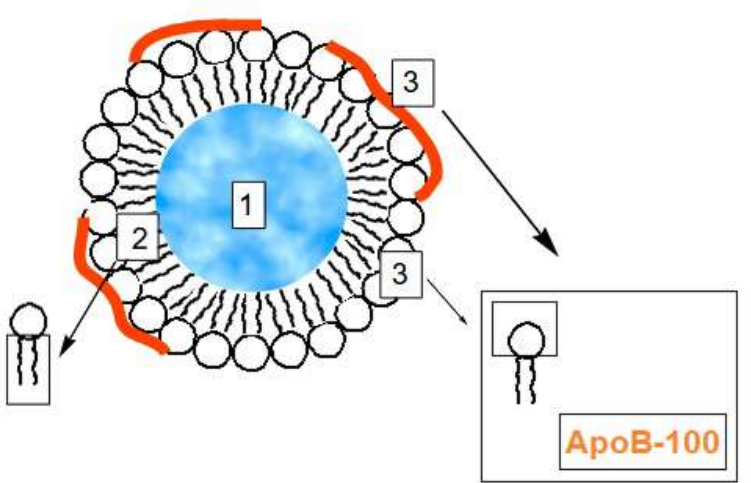

Figura 4.2. (A) Perfil da curva $p(r)$ para as partículas de LDL, obtida pelo método IFT (programa GNOM). Os números indicam as regiões associadas ao núcleo da partícula (1), aos hidrocarbonetos dos fosfolipídios (2) e às cabeças dos fosfolipídios e à ApoB-100 (3). A seta indica a dimensão máxima dos monômeros que, nesse caso, foi indicado como 245 Å. (B) Esquema ilustrativo de uma partícula de LDL indicando seus constituintes, cujas contribuições são associadas às regiões das curvas $p(r)$.

É esperado que a função $p(r)$ assuma o valor zero na região correspondente à máxima dimensão da LDL, cujo diâmetro médio está em torno de $250 \AA$, podendo este valor variar para cada amostra. No entanto, a $p(r)$ pode não ser nula neste ponto, como no caso do resultado apresentado na Figura 4.2, indicando a presença de elementos não monoméricos no sistema. No caso da análise da LDL nativa, isto pode indicar a formação de oligômeros, em decorrência de instabilidades intrínsecas às condições extracorpóreas e da manipulação da 
amostra, ainda que adotadas as condições para evitar a degradação e modificação da partícula. Por esta razão, os resultados para as amostras oxidadas serão comparados entre si, mas tendo como referência os resultados para a amostra nativa. Dessa forma, se garante que as alterações discutidas serão apenas decorrentes do processo oxidativo. Pontuamos aqui que, neste trabalho, faremos uso da terminologia nativa para indicar a LDL sem qualquer indução de modificação in vitro. Os resultados gerais das análises de SAXS, obtidos para o ensaio de oxidação, são apresentados na Figura 4.3. Estes resultados correspondem às condições de reação combinando $C_{M}$ e $t_{R}$ de mesmo índice. Por exemplo, a amostra identificada como 'oxidada 1', foi obtida pela reação de oxidação a uma concentração molar de $\mathrm{CuSO}_{4}$ de 35 $\mu \mathrm{M}\left(\mathrm{C}_{1}=35 \mu \mathrm{M}\right)$ e com duração de $1 \mathrm{~h} 20 \mathrm{~min}\left(\mathrm{t}_{1}=1 \mathrm{~h} 20 \mathrm{~min}\right)$. Um esquema do ensaio, indicando as amostras cuja análise dos dados corresponde aos resultados apresentados, também consta na figura para um melhor entendimento.

A oxidação da LDL, em níveis mais baixos, é sabida ser indutora da agregação dessas partículas. Já a oxidação em níveis mais elevados, resulta em perda da integridade da partícula de LDL [13]. Os resultados na Figura 4.3, se mostraram coerentes com estes referidos estados de agregação e perda de integridade.

Nas curvas mostradas na Figura 4.3A, nota-se um aumento da inclinação dessas na região de baixos $q \mathrm{~s}$, indicativo da formação de oligômeros nas amostras oxidadas. Já as pequenas variações das intensidades dos máximos, para valores maiores de $q$, sugerem que alterações da partícula monomérica também ocorrem. O aumento da dimensão máxima, nas curvas $p(r)$ das amostras oxidadas, em comparação com os resultados para a LDL nativa, é também um indicativo da presença de oligômeros. Ainda com base nos resultados das curvas $p(r)$ (Figura 4.3B), há também um indicativo de alterações estruturais, na partícula de LDL monomérica, devido às variações que estas curvas apresentam. Sendo assim, os resultados sugerem que uma fração das partículas sofra alterações, em decorrência do processo oxidativo, que resultam na agregação da LDL, enquanto uma segunda fração permanece monomérica, mas apresentando alterações estruturais. Estas alterações estruturais estariam relacionadas à distribuição de densidade eletrônica. Tais aspectos são evidenciados nas Figuras 4.4 e 4.5, por meio da reapresentação dos resultados da Figura 4.3.

Vale ressaltar que, as variações observadas, tanto nas curvas $I(q)$ como nas $p(r)$, também poderiam ser resultantes de variações nas dimensões das partículas, e não da formação de oligômeros. No entanto, já foi descrito, em estudos anteriores do nosso grupo, 
não haver alterações significativas nos diâmetros das partículas em função de sua oxidação $[45,53]$. Ainda assim, este será um aspecto verificado mais adiante.
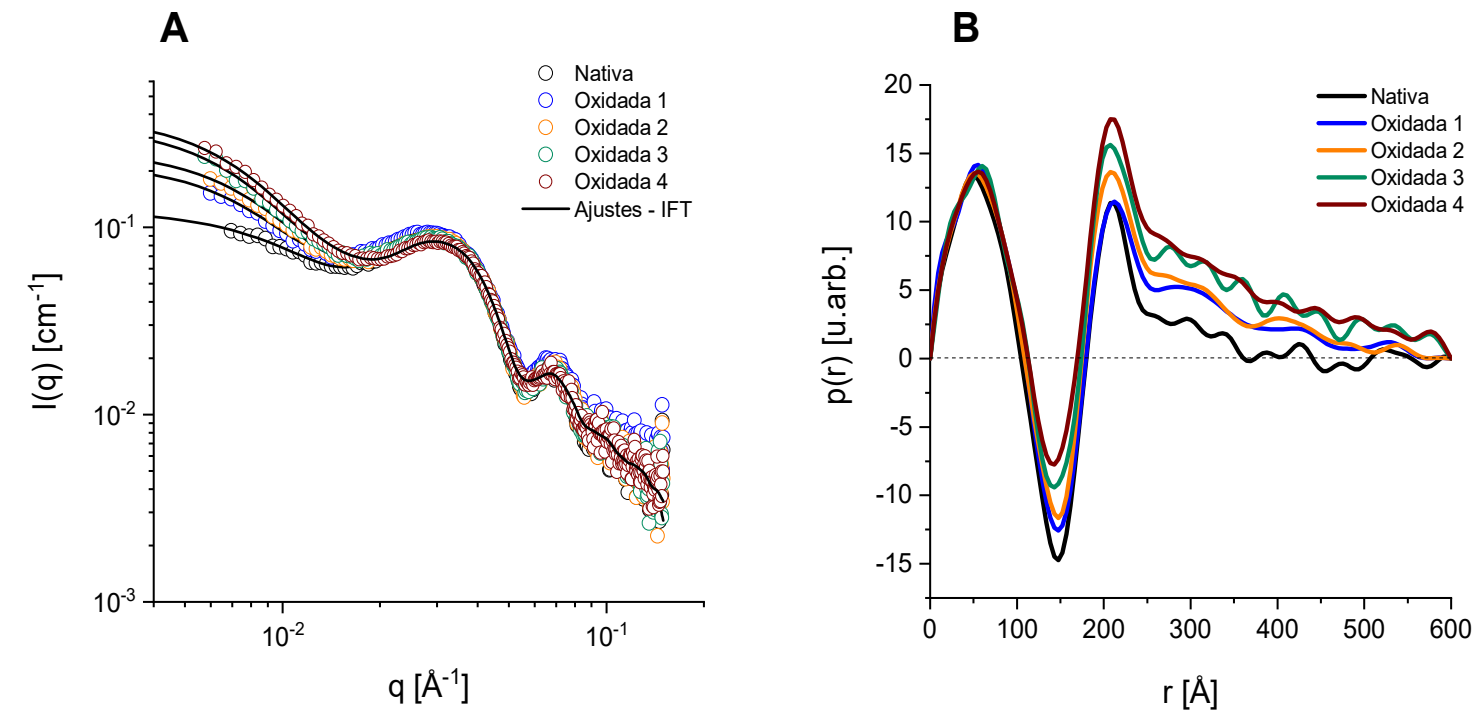

$$
\text { C } \quad \begin{aligned}
\mathrm{C}_{1} & =35 \mu \mathrm{M} \\
\mathrm{C}_{2} & =50 \mu \mathrm{M} \\
\mathrm{C}_{3} & =90 \mu \mathrm{M} \\
\mathrm{C}_{4} & =160 \mu \mathrm{M}
\end{aligned}
$$
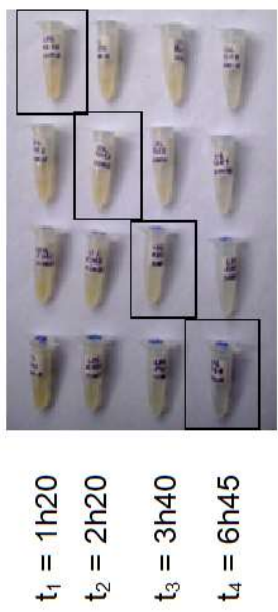

Figura 4.3. Curvas de espalhamento (A) e curvas das funções $p(r)$ (B) para as amostras de LDL nativa e oxidadas, nas condições que combinaram $\mathrm{C}$ e $\mathrm{t}$ de mesmo índice. (C) Esquema dos ensaios de oxidação in vitro da LDL: Cada linha corresponde a uma mesma concentrações de $\mathrm{CuSO}_{4} \mathrm{e}$ tempos de reação variados. Cada coluna, a um mesmo tempo de reação e concentração de $\mathrm{CuSO}_{4}$ diferentes. Os quadros indicam as amostras cujos resultados são apresentados em (A) e (B). Em (A), os símbolos correspondem aos dados experimentais e, as linhas contínuas, aos ajustes pelo método IFT. 


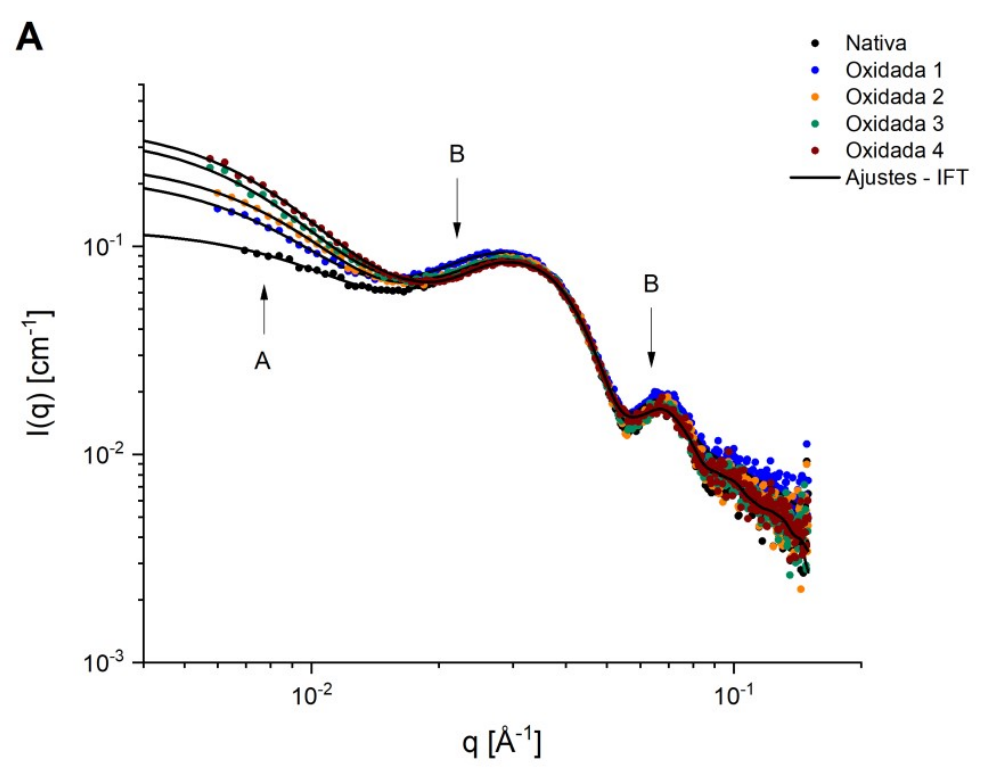

B

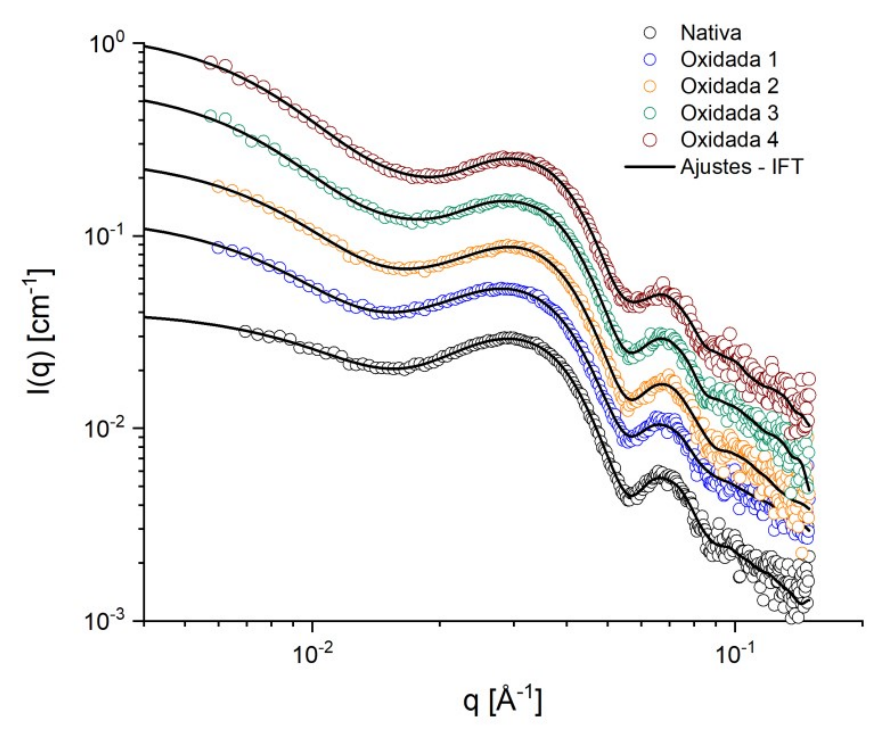

Figura 4.4. A) Curvas de intensidades espalhadas, em função de q, para as análises da LDL oxidada in vitro. Os pontos representam os dados experimentais enquanto as curvas teóricas, para os ajustes pelo método IFT, são representadas pelas linhas. A região indicada por A corresponde aos indicativos de formação de oligômeros da LDL. As regiões indicadas por B sugerem alterações de densidade eletrônica no interior das partículas. B) Os valores de $I(q)$ foram multiplicados por um dado fator, para o deslocamento das curvas, possibilitando uma melhor visualização dos ajustes e do perfil característico dos dados de espalhamento das partículas de LDL. 


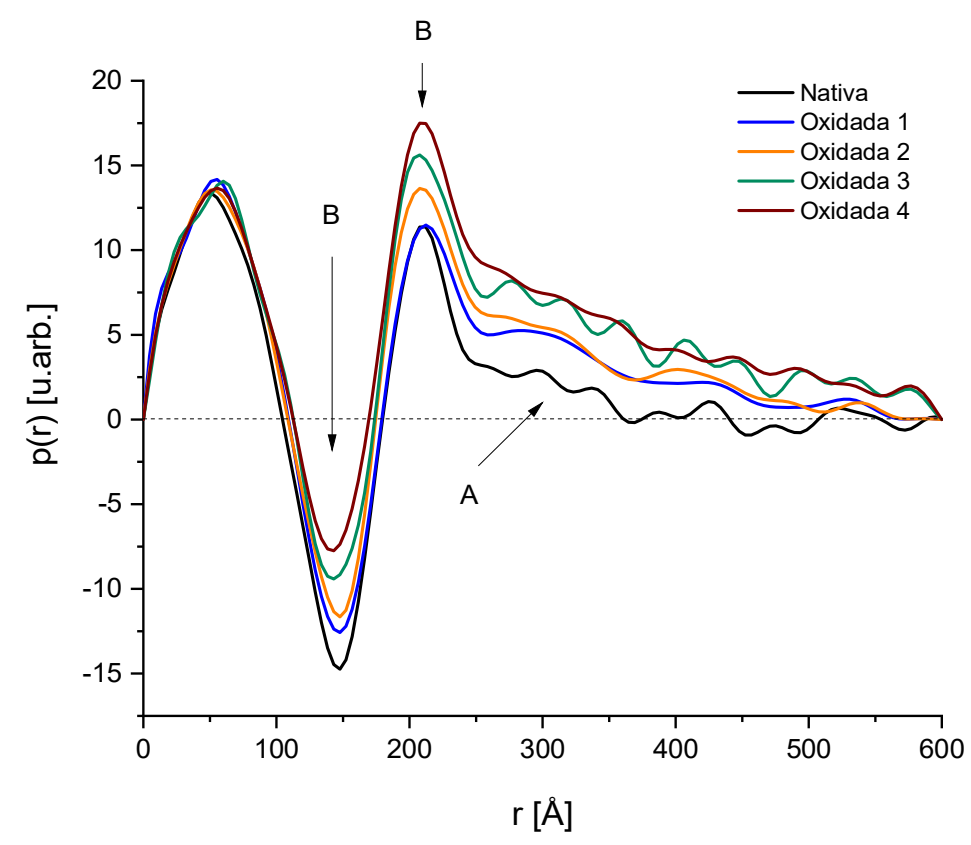

Figura 4.5. Curvas $p(r)$ para as análises da LDL oxidada in vitro, geradas pelo ajuste dos dados de espalhamento pelo método IFT. A região indicada por 'A' corresponde aos indicativos de formação de oligômeros da LDL. As regiões indicadas por 'B' sugerem alterações de densidade eletrônica nas partículas.

Uma avaliação mais detalhada foi possível combinando-se os resultados, de modo que, os efeitos de tempo de reação e concentração do agente oxidante pudessem ser avaliados individualmente. Para a avaliação do efeito temporal, na estrutura da LDL oxidada in vitro, foram comparados os resultados das amostras oxidadas a uma mesma concentração de cobre, em função de diferentes tempos de reação. Já para a análise do efeito da concentração, a comparação se deu entre os resultados das amostras oxidadas, durante um mesmo tempo de reação, sob diferentes concentrações do agente oxidante. Os resultados totalizaram quatro conjuntos, que apresentaram informações similares. Devido a isso, um dos conjuntos de dados foi adotado para apresentação e discussão dos resultados. Os demais resultados podem ser vistos no Anexo I.

\section{Evolução temporal das alterações estruturais induzidas pela oxidação}

Os resultados para a LDL oxidada, a partir de reações a $35 \mu \mathrm{M}$ de $\mathrm{CuSO}_{4}$, são apresentados nas Figuras 4.6 e 4.7. As incertezas associadas aos dados não foram inseridas, para uma melhor visualização dos resultados (Figura 4.6). Para todas as análises foi estabelecido o valor de diâmetro máximo de 600 A. Este valor foi determinado por testes 
iniciais, realizados com os dados que indicaram um maior perfil de oligomerização das amostras, e fixado para todas as demais análises. Considerando que os ensaios foram realizados com uma mesma amostra de partida, para todo o conjunto de reações, nenhuma normalização para os dados foi adotada.

A

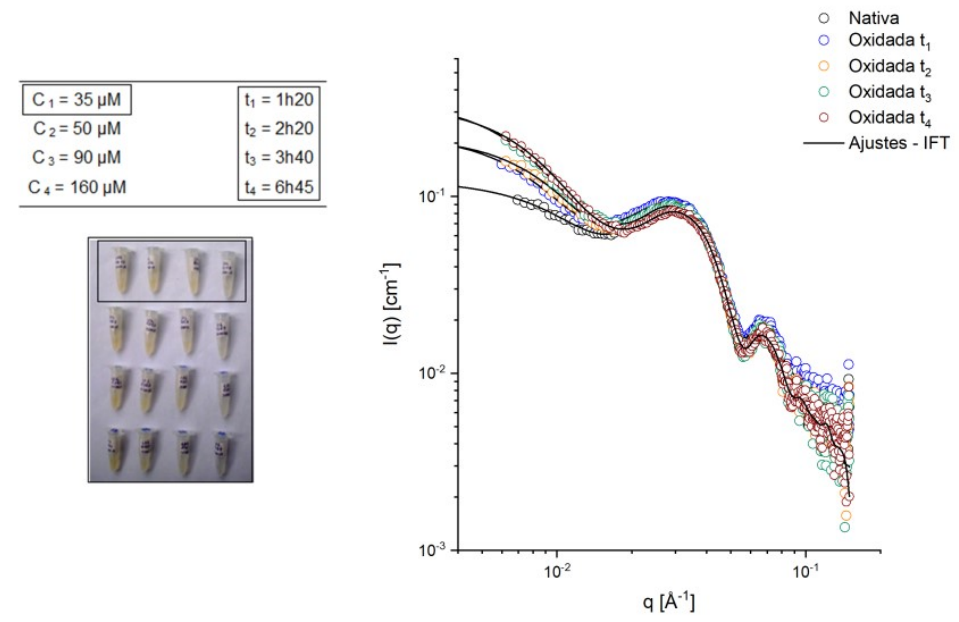

B

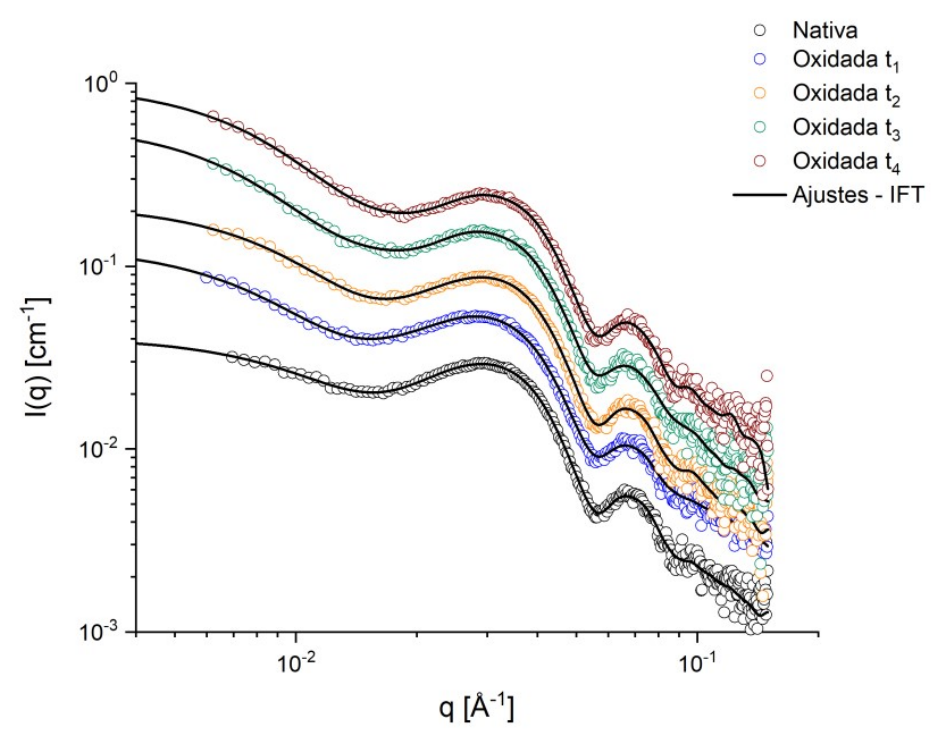

Figura 4.6. (A) Esquema dos ensaios de oxidação e evolução temporal das curvas $I(q)$, indicando alterações estruturais da partícula e do estado oligomérico, nas amostras de LDL oxidada. Os símbolos correspondem aos dados experimentais e, as linhas contínuas, aos ajustes pelo método IFT. B) Os valores de $I(q)$ foram multiplicados por um dado fator, para o deslocamento das curvas, possibilitando uma melhor visualização dos ajustes e do perfil característico dos dados de espalhamento das partículas de LDL. 
Os valores de mínimos e máximos, extraídos das curvas $p(r)$ de cada amostra, são mostradas na Figura 4.8, sendo possível ver a variação desses valores, em função do tempo de oxidação da LDL.

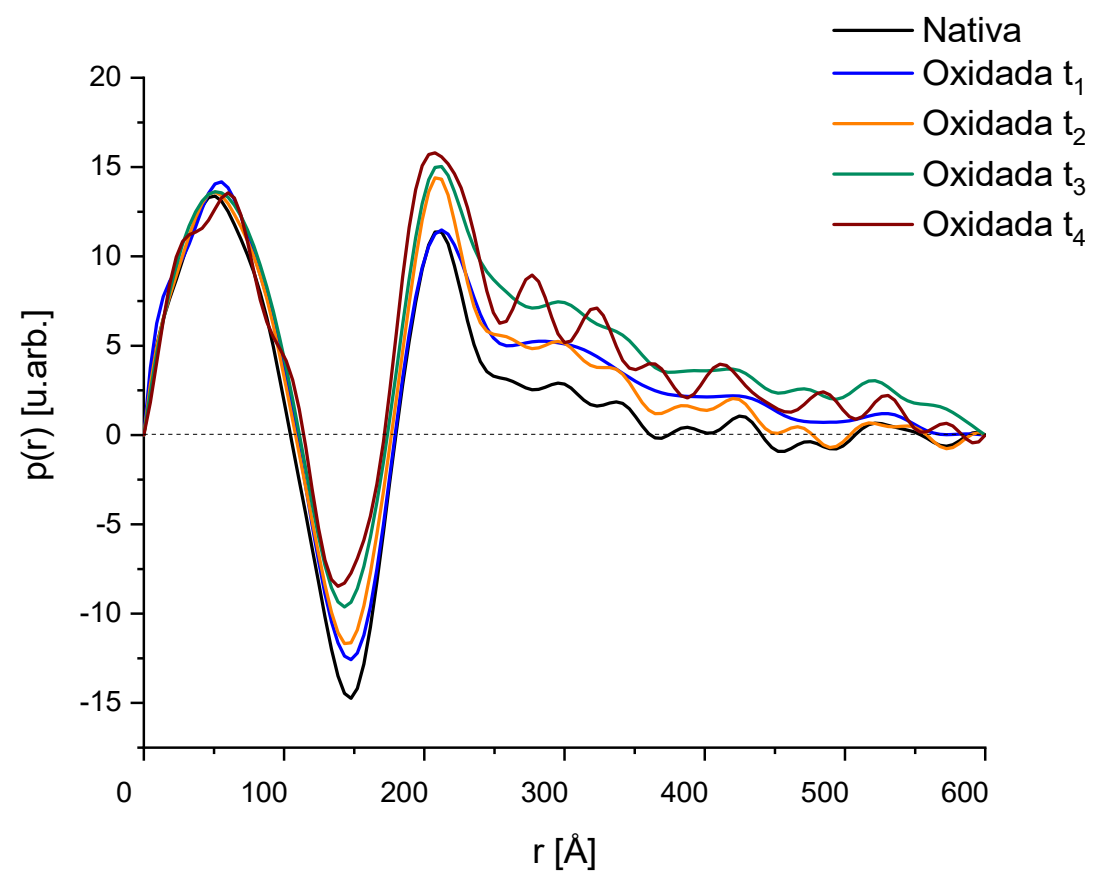

Figura 4.7. Evolução temporal das curvas $p(r)$, indicando alterações estruturais da partícula e do estado oligomérico, nas amostras de LDL, em decorrência da oxidação.

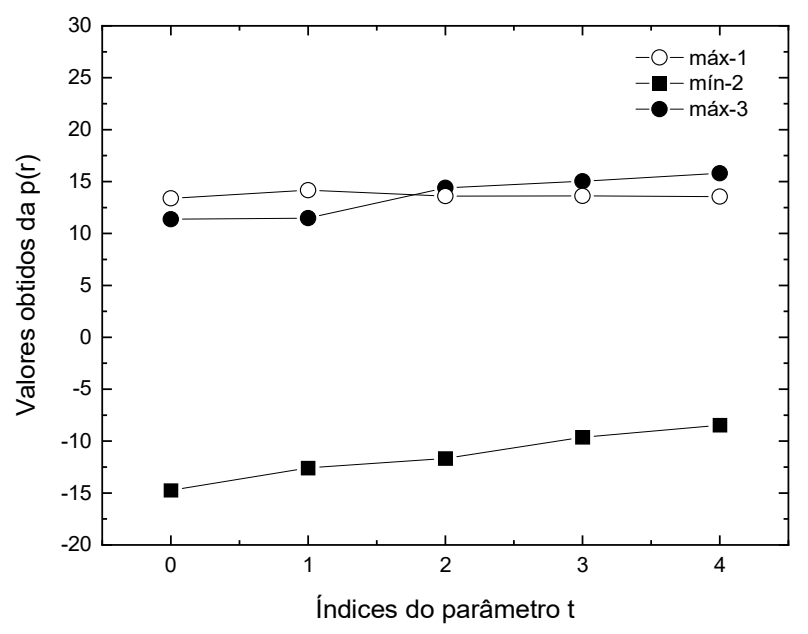

Figura 4.8. Variação dos valores dos máximos e do mínimo, característicos da $p(r)$ das partículas de LDL, em função do tempo de oxidação. Legenda. máx-1: valor do primeiro máximo da $p(r)$; mín-2: valor do mínimo da $p(r)$; máx-3: valor do segundo máximo da $p(r)$; os números 1,2 e 3 fazem menção aos valores dos máximos e mínimos indicados na Figura 4.2. 
Considerando a contribuição dos diferentes componentes da LDL, para o perfil da curva $p(r)$ (Figura 4.2), pode-se inferir qual região da partícula foi afetada pela oxidação. Os resultados apresentados na Figura 4.7, mostram que a região inicial das curvas, referentes às amostras nativa e oxidadas, permanece sem modificações consideráveis. Isto é facilmente visualizado na Figura 4.8, gráfico no qual se observa que os valores para o primeiro máximo da $p(r)$ mostram uma estabilidade. Logo, esse resultado sugere a não alteração do núcleo da LDL, nas condições de oxidação deste ensaio. Este resultado é coerente com a descrição de que alterações nesta região são associadas apenas a condições muito drásticas de oxidação, em geral, resultantes de tempos de reação de mais de 18h [80]. Para as demais regiões da $p(r)$, foram observadas variações entre todas as amostras oxidadas, tanto em relação à amostra nativa, como entre si.

É esperado que a preservação estrutural da partícula de LDL ocorra enquanto o seu conteúdo de antioxidantes não for consideravelmente consumido. Após esta fase, os processos de modificação têm início, primeiramente por ataque aos ácidos graxos poli-insaturados, constituintes dos lipídios. A fase seguinte, ainda relacionada à oxidação dos lipídios, envolve eventos que resultarão na formação de um radical hidroperóxido lipídico, processo que envolve a incorporação de oxigênio $\left(\mathrm{O}_{2}\right)$. Esta incorporação de $\mathrm{O}_{2}$ pode contribuir para um aumento da densidade eletrônica [80] nas cadeias carbônicas dos fosfolipídios. A alteração do mínimo da $p(r)$ pode, portanto, ser associada aos eventos iniciais da oxidação da LDL, caracterizando a peroxidação lipídica que, como descrito, afeta a cauda de hidrocarbonetos dos fosfolipídios constituintes da monocamada. A amostra oxidada por $1 \mathrm{~h} 20$ min, menor dos tempos de reação, mostrou apenas alterações no valor deste mínimo, em comparação com a $p(r)$ da amostra nativa, mostrando coerência com o fato de que estes devem ser os primeiros eventos oxidativos na LDL. As oxidações por tempos maiores também induziram modificações, indicadas nesta região da curva, sendo os valores de mínimos crescentes com o tempo de oxidação, como se verifica na Figura 4.8.

Por último, no processo de oxidação da LDL, como resultado da degradação de produtos da oxidação de lipídios em aldeídos, ocorre a ligação desses a ApoB-100. Este também pensamos ser um fator de aumento da densidade eletrônica na camada externa da LDL, já que há ligação de moléculas à apolipoproteína da LDL. As variações do segundo máximo na $p(r)$, para as amostras oxidadas, poderia ter relação com esses eventos oxidativos. Para a oxidação até 1 h 20 min, não foram observadas modificações relacionadas ao acima descrito. Para os tempos acima de 1 h 20 min, foram observados aumentos gradativos para os 
valores do segundo máximo (Figuras 4.7 e 4.8), suportando a ideia de que estes não são os eventos iniciais da oxidação. Embora pouco descrito, relacionado à peroxidação lipídica, é sábio que as cabeças dos fosfolipídios também podem sofrer processos oxidativos [82]. Estes estariam refletidos também no segundo máximo da $p(r)$ da LDL, não sendo possível uma distinção entre modificações ocorridas nas cabeças dos fosfolipídios ou na ApoB-100, por meio desta abordagem.

Os resultados acima indicam a dependência temporal que a oxidação in vitro da LDL apresenta, mostrando que tais eventos resultam em alterações estruturais destas partículas, e não apenas moleculares, como as descritas para a peroxidação lipídica. Os resultados também sugerem que estas alterações estruturais se iniciam por modificações nas cadeias carbônicas dos fosfolipídos, se estendendo para cabeça destes e/ou para a ApoB-100. Tais alterações envolvem a mudança na distribuição da densidade eletrônica no interior da LDL. Logo, com base nos resultados acima, a camada da LDL é a região afetada na oxidação, estando em conformidade com o que se descreve na literatura para os eventos oxidativos, para tempos inferiores a 12 horas [80]. Uma descrição mais detalhada, de aspectos do processo de oxidação da LDL que tem relação com a discussão acima, é mostrada no anexo II.

Como foi dito ao início da seção, um dos conjuntos de resultados foi adotado para as discussões. Os resultados adotados, e acima apresentados, correspondem à menor concentração de $\mathrm{CuSO}_{4}$ empregada nos ensaios de oxidação. No entanto, foi possível observar, como pode ser visto na compilação de todos os resultados (Anexo I), que o aumento da concentração conduz a diferentes alterações das curvas $p(r)$, embora seja visto um comportamento semelhante. A escolha, por discutir os resultados relacionados ao menor valor de concentração, foi baseada no fato de que as demais concentrações já configuram condições muito drásticas de oxidação. Mas, destacamos que só foi possível esta constatação com base no estudo realizado. Embora supuséssemos se tratar de concentrações muito elevadas, não era conhecido o nível de alterações estruturais que estas pudessem acarretar nas partículas de LDL.

Sendo o aumento da suscetibilidade da LDL à agregação uma característica do dano oxidativo, e a formação de seus oligômeros apontada como um mecanismo relacionado ao desenvolvimento das placas e lesões ateroscleróticas, a mudança do estado oligomérico das amostras oxidadas também foi investigada. A metodologia aplicada por Oliveira et al [51] ao estudo da formação de agregados da LDL, induzida por aquecimento, foi estudada e aqui aplicada ao estudo oxidativo. Assim como no referido trabalho, em nosso estudo, o perfil de 
espalhamento total do sistema pode ser escrito como $I(q)=I(q)_{\text {mon }} I(q)_{\text {olig }}=P(q) S(q)$, levando em consideração a oligomerização da LDL.

Sendo assim, a análise dos dados envolveu, primeiramente, o desacoplamento entre o fator de forma $P(q)$ e o fator de estrutura $S(q)$, por meio do método da IFT generalizada (GIFT). Com base no que já foi mencionado, este desacoplamento se justifica pelo fato de ser o fator de forma um parâmetro relacionado às informações das partículas monoméricas constituintes da amostra, enquanto o fator de estrutura está relacionado às interações entre essas partículas que, nesse caso, resultam nos oligômeros, ou agregados. A fim de exemplificar o que esta análise fornece, são apresentadas na Figura 4.9, as curvas para os fatores de forma e de estrutura, obtidos pela aplicação do método GIFT aos dados experimentais, dados estes também mostrados na figura. Nota-se que o desacoplamento ocorre na região de baixos $q$ s, no início da curva de $I(q)$. A curva $S(q)$ se ajusta bem aos dados dessa região, cuja resolução experimental é maior, enquanto a curva $P(q)$ tem seu ajuste satisfatório para valores maiores de $q$, correspondente à região da curva de intensidades espalhadas por objetos menores. Isto decorre da relação da resolução experimental do SAXS com os valores de $q$ adotados. Por essa razão, estudar e caracterizar os oligômeros, é que foi adotada a coleta de dados no LNLS, única possibilidade, na época, que permitia esse estudo.

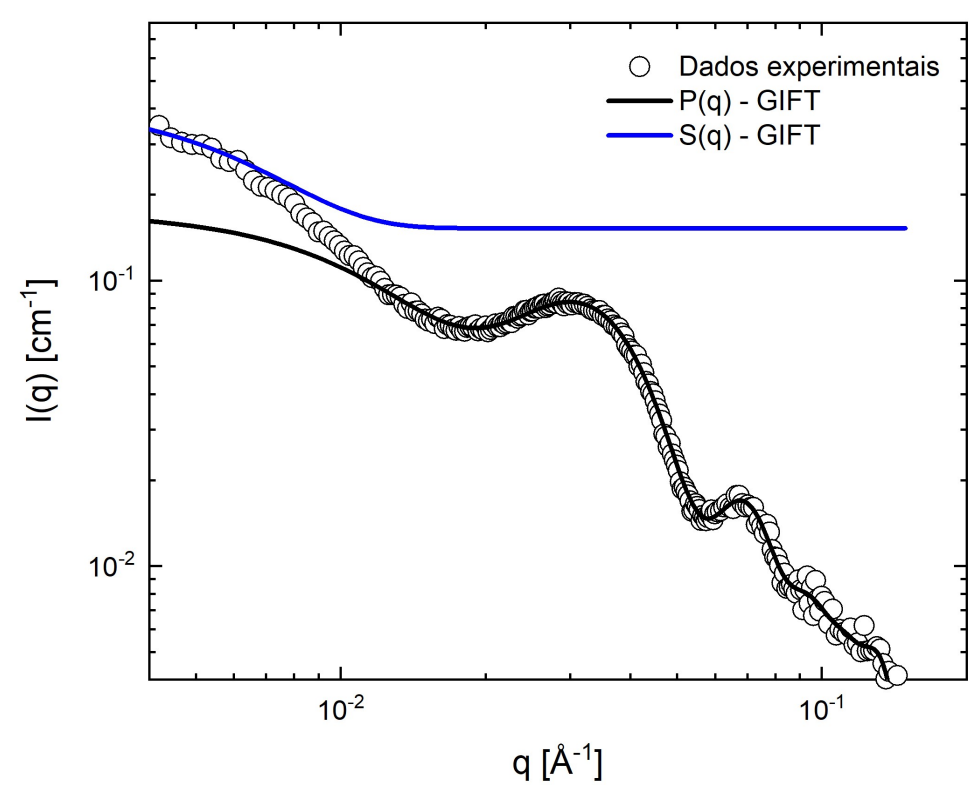

Figura 4.9. Exemplo de um resultado do processo de desacoplamento. Resultados da aplicação do método GIFT, pelo uso do programa WGIFT, para uma amostra de LDL oxidada. São mostradas as curvas para os fatores de forma $P(q)$ e de estrutura $S(q)$, e os dados experimentais analisados. 
Para sistemas compostos por oligômeros globulares, $S(q)$ pode ser descrito por um modelo que considera a expressão de Guinier (equação 3.2) para descrever o comportamento das intensidades espalhadas a baixos ângulos $[53,75]$. Oliveira et al mostraram ser este o fator de estrutura mais adequado à descrição dos dados experimentais de agregados da LDL [75], por isto a escolha desta abordagem para o presente trabalho. A descrição de um fator de estrutura, dado em função do raio de giro médio dos oligômeros $\left(R_{G}^{\text {olig }}\right)$, possibilita o cálculo de intensidades de espalhamento teóricas referentes aos oligômeros $\left(I(q)_{\text {olig }}\right)$, por extrapolação da expressão de Guinier para valores muito pequenos de $q$ [75]. As curvas $I(q)_{\text {olig }}$, geradas com as análises com o método GIFT, foram analisadas pelo método IFT, para o ajuste dos dados de intensidade espalhada e geração das curvas $p(r)$. Esta metodologia de análise por IFT foi a mesma adotada na etapa anterior do estudo, tendo como diferença o uso de toda a informação de intensidade espalhada $I(q)$, para o primeiro caso, ou apenas das informações referentes aos objetos espalhadores maiores, $I(q)_{\text {olig }}$, no presente caso.

Para a construção dos modelos tridimensionais dos oligômeros, a abordagem de modelagem ab initio (dummy atoms) foi a empregada. Os resultados compilados são apresentados na Figura 4.10, na qual são mostrados os ajustes das curvas $I(q)_{\text {olig }}$, pelo método IFT (A), as curvas $p(r)$ resultantes destes ajustes (B) e os modelos tridimensionais para os oligômeros da LDL, resultantes da modelagem ab initio.

O perfil das curvas $p(r)$ (Figura 4.10) sugere estruturas globulares para todos os casos. Para as amostras oxidadas, o formato não totalmente simétrica dessas curvas indica estruturas globulares, mas não com simetria esférica (Figura 4.10B), o que se mostra coerente com os modelos tridimensionais (Figura $4.10 \mathrm{C}$, b-e). Os modelos indicam a presença de oligômeros de mesmas dimensões aproximadas, para as amostras obtidas com os diferentes tempos de oxidação, sugerindo que não ocorre um aumento significativo da dimensão dos agregados, mas podendo ocorrer um aumento da fração de partículas agregadas. Outro aspecto observado foi que, mesmo na amostra nativa, já se observa a presença de agregados, embora em menor fração. Isso indica que pode ter havido algum impacto na estrutura e organização dessa amostra, dadas as condições de laboratório. 
A

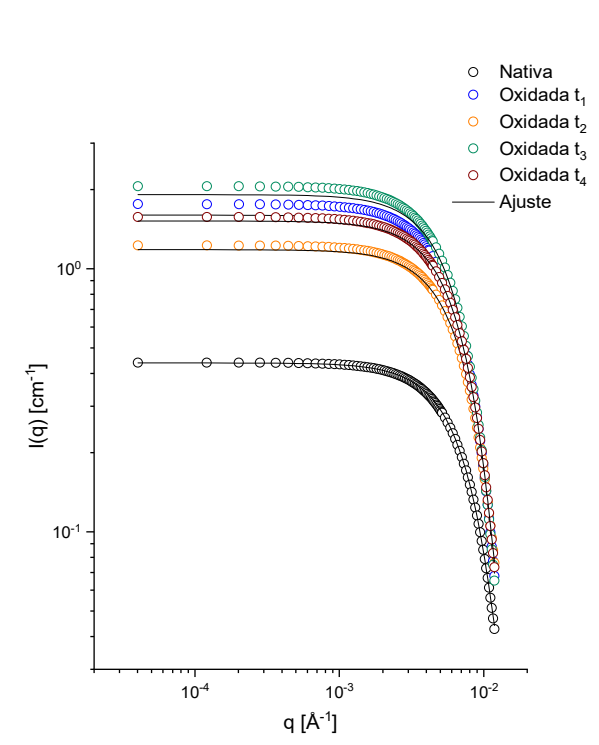

B

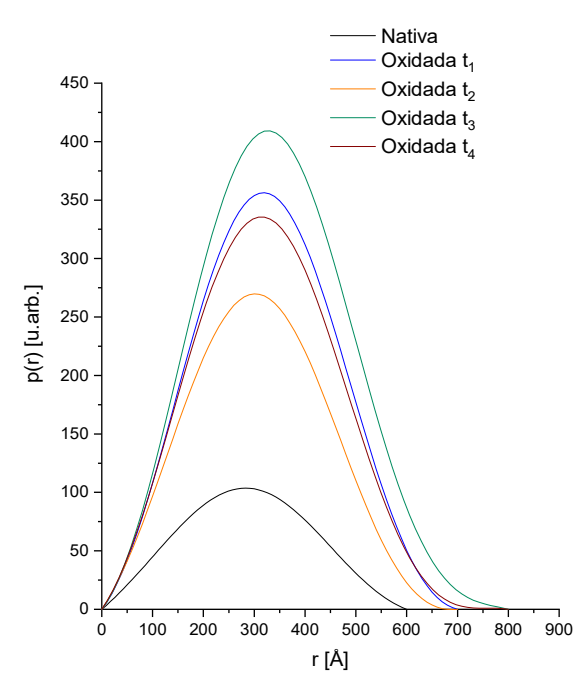

C
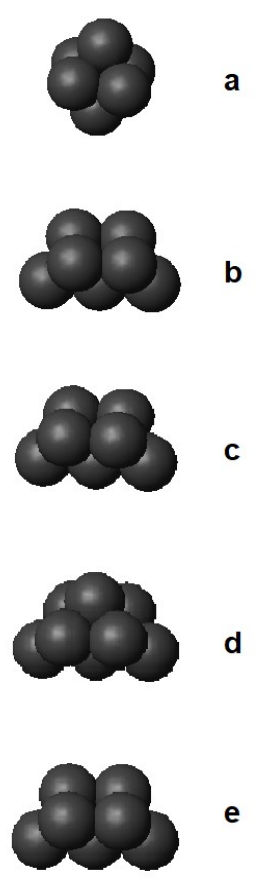

Figura 4.10. Resultados para caracterização dos agregados das partículas de LDL. (A) Ajuste das curvas $I(q)_{\text {olig }}$ pelo método IFT, sendo os dados teóricos de intensidades espalhadas representados pelos símbolos e as linhas contínuas correspondem aos ajustes pelo método IFT. (B) Curvas $p(r)$ resultantes dos ajustes pelo IFT. (C) Modelos tridimensionais, obtidos por modelagem ab initio, para os oligômeros formados pelos monômeros de LDL: a) LDL nativa, b) LDL oxidada $t_{1}$, c) LDL oxidada $t_{2}$, d) LDL oxidada $\left.t_{3}, e\right)$ LDL oxidada $t_{4}$.

\section{Evolução das alterações estruturais em função da concentração de íons $\mathrm{Cu}^{2+}$}

Os resultados, em função da concentração de $\mathrm{CuSO}_{4}$ na reação, também indicaram modificações gradativas nas partículas de LDL. Estes são apresentados nas Figuras 4.11 e 4.12. As variações dos valores dos máximos e do mínimo extraídos das curvas $p(r)$ também são apresentadas na Figura 4.13. 
A

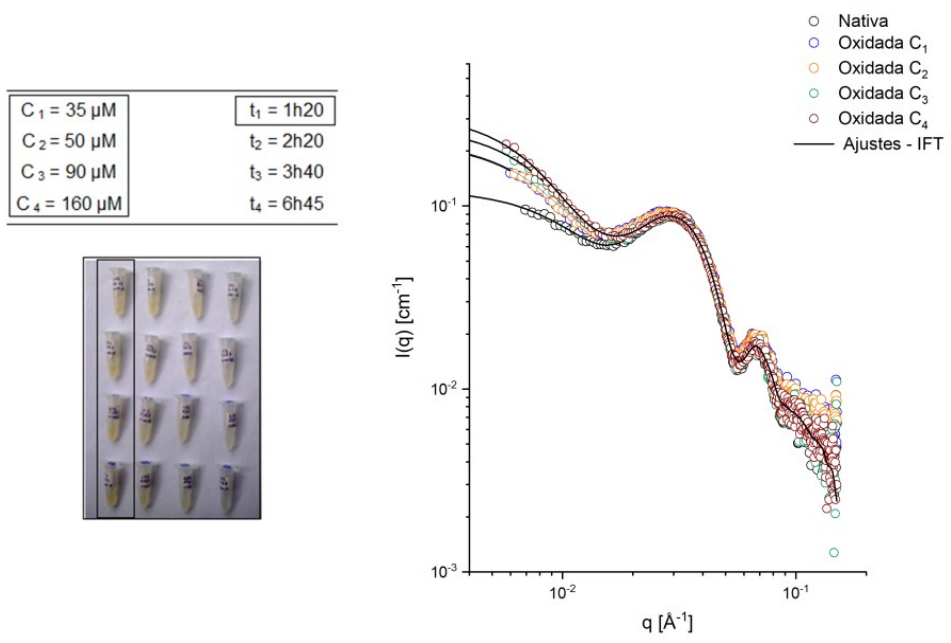

B

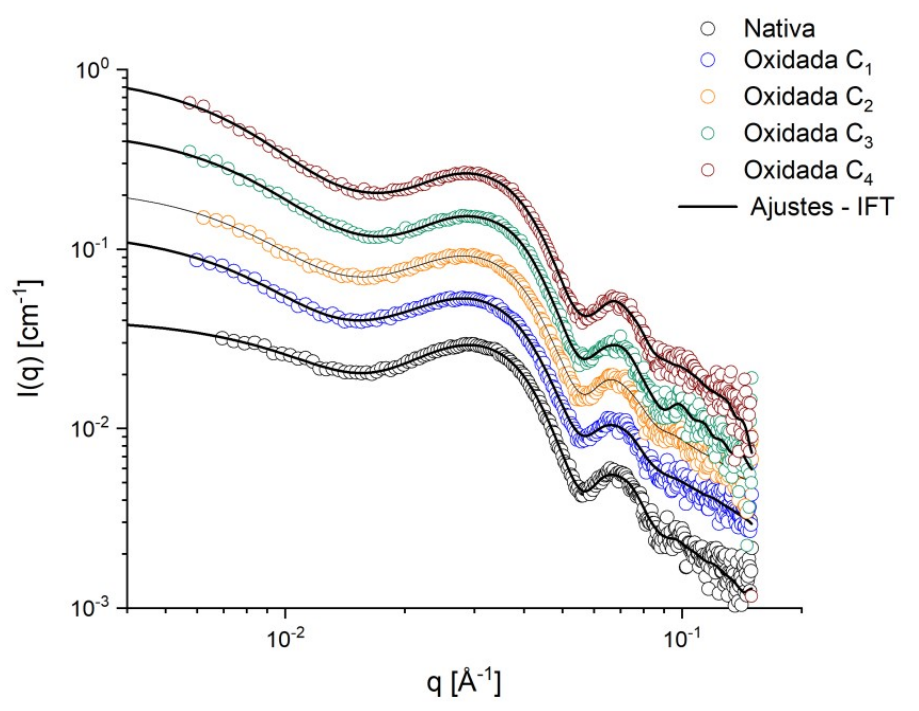

Figura 4.11. A) Evolução das curvas $I(q)$, em função da concentração do agente indutor da oxidação, indicando alterações estruturais e do estado oligomérico nas amostras de LDL. Os símbolos correspondem aos dados experimentais e, as linhas contínuas, aos ajustes pelo método IFT. B) Os valores de $I(q)$ foram multiplicados por um dado fator, para o deslocamento das curvas, possibilitando uma melhor visualização dos ajustes e do perfil característico dos dados de espalhamento das partículas de LDL. 


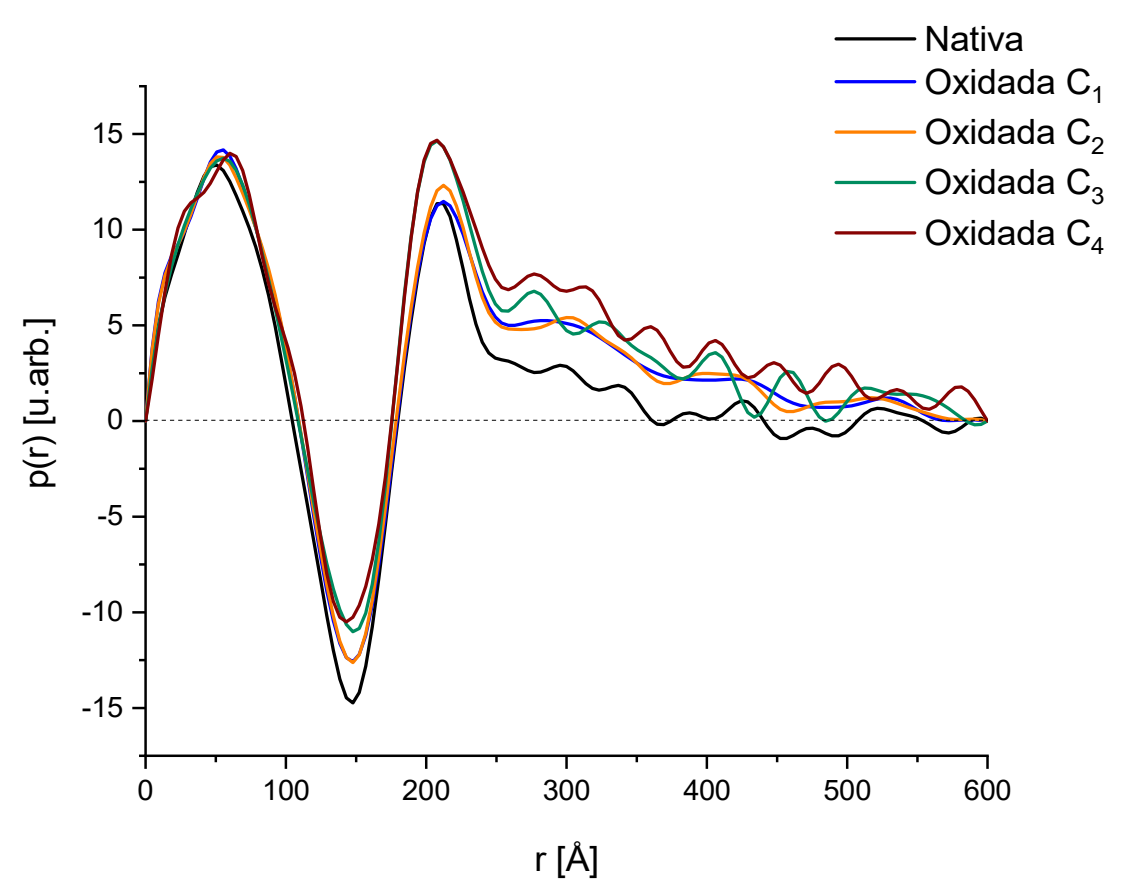

Figura 4.12. Evolução das curvas $p(r)$, em função da concentração do agente indutor da oxidação, indicando alterações estruturais e do estado oligomérico nas amostras de LDL.

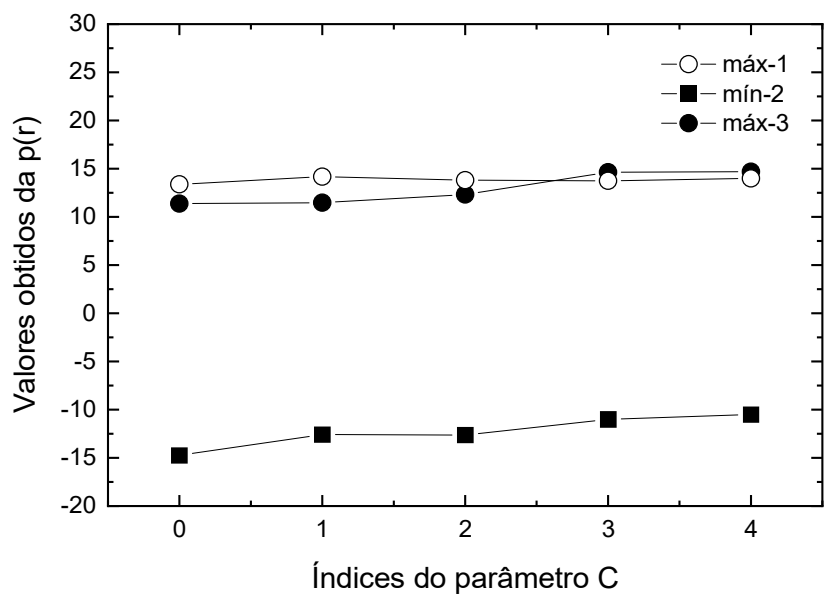

Figura 4.13. Variação dos valores dos máximos e do mínimo, característicos da $p(r)$ das partículas de LDL, em função da concentração do agente indutor da oxidação. Legenda. máx-1: valor do primeiro máximo da $p(r)$; mín-2: valor do mínimo da $p(r)$; máx-3: valor do segundo máximo da $p(r)$; os números 1, 2 e 3 fazem menção aos valores dos máximos e mínimos indicados na Figura 4.2.

Observa-se que a dependência temporal pareceu ser mais efetiva, em comparação ao efeito da concentração do agente oxidante. O caso referente aos dois primeiros valores de 
concentrações $\left(\mathrm{C}_{1}\right.$ e $\left.\mathrm{C}_{2}\right)$, para os quais não se observa diferenças notáveis para os resultados de SAXS, Figuras 4.11 e 4.12, é um exemplo que embasa isto. Estes indicam que, mesmo variando-se a concentração, sem um intervalo de tempo, o processo não ocorre. Isto reforça que há uma dependência, no processo de oxidação da LDL, que se reflete nas alterações estruturais dessa partícula.

Com relação à oligomerização, o comportamento das amostras submetidas à oxidação em diferentes concentrações de $\mathrm{CuSO}_{4}$ se mostrou semelhante ao das que foram oxidadas em tempos de reação distintos, isto é, o padrão de formação de oligômeros se mostrou semelhante ao caso da investigação temporal. Os resultados sugerem a formação de agregados globulares, que não variam significativamente em dimensão, podendo haver diferentes frações de agregação, nas diferentes amostras. Os resultados são apresentados na Figura 4.14, na qual são mostrados os ajustes das curvas $I(q)_{\text {olig }}$, pelo método IFT (A), as curvas $p(r)$ resultantes destes ajustes (B) e os modelos tridimensionais para os oligômeros da LDL, resultantes da modelagem ab initio.
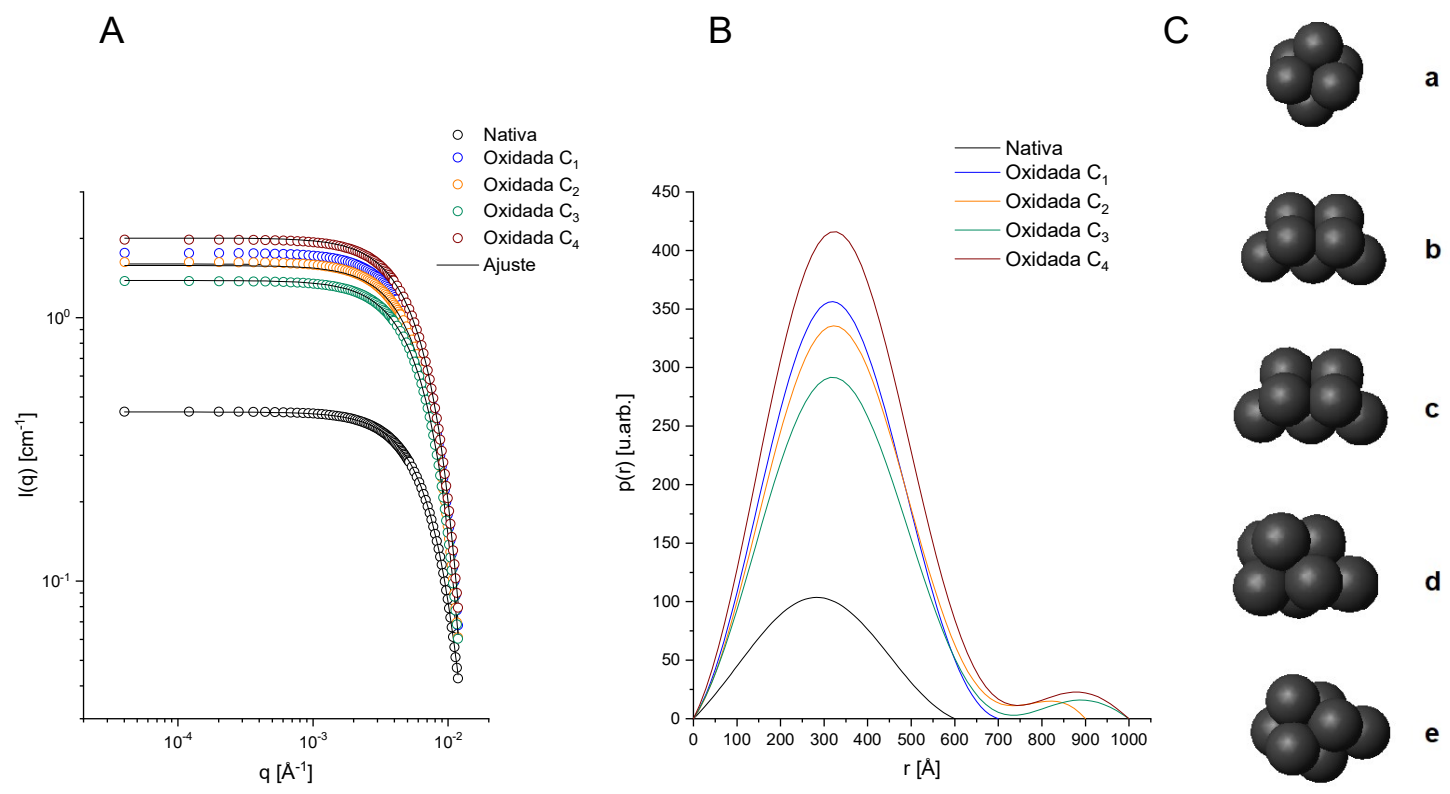

Figura 4.14. Resultados para caracterização dos agregados das partículas de LDL. (A) Ajuste das curvas $I(q)_{\text {olig }}$, pelo método IFT, sendo os dados teóricos de intensidades espalhadas representados pelos símbolos e as linhas contínuas correspondem aos ajustes pelo método IFT. (B) Curvas $p(r)$ resultantes dos ajustes pelo IFT. (C) Modelos tridimensionais, obtidos por modelagem ab initio, para os oligômeros formados pelos monômeros de LDL: a) LDL nativa, b) LDL oxidada $\mathrm{C}_{1}$, c) LDL oxidada $\mathrm{C}_{2}$, d) LDL oxidada $\mathrm{C}_{3}$, e) LDL oxidada $\mathrm{C}_{4}$. 


\subsubsection{Modelagem dos dados de SAXS}

\section{Aplicação na investigação das alterações de densidade eletrônica a $37^{\circ} \mathrm{C}$}

Nesta seção, serão apresentados os resultados de um estudo que avaliou se, estando a LDL em condições mais próximas às fisiológicas, as alterações de densidade eletrônica, provocadas pela oxidação, também ocorreriam. Para tal, foi considerada a evolução temporal da oxidação e seus impactos na distribuição da densidade eletrônica da partícula. A escolha pela evolução temporal teve por base os resultados apresentados na seção 4.1.1. A concentração de $\mathrm{CuSO}_{4}$ foi ajustada, a fim de induzir uma oxidação menos drástica, quando comparada à do estudo anterior. Adotou-se para essas reações a concentração de $20 \mu \mathrm{M}$, correspondendo a, aproximadamente, $2 \times 10^{-8}$ mols de $\mathrm{CuSO}_{4}$ para cada $1 \mathrm{mg}$ de proteína da LDL.

Outro parâmetro modificado foi a temperatura das reações de oxidação, para a qual foi adotada a temperatura média corpórea $\left(37^{\circ} \mathrm{C}\right)$. Os dados de SAXS também foram coletados a essa mesma temperatura. Os tempos de reação foram de $30 \mathrm{~min}, 1 \mathrm{~h}, 2 \mathrm{~h}$ e $7 \mathrm{~h}$.

$\mathrm{Na}$ temperatura de $37^{\circ} \mathrm{C}$, o colesterol do núcleo da $\mathrm{LDL}$ se apresenta em seu estado não estratificado, não sendo conhecido um papel fisiológico para esta não estratificação, como já foi mencionado no capítulo introdutório. Este ensaio pode esclarecer se a organização lipídica, do núcleo da LDL, pode ser um fator de inibição das variações de densidade eletrônica, observadas quando a partícula é exposta à oxidação. A escolha dos tempos de reação teve como base a cinética dos eventos oxidativos da LDL, descritos na literatura. De acordo com a descrição da cinética de oxidação induzida por íons $\mathrm{Cu}^{2+}$, apresentada por Esterbauer et al [29], este processo pode ser dividido em três fases. Durante a primeira delas, a fase lag com duração aproximada de $2 \mathrm{~h}$, ocorre o consumo dos antioxidantes da LDL. Nessa fase, a peroxidação lipídica ocorre em níveis ainda muito baixos. A fase seguinte, denominada pelos autores de fase de propagação, se caracteriza pelo aumento, ou aceleração, da peroxidação lipídica. A terceira e última fase é caracterizada pela decomposição dos produtos gerados na propagação, resultando na formação de aldeídos.

Para os primeiros estudos aqui apresentados (seção 4.1.1) adotamos as análises pelo método IFT. A relativa simplicidade deste método foi adequada à proposta, que envolveu a varredura de diferentes condições para as reações de oxidação da LDL. Além disso, no caso da LDL, vimos que esta análise pode trazer informações relevantes, corroborada pelo que se 
encontra descrito na literatura. Já neste estudo, a modelagem de dados de SAXS foi o método de análise aplicado, mas mantendo o IFT para comparação dos resultados.

Sendo as investigações direcionadas às alterações nas partículas monoméricas, os dados de SAXS foram coletados em uma configuração experimental, e consequentemente, a uma resolução, adequada a esta escolha. Os dados foram coletados no equipamento Xeuss 2.0 (GFCx-IFUSP) com distância amostra detector de 1,2 m, como descrito na metodologia. Adotando-se esta configuração, as curvas de $I(q)$ não contêm a informação de oligômeros e foram diretamente empregadas como os dados de entrada para o modelo, sem a necessidade de uma etapa de desacoplamento. Para demonstrar a efetividade desta escolha, um dos dados do conjunto foi analisado pelo método GIFT. O resultado, mostrado na Figura 4.15, mostra a curva $P(q)$, obtida com o desacoplamento, descrevendo exatamente a mesma curva que a dos dados experimentais de intensidades espalhadas $I(q)$.

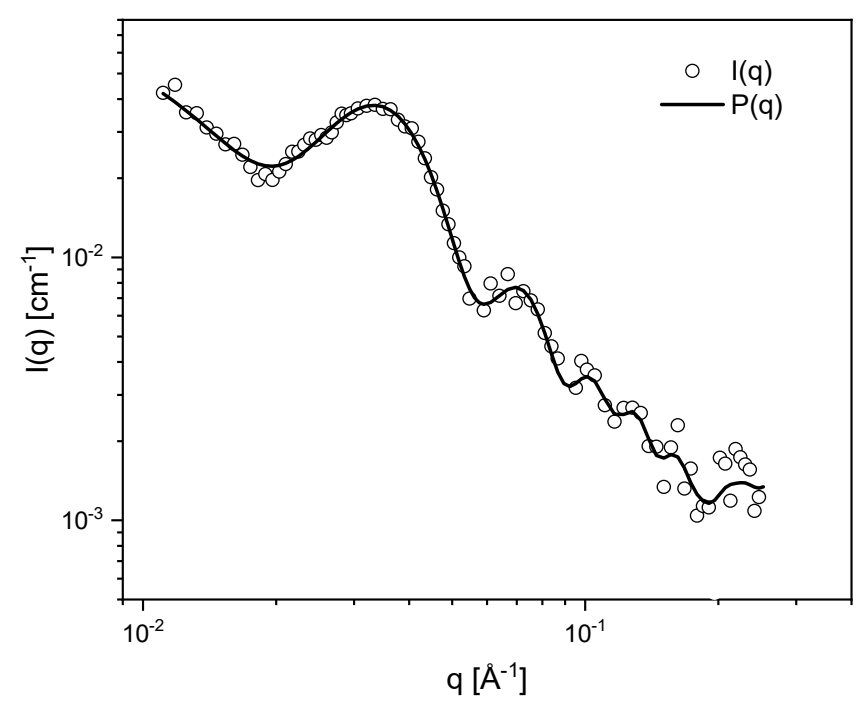

Figura 4.15. Resultado do desacoplamento, empregando o método GIFT aos dados de espalhamento de uma amostra de LDL oxidada, mostrando as curvas para os fatores de forma $P(q)$ e os dados experimentais $I(q)$ sobrepostos.

Como o modelo adotado tem o contraste de densidade eletrônica $(\Delta \rho)$ como um de seus parâmetros, optamos por trabalhar com uma amostra controle, não oxidada. A descrição desta amostra consta da metodologia e, apenas destacamos aqui que, o uso desta se justifica para garantir uma amostra de LDL não oxidada, mas que estivesse exatamente nas mesmas 
condições das oxidadas. Essas condições se referem ao meio, cuja densidade eletrônica irá determinar o contraste de espalhamento. Apesar das baixas concentrações de $\mathrm{CuSO}_{4}$ e EDTA, e da provável não influência destes no espalhamento, optamos pelo uso da amostra controle, para excluir qualquer dúvida relacionada a este aspecto.

\section{Caracterização das amostras}

As amostras foram caracterizadas, por meio das técnicas de espalhamento de luz dinâmico (DLS) e espectroscopia UV-vis, para a determinação do raio hidrodinâmico médio $\left(R_{H}\right)$ e avaliação do conteúdo de antioxidante das partículas de LDL.

O DLS é comumente empregado na determinação da dimensão de partículas em solução, por meio do cálculo do raio hidrodinâmico $\left(R_{H}\right)$. Em um experimento de DLS, um feixe laser incide sobre a amostra e a luz espalhada é captada, em função do tempo, por um detector. Considerando que as partículas em solução descrevem um movimento Browniano, pode-se estabelecer uma correlação entre as intensidades de luz espalhadas, como uma função temporal. Desse modo, os dados de um experimento de DLS correspondam à chamada função de correlação $C(t)$ [70]. A Figura 4.16 mostra as curvas $C(t)$ obtidas com os experimentos de DLS. A figura apresenta os dados experimentais e os respectivos ajustes. Os valores de $R_{H}$ determinados com as análises de DLS, para a amostra controle e para as amostras oxidadas, são apresentados na tabela 4.3 .

$\mathrm{O}$ valor de $R_{H}$, para a amostra não oxidada, foi coerente com o esperado para as partículas de LDL [83]. Comparando-se este valor com o $R_{H}$ médio das partículas oxidadas, os resultados sugerem que não há variações nas dimensões das partículas, em decorrência da oxidação. Embora a caracterização de oligômeros não tenha sido um objetivo nesta etapa do trabalho, os resultados das análises por DLS foram úteis para indicar a contribuição destes nas amostras oxidadas. O decaimento exponencial única, das curvas de correlação, indica que não há a presença significativa de populações de diferentes dimensões, sugerindo que estas condições de oxidação não levaram a uma elevada formação de oligômeros nas amostras. 


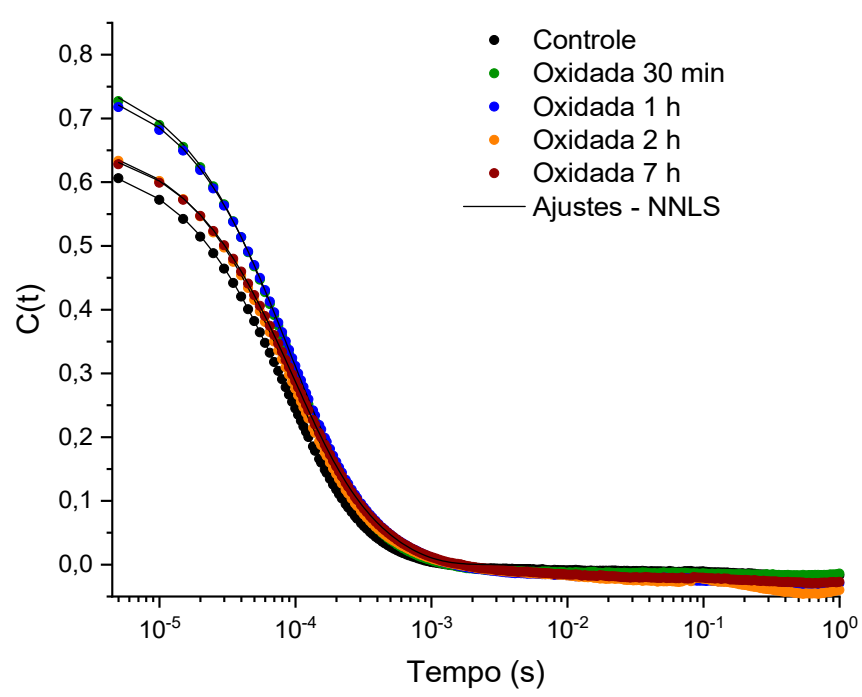

Figura 4.16. Curvas de correlação $C(t)$, resultantes dos experimentos de DLS, para as amostras controle e oxidadas.

Tabela 4.3. Valores de raio hidrodinâmico médio $\left(R_{H}\right)$ para a amostra controle e as amostras oxidadas.

\begin{tabular}{cc}
\hline Amostra & $R_{H \text { DLS }}(\mathrm{nm})$ \\
\hline Controle & $10,8 \pm 1,6$ \\
Oxidada 30 min & $10,4 \pm 1,4$ \\
Oxidada $1 \mathrm{~h}$ & $11,1 \pm 2,2$ \\
Oxidada $2 \mathrm{~h}$ & $11,5 \pm 2,0$ \\
Oxidada $7 \mathrm{~h}$ & $11,5 \pm 2,2$ \\
\hline
\end{tabular}

Quanto aos resultados da espectroscopia UV-vis (Figura 4.17), estes indicaram o nível de oxidação das amostras. A aplicação desta técnica será mais bem detalhada no capítulo dos resultados ópticos, apenas faremos aqui uma associação entre as absorbâncias e o consumo de antioxidantes, considerando que, quanto menores as absorbâncias nos espectros, menor é o conteúdo de antioxidantes numa dada amostra. Para a amostra oxidada por 30 minutos o espectro de absorção se mostrou semelhante ao da amostra controle. Já para as amostras oxidadas durante 1 e 2 horas, há gradativa redução dos valores de absorção, indicando o consumo dos antioxidantes das partículas, conforme o tempo de oxidação aumenta. Para a amostra oxidada por $7 \mathrm{~h}$, há o consumo total dos antioxidantes, com os valores de absorção sendo nulos. Com esses resultados, os diferentes níveis de oxidação induzidos nas amostras foram verificados, sendo um indicativo de que a escolha dos tempos de reação esteve em acordo com o desejado, isto é, permitiu a obtenção de amostras em diferentes estágios de oxidação da LDL. 
Vale destacar que, esta redução do conteúdo de antioxidantes nas partículas, como efeito da oxidação, e com consequente redução dos valores de absorbâncias, já é conhecido. Apenas foram empregadas essas análises para uma verificação de que as amostras estavam em diferentes níveis, ou estágios, de oxidação.

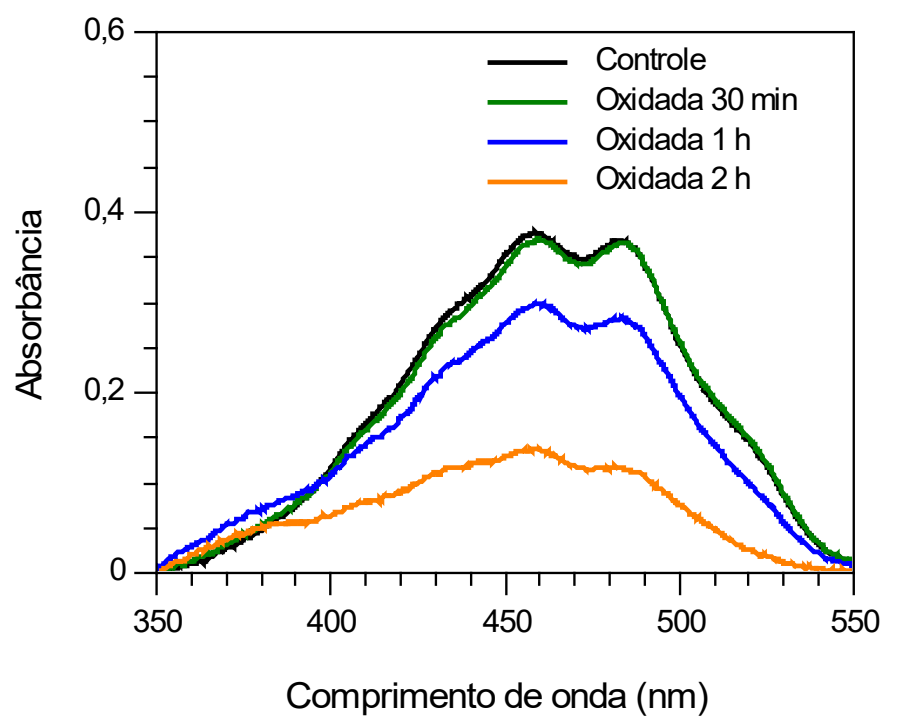

Figura 4.17. Redução do conteúdo de antioxidantes na LDL oxidada. Espectros de absorção para a amostra não oxidada (controle) e para as oxidadas, em três tempos de reação diferentes. O espectro de absorção resultante da análise da amostra oxidada por $7 \mathrm{~h}$ não é mostrado, pois o consumo de antioxidantes carotenoides foi total para esta amostra.

\section{Análises com o método IFT}

As curvas $p(r)$, resultantes das análises pelo método IFT, constam na Figura 4.18. Estas curvas se mostraram com mais oscilações se comparadas, por exemplo, às do estudo anterior. Devido a isso, as variações da região inicial das curvas, correspondentes ao primeiro máximo, não foram consideradas relevantes.

O perfil de evolução das curvas $p(r)$, em função do tempo de oxidação, foi semelhante ao observado no estudo anterior (seção 4.1.1). O resultado da análise para a amostra oxidada por $1 \mathrm{~h}$ indicou, como alteração mais significativa, o aumento do valor do mínimo da $p(r)$. Para os tempos de oxidação maiores, variações do segundo máximo ocorreram. Portanto, esses resultados indicam que as alterações de densidade eletrônica, na partícula de LDL, também ocorrem quando a oxidação é induzida em temperatura fisiológica. 
Sugerem ainda que, mesmo nessas condições, tais alterações continuam relacionadas a eventos que acometem a monocamada da LDL.

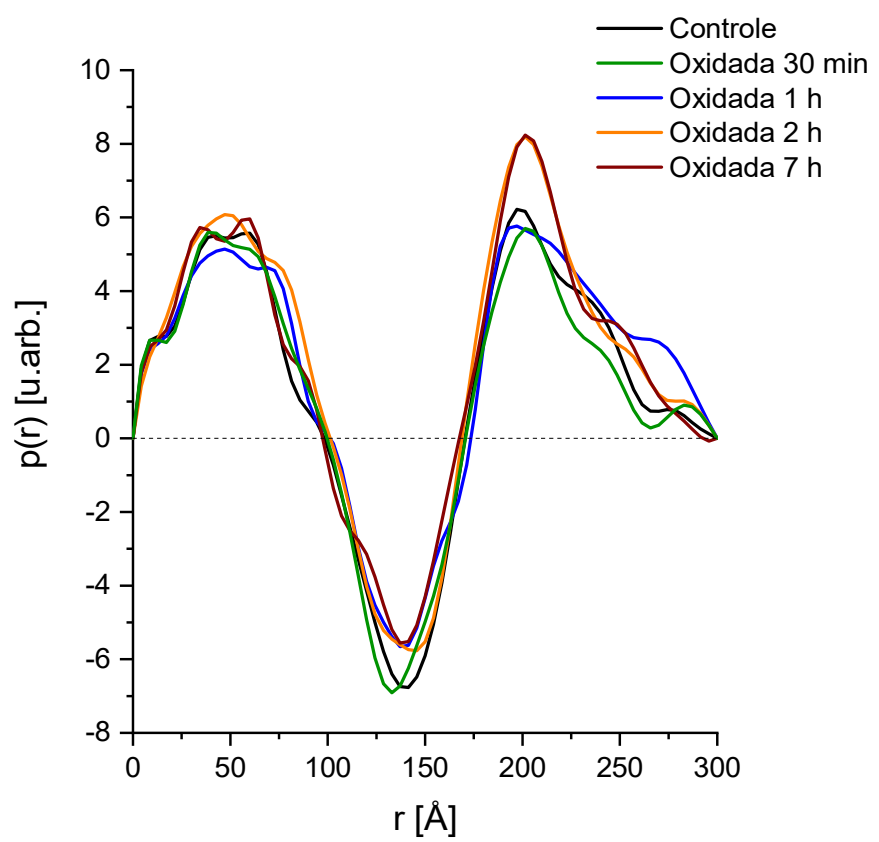

Figura 4.18. Curvas $p(r)$, obtidas com as análises pelo método IFT, para a amostra controle e as amostras oxidadas.

\section{Análises com a modelagem dos dados}

Os dados de intensidades espalhadas $I(q)$ foram analisados com o modelo descrito, na seção 2.1.2, para determinação dos valores de raio total da partícula $(R)$ e de contraste de espalhamento relativo $(\mu)$. Os valores de $R$ não indicaram variações em função da oxidação da partícula, como é mostrado na Tabela 4.4, corroborando os dados de caracterização das amostras, pela técnica de DLS.

Tabela 4.4. Valores de raio médio $(R)$ retornados pela modelagem dos dados de SAXS para a amostra controle e as amostras oxidadas. As incertezas foram retornadas pela modelagem dos dados.

\begin{tabular}{cc}
\hline Amostra & $R(\AA)$ \\
\hline Controle & $129,2 \pm 0,8$ \\
Oxidada 30 min & $128,1 \pm 0,7$ \\
Oxidada 1 h & $130,5 \pm 0,9$ \\
Oxidada 2 h & $130,2 \pm 0,6$ \\
Oxidada 7 h & $130,5 \pm 0,6$ \\
\hline
\end{tabular}


Os resultados para $\mu$ são apresentados na Tabela 4.5 e nos gráficos 4.19 e 4.20. Como já foi mencionado, devido à complexa constituição da LDL, esta partícula vai apresentar regiões com contrastes de espalhamento de sinais contrários, fazendo com que o contraste de espalhamento relativo $\mu$ possua um valor negativo. Para a apresentação e discussão dos resultados, adotaremos os valores absolutos de $\mu(|\mu|)$, para uma interpretação mais intuitiva. A tabela 4.5 mostra os tempos de reação e os eventos que podem ser a eles associados, com base na cinética do processo de oxidação in vitro da LDL, mencionada acima. Os correspondentes valores de $|\mu|$ também são apresentados.

Tabela 4.5. Valores de tempo de reação e $|\mu|$, em relação ao fenômeno da cinética da oxidação. As incertezas foram retornadas pela modelagem dos dados.

\begin{tabular}{ccc}
\hline Tempos de reação $\left(t_{\mathrm{R}}\right)$ & Evento - Cinética de oxidação & $|\mu|$ \\
\hline $\mathrm{t}_{0}=0 \mathrm{~min}$ & - & $2,0 \pm 0,1$ \\
$\mathrm{t}_{1}=30 \mathrm{~min}$ & Consumo parcial de antioxidantes & $2,1 \pm 0,1$ \\
$\mathrm{t}_{2}=1 \mathrm{~h}$ & Consumo total dos antioxidantes & $2,0 \pm 0,1$ \\
$\mathrm{t}_{3}=2 \mathrm{~h}$ & Meados da fase de propagação & $1,76 \pm 0,08$ \\
$\mathrm{t}_{4}=7 \mathrm{~h}$ & Meados da fase de decomposição & $1,66 \pm 0,07$ \\
\hline
\end{tabular}

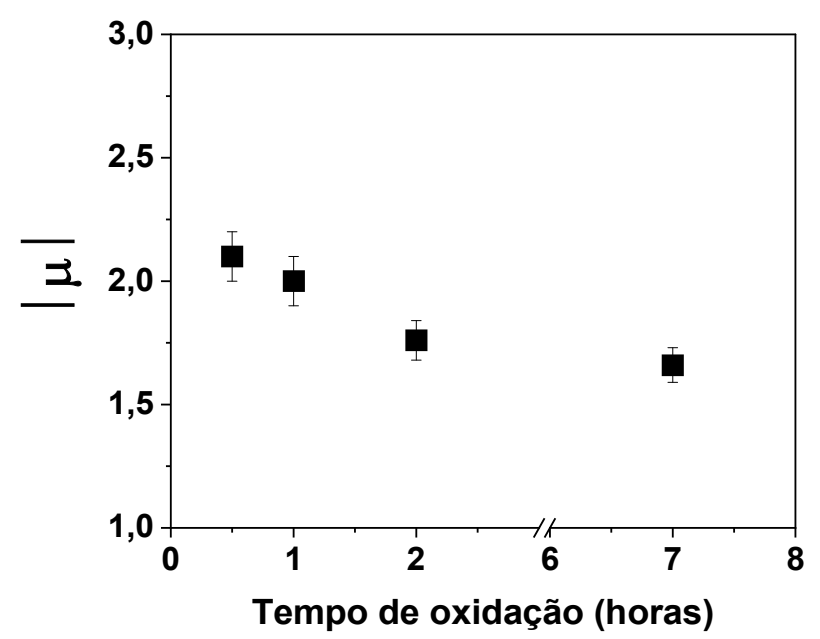

Figura 4.19. Valores de $|\mu|$, obtidos com a modelagem dos dados de SAXS, em função do tempo de oxidação da amostra de LDL.

O gráfico, apresentado na da Figura 4.19, mostra os resultados para as amostras oxidadas, nos quais se observa uma redução dos valores de $|\mu|$, em função do tempo de 
oxidação. Isto é coerente com o discutido anteriormente, sobre a oxidação conduzir à modificações na camada da LDL, relacionadas ao aumento da densidade eletrônica dessa região, como resultado dos eventos de incorporação de $\mathrm{O}_{2}$ ou de aldeídos. Sendo assim, estas reduções nos valores de $|\mu|$ seriam decorrentes do aumento da densidade eletrônica na monocamada $\left(\Delta \rho_{c}\right)$, fazendo com que o contraste relativo, valor absoluto de $\mu=\Delta \rho_{n} / \Delta \rho_{c}$, fosse reduzido.

No entanto, no gráfico da Figura 4.19, foram comparados apenas os valores de $|\mu|$ referentes às amostras oxidadas. Considerando também o valor para a amostra não oxidada (Figura 4.20), observa-se que, a amostra oxidada por 30 minutos apresentou um valor de $|\mu|$ maior que o da não oxidada, indicando o oposto do que ocorre ao longo da oxidação. Uma possível explicação para este caso seria uma redução da densidade eletrônica da monocamada, devido ao consumo de antioxidantes, ainda que este consumo não seja perceptível nos espectros de absorção. Isto porque, com base na Tabela 4.5, este tempo de reação corresponde a uma etapa de consumo desses antioxidantes e de ocorrência mínima da oxidação dos lipídios. Esta última, a oxidação dos lipídios, é que associamos à redução de $|\mu|$. Foi ainda interessante notar que, o perfil da $p(r)$ (Figura 4.18) para esta amostra, LDL oxidada por 30 minutos, também é diferente do observado para as demais. O valor do mínimo foi ligeiramente menor que o mínimo na curva referente a amostra da LDL não oxidada, enquanto, para os demais tempos de reação, os resultados mostram que este parâmetro assume valores maiores, em relação à não oxidada.

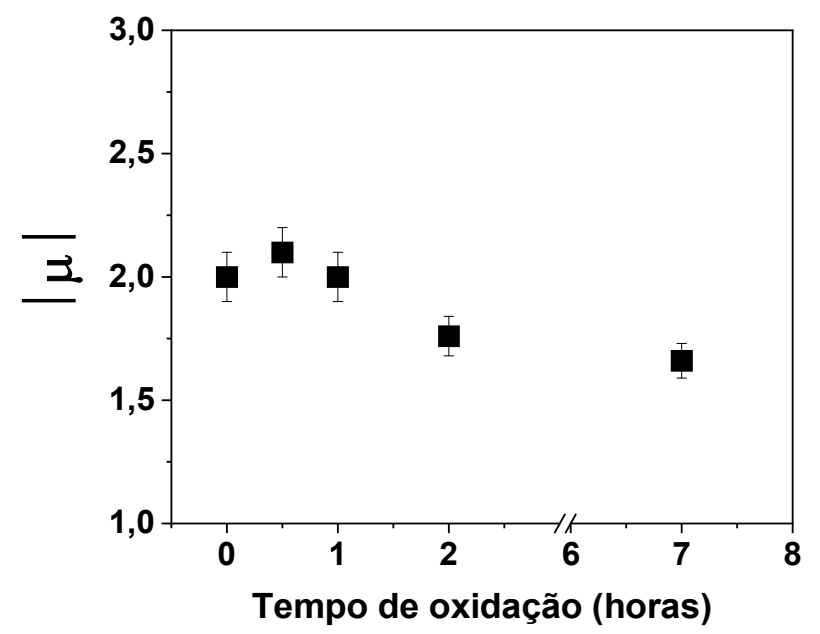

Figura 4.20. Valores de $|\mu|$, obtidos com a modelagem dos dados de SAXS, em função do tempo de oxidação da amostra de LDL, em comparação com a amostra não oxidada. 
Os resultados dos dois ensaios, e das duas diferentes abordagens de análises de dados, são consistentes entre si. A vantagem da modelagem dos dados está em fornecer uma abordagem quantitativa, por meio da determinação de um parâmetro único e facilmente avaliável entre diferentes amostras. Por outro lado, os resultados das análises pelo método IFT, foram fundamentais para a suposição de que as alterações de densidade eletrônica, que geram as variações nos valores de $|\mu|$, ocorrem por eventos que afetam a monocamada da partícula.

\section{Aplicação a um estudo in vivo: impacto do tratamento farmacológico na estrutura da LDL}

As análises empregando a modelagem de dados, e as discussões dos resultados obtidos, possibilitaram a aplicação desta abordagem a um estudo in vivo, no qual investigamos as alterações estruturais e de propriedades ópticas da LDL, em decorrência da ação farmacológica de drogas, usualmente empregadas no tratamento do infarto. Foram avaliadas amostras de LDL obtidas dos indivíduos após um episódio de infarto agudo do miocárdio, sendo estas consideradas pertencentes ao instante inicial do tratamento (T0), e após 6 meses de intervenção (T6). Os pacientes, recrutados no Hospital São Paulo da Escola Paulista de Medicina-UNIFESP-SP, foram tratados com uma das quatro terapias combinadas antiplaquetário-estatinas: Sinvastatina/ezetimida-Ticagrelor (SIMVA/E-TICA), Sinvastatina/ezetimida- Clopidogrel (SIMVA/E- CLOP), Rosuvastatina-Ticagrelor (RSVTICA) e Rosuvastatina-Clopidogrel (RSV-CLOP).

Este foi um estudo amplo, envolvendo diferentes colaboradores, o que possibilitou a aplicação de diferentes técnicas e conclusões baseadas em variadas abordagens. A descrição completa do estudo pode ser vista na referência [50]. Neste tópico serão apresentaremos os resultados de SAXS.

As Figuras 4.21 e 4.22 mostram os resultados obtidos com as análises estatísticas, empregando os valores retornados pela modelagem dos dados de espalhamento. Os parâmetros avaliados foram o raio da partícula $R$ e o contraste de espalhamento relativo $\mu$. 


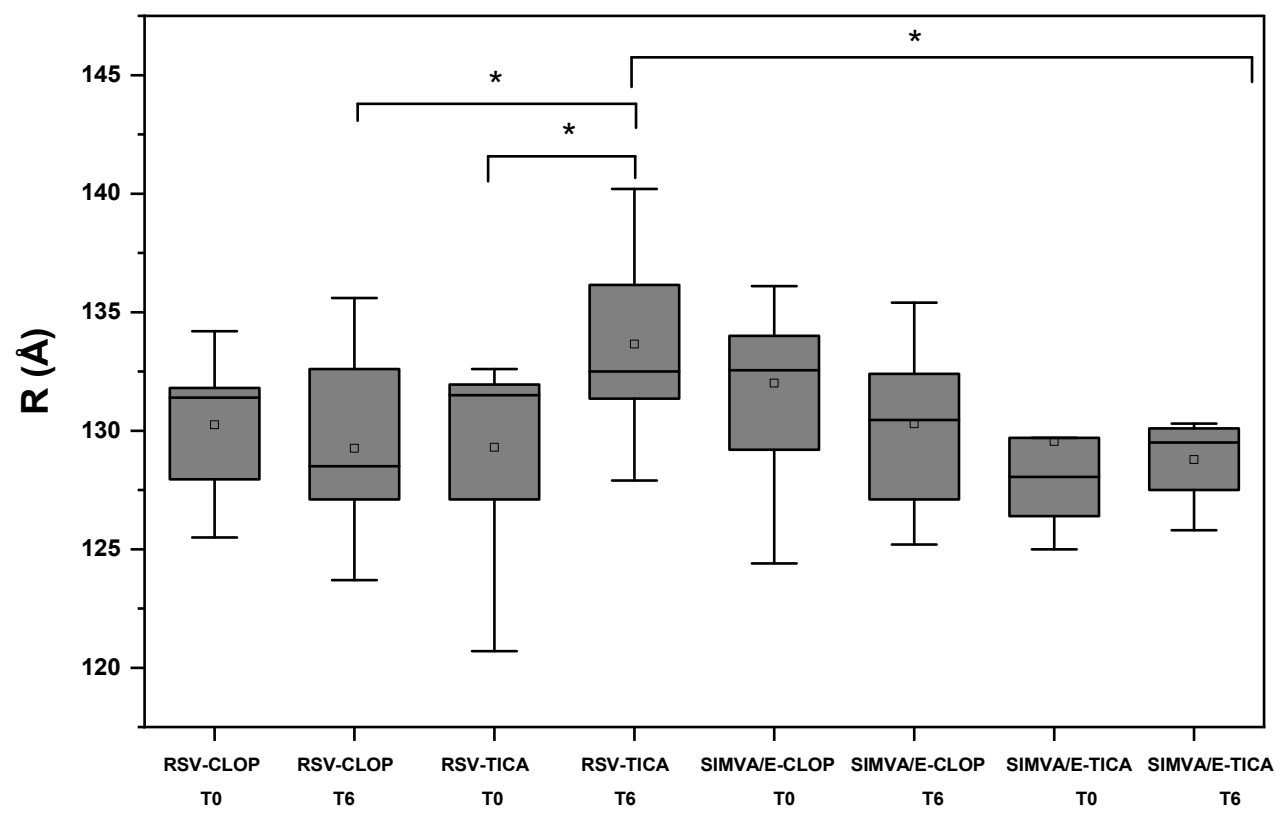

Figura 4.21. Resultados estatísticos (Box-plot) para $R$ para as terapias antiplaquetário-estatina, ao início do tratamento $(\mathrm{T}=0)$ e após 6 meses de tratamento $(\mathrm{T}=6)$. Sinvastatina/ezetimida-Ticagrelor (SIMVA/E-TICA), Sinvastatina/ezetimida-Clopidogrel (SIMVA/E-CLOP), Rosuvastatina-Ticagrelor (RSV-TICA), Rosuvastatina-Clopidogrel (RSV-CLOP). ( ${ }^{*}$ diferença significativa; $p<0,05$ )

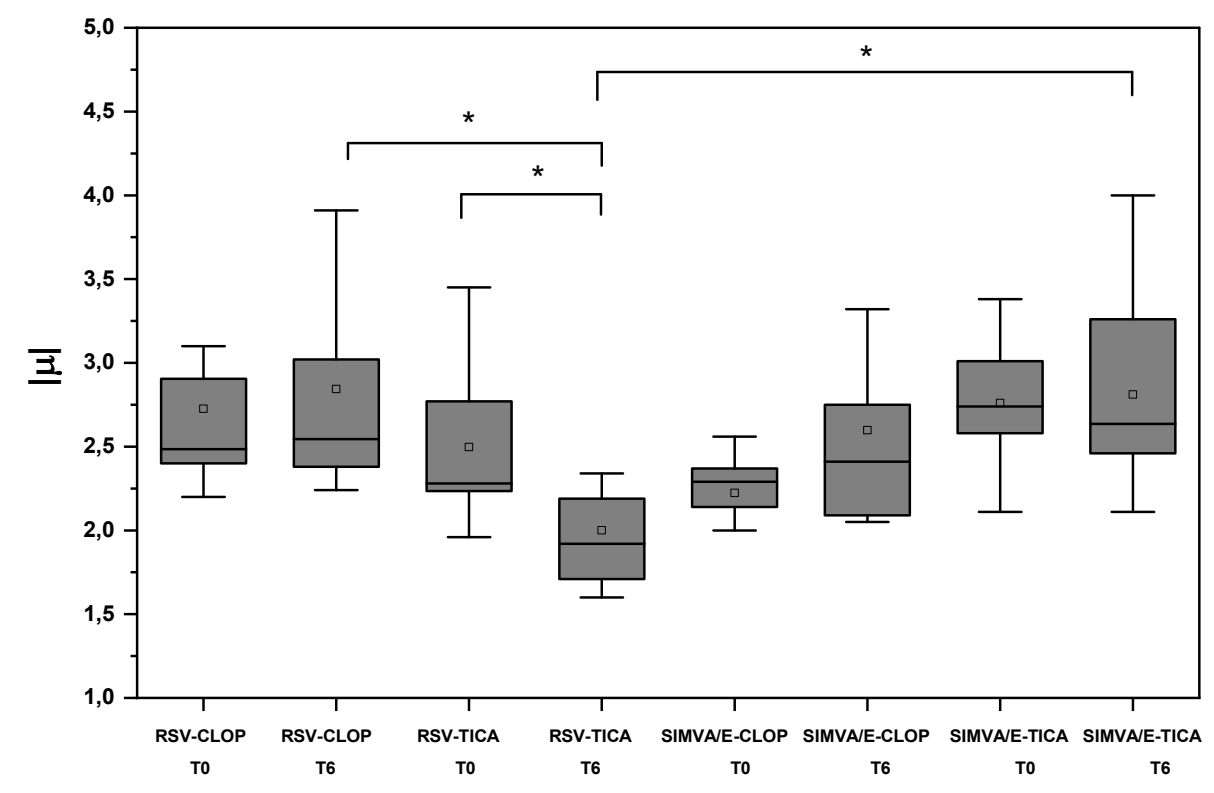

Figura 4.22. Resultados estatísticos (Box-plot) para $|\mu|$ para as terapias antiplaquetário-estatina, ao início do tratamento $(\mathrm{T}=0)$ e após 6 meses de tratamento $(\mathrm{T}=6)$. Sinvastatina/ezetimida-Ticagrelor (SIMVA/E-TICA), Sinvastatina/ezetimida-Clopidogrel (SIMVA/E-CLOP), Rosuvastatina-Ticagrelor (RSV-TICA), Rosuvastatina-Clopidogrel (RSV-CLOP). ( ${ }^{*}$ diferença significativa; $p<0,05$ ) 
As diferenças nos valores médios dos parâmetros foram significativas para os seguintes casos:

$$
\begin{aligned}
& R: \text { T6 - RSV-TICA > T6 - RSV-CLOP; } \\
& R: \text { T6 - RSV-TICA > T6 - SIMVA/E-TICA; } \\
& R: \text { T6 - RSV-TICA > T0 - RSV-TICA; } \\
& |\mu|: \text { T6 - RSV-CLOP > T6 - RSV-TICA; } \\
& |\mu|: \text { T6 - SIMVA/E-TICA > T6 - RSV-TICA; } \\
& |\mu|: \text { T0 - RSV-TICA > T6 - RSV-TICA. }
\end{aligned}
$$

Tais resultados indicaram que há um aumento do raio das partículas de LDL quando o tratamento é realizado com a combinação RSV-TICA. Já para o contraste de espalhamento relativo, ouve um aumento do valor de $|\mu|$ para o grupo SIMVA/E-TICA. Considerando que as partículas de LDL menores e mais densas (sdLDL) são reportadas como mais aterogênicas, o estudo concluiu ser o tratamento com a combinação RSV-TICA, o mais eficiente, uma vez que leva ao aumento de $R$. No entanto, para o contraste de espalhamento relativo, se considerado o estudo in vitro e o dano oxidativo da partícula de LDL, o aumento de seu valor absoluto reporta uma maior eficiência do tratamento. Com base nisso, o tratamento com a combinação SIMVA/E-TICA teria sido o tratamento mais eficaz.

De modo geral, os resultados de SAXS indicaram ser uma maior eficiência dos tratamentos, no que se refere às características de funcionalidade da LDL, associada à presença do ticagrelor na terapia combinada. Tal resultado está de acordo com resultados obtidos por meio de outras técnicas de análise, tanto físicas como de subfrações da LDL [50].

\subsection{Termodifusão das partículas de LDL}

\subsubsection{Determinação do $S_{\mathrm{T}}$ para a LDL nativa}

Sabe-se que as partículas de LDL, provenientes de diferentes indivíduos, podem apresentar diferenças de composição ou estruturação como, por exemplo, diferentes conteúdos lipídicos ou de antioxidantes. Podem ainda apresentar diferentes níveis de modificação, decorrentes de processos como oxidação ou glicação. Considerando que tais diferenças poderiam impactar parâmetros de caracterização física dessas partículas, como o 
$S_{T}$, a mesma metodologia experimental foi aplicada a duas amostras diferentes. Ou seja, provenientes de duas amostras de plasma diferentes. As amostras foram identificadas como amostra 1 e 2. Para esses primeiros experimentos, as amostras de LDL foram mantidas com EDTA a $10 \mathrm{mM}$, visando à máxima preservação do conteúdo antioxidante, bem como da integridade das partículas.

\section{Espectroscopia UV-vis}

O aquecimento, que induz o gradiente térmico nas amostras de LDL, é resultante da absorção da luz por estas partículas. A absorção de luz, por uma dada partícula, pode ser avaliada a partir de seu espectro de absorção, podendo ser quantificada pelo coeficiente de absorção $(\alpha)$. No caso da LDL, suas moléculas absorvedoras são, predominantemente, os antioxidantes lipofílicos presentes em sua estrutura. A ApoB-100 também apresenta uma contribuição, na absorbância na região de $280 \mathrm{~nm}$, característica de proteínas. A Figura 4.23 apresenta os resultados obtidos com a espectroscopia UV-vis, para as duas amostras em estudo.

No entanto, fenômenos físicos distintos podem ocorrer a partir da incidência da luz sobre um meio, e foi considerada a contribuição também dos efeitos de espalhamento nos dados dos espectros de UV-vis. Tais efeitos podem conduzir a valores de absorbância superestimados e, consequentemente, a uma determinação incorreta dos valores de $\alpha$, do qual é dependente a amplitude da lente térmica, definida na equação 2.21. Considerando que as partículas de LDL possuem dimensão consideravelmente menor que os comprimentos de onda da luz incidente, os efeitos de espalhamento podem ser bem descritos pelo espalhamento Rayleigh [77, 78]. O espalhamento Rayleigh possui dependência com o inverso do comprimento de onda da luz incidente $\left(\lambda^{-4}\right)[77,78]$, sendo sua contribuição, portanto, crescente conforme os valores de comprimento de onda se tornam menores. Nos espectros apresentados na Figura 4.23 nota-se um indicativo da ocorrência do espalhamento Rayleigh, uma vez que a linha de base dos espectros se mostra elevada, na região entre 300 e $400 \mathrm{~nm}$. Desse modo, procedeu-se o desconto da contribuição de espalhamento dos dados obtidos, de acordo com o estabelecido em nosso grupo [46]. A Figura 4.24 mostra os espectros

originalmente adquiridos, as curvas correspondentes aos ajustes realizados para o espalhamento, e o espectro de absorção final, determinado para cada amostra de LDL. 

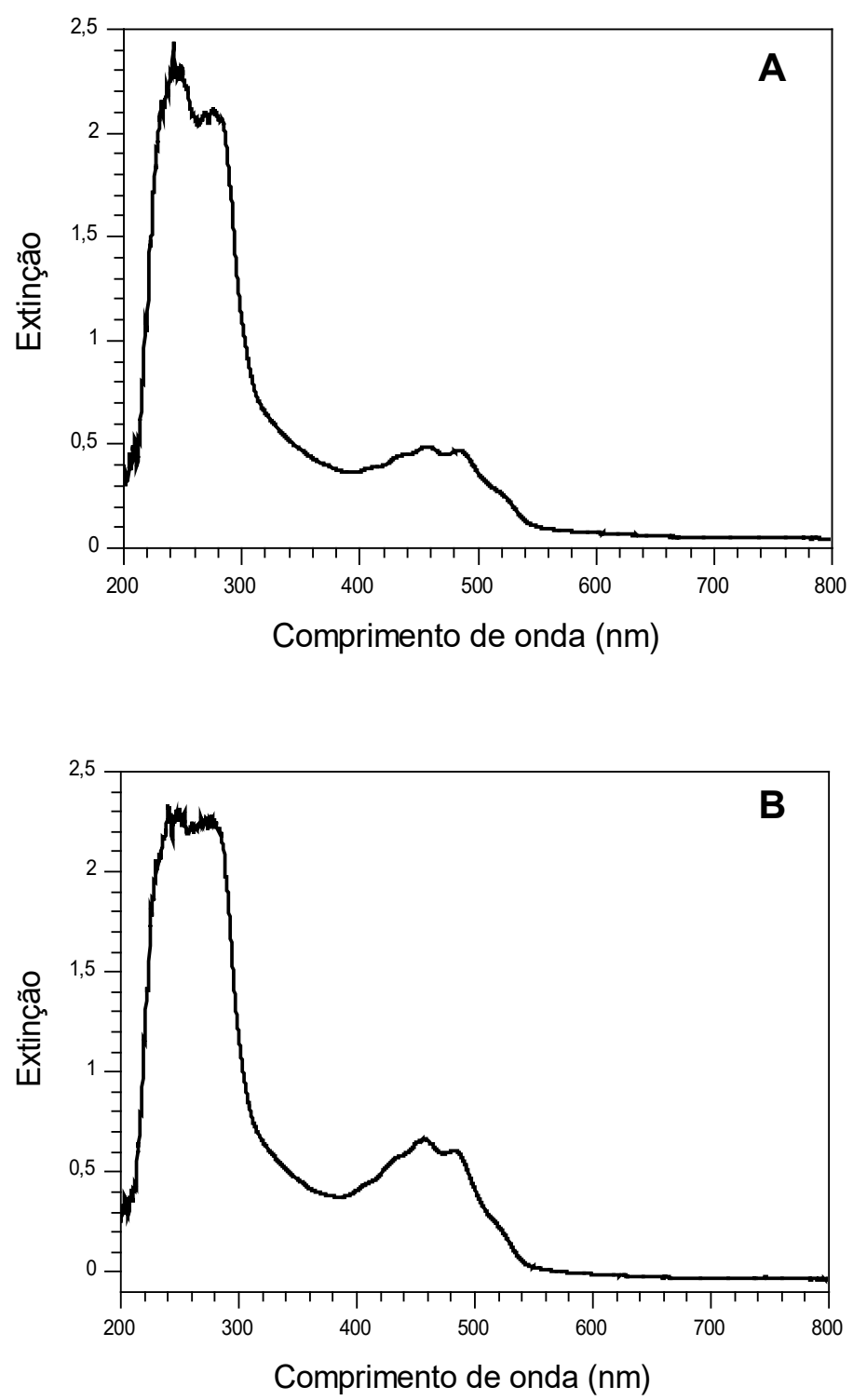

Figura 4.23. Espectros UV-vis para as amostras de LDL nativa, apresentando os valores de extinção em função dos comprimentos de onda, na faixa entre 200 e $800 \mathrm{~nm}$. Em (A) é mostrado o resultado para a amostra 1 e em (B) e o espectro para a amostra 2. 

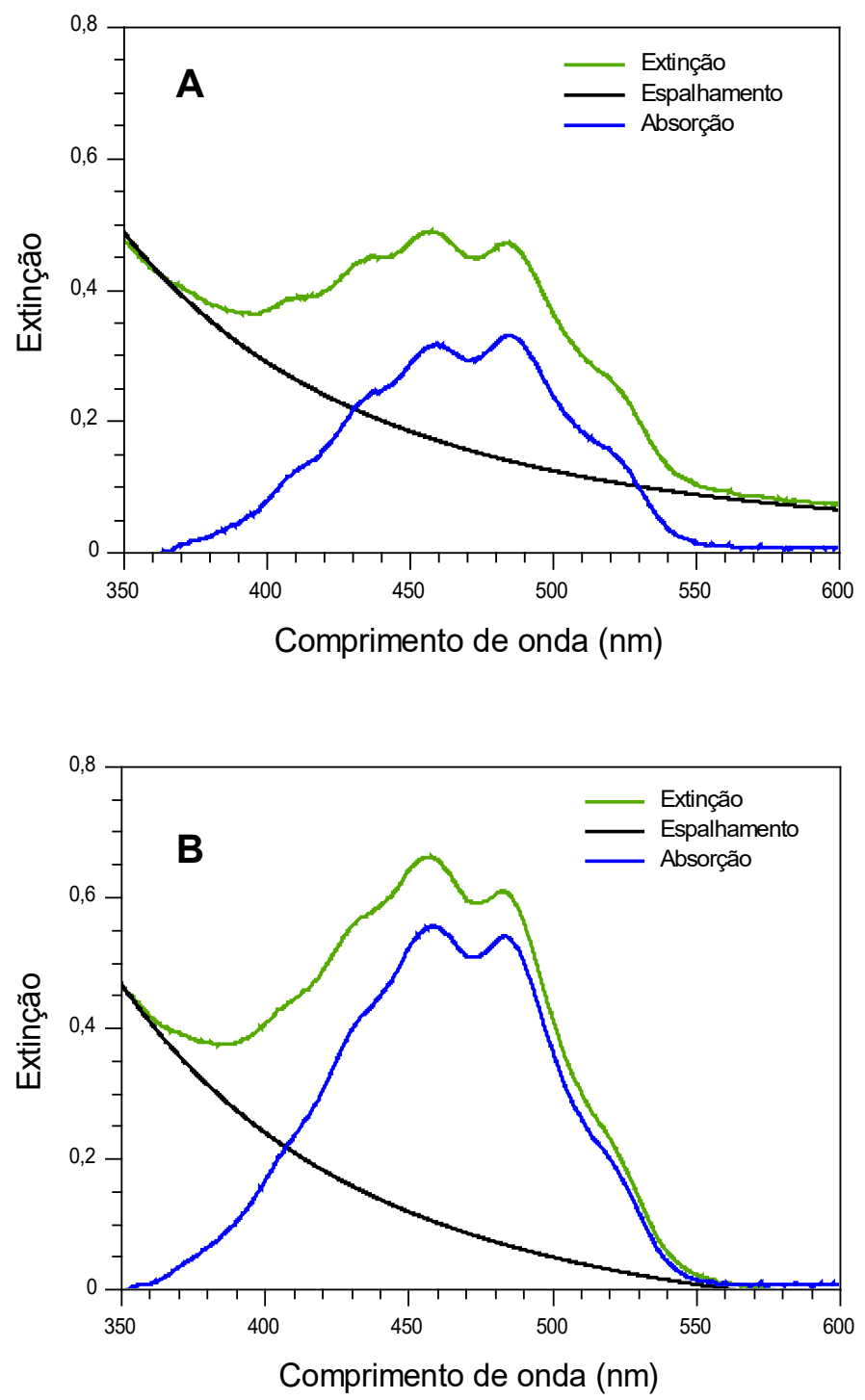

Figura 4.24. Tratamento dos dados de espectroscopia UV-Vis para as amostras 1(A) e 2 (B). São mostrados os espectros de extinção, ajustes teóricos para a contribuição do espalhamento e espectros de absorção finais. Os espectros em (A) e (B) foram mantidos com a mesma escala.

Para uma visualização comparativa, entre os espectros de absorção relacionados às duas amostras, os dados foram normalizados pelas concentrações de proteína. Tais espectros normalizados são apresentados na Figura 4.25. Os resultados mostraram espectros de absorção característicos da LDL $[45,46]$, nos quais se observa as diferentes contribuições, devidas à constituição heterogênea dessas partículas. É destacada a faixa de comprimentos de onda de 350 a $600 \mathrm{~nm}$, na qual podem ser notados os máximos de absorção dos antioxidantes carotenóides $(\lambda \approx 440-480 \mathrm{~nm})$. Este intervalo também compreende a absorção das amostras em $\lambda=532 \mathrm{~nm}$, o comprimento de onda utilizado nos experimentos de ZS. A partir dos 
valores de absorção em $532 \mathrm{~nm}$, os coeficientes de absorção óptica $(\alpha)$ das amostras foram determinados.

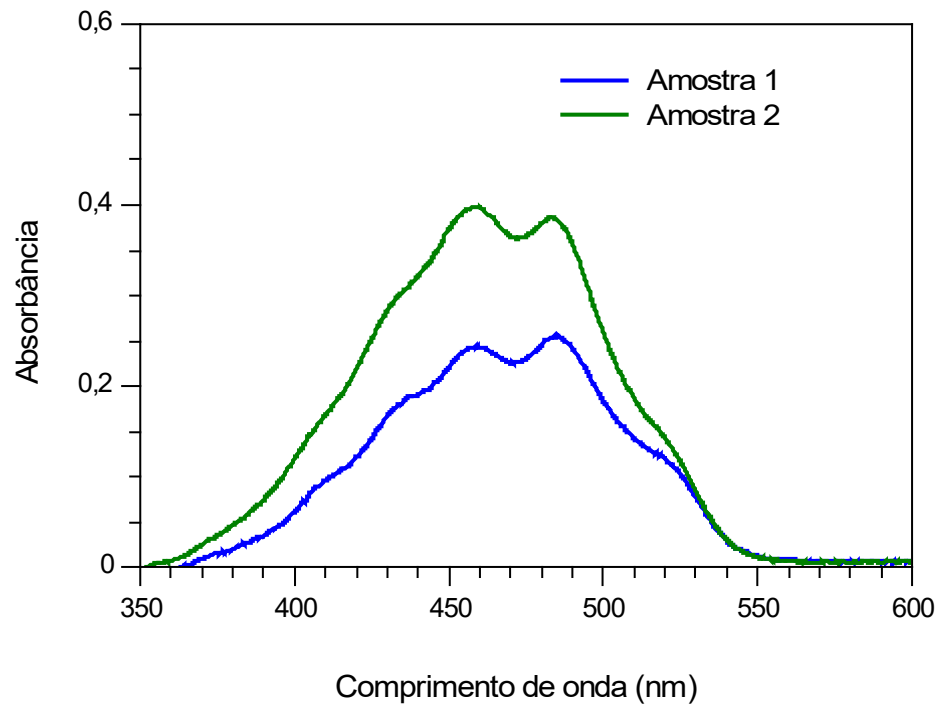

Figura 4.25. Espectros de absorção para comprimentos de onda entre 350 e $600 \mathrm{~nm}$, permitindo avaliar os níveis de antioxidantes carotenóides nas amostras de LDL. Os dados foram normalizados pela concentração de proteína nas amostras.

Além da determinação de $\alpha$, os resultados de absorção foram úteis na indicação do conteúdo de antioxidantes nas amostras. Além da visualização dos espectros de absorção, mostrados na Figura 4.23, os valores de absorbância em $484 \mathrm{~nm}\left(A_{484 \mathrm{~nm}}\right)$ podem fornecer uma informação quantitativa do conteúdo de antioxidantes $[48,50]$. Esse comprimento de onda corresponde ao segundo máximo de absorção dos carotenoides, e foi adotado como um indicativo do estágio oxidativo das duas amostras investigadas. Os valores de $A_{484} \mathrm{~nm}$, originais e normalizados pela concentração de proteínas $\left(A_{c}\right)$, de cada uma das amostras, são apresentados na tabela 4.6 .

Tabela 4.6. Valores das absorbâncias a $484 \mathrm{~nm}$, extraídos dos dados dos espectros de absorção e após normalização pela concentração das amostras ( $A_{484 \mathrm{~nm}}$ e $A_{c}$, respectivamente), para as amostras 1 e 2 .

\begin{tabular}{ccc}
\hline Amostra & $A_{484 n m}(\mathrm{DO})$ & $A_{c}\left(\mathrm{DO} \mathrm{mg}{ }^{-1} \mathrm{~mL}\right)$ \\
\hline Amostra 1 & $0,330 \pm 0,001$ & $0,254 \pm 0,001$ \\
Amostra 2 & $0,541 \pm 0,001$ & $0,386 \pm 0,001$ \\
\hline
\end{tabular}


Os resultados, apresentados na Figura 4.25 e Tabela 4.6, indicaram um menor conteúdo de antioxidantes na amostra 1 . Já na região de $\lambda=532 \mathrm{~nm}$, os espectros de absorção não apresentam grande discrepância, indicando que as duas amostras devem apresentar valores semelhantes para $\alpha$ e $\theta_{\mathrm{LT}}$.

\section{Espalhamento de luz dinâmico (DLS)}

As amostras foram analisadas, pela técnica de espalhamento de luz dinâmico, para verificar se os valores de raio médio das partículas de LDL, obtidas com a ultracentrifugação, estavam de acordo com os valores esperados. As Figuras 4.26 e 4.27 mostram as curvas de correlação e os histogramas das intensidades relativas, normalizada por número de partículas, em função dos diâmetros, para cada uma das amostras analisadas. Na tabela 4.7 são apresentados os valores de raio médio, determinados com as análises de DLS, e os valores esperados, com base na literatura. Os valores determinados estão no intervalo de valores esperados [83].

A

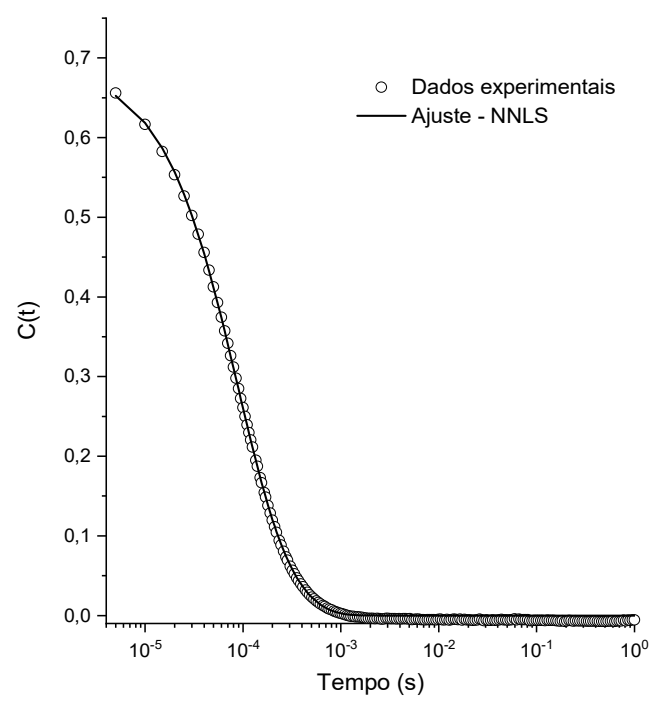

B

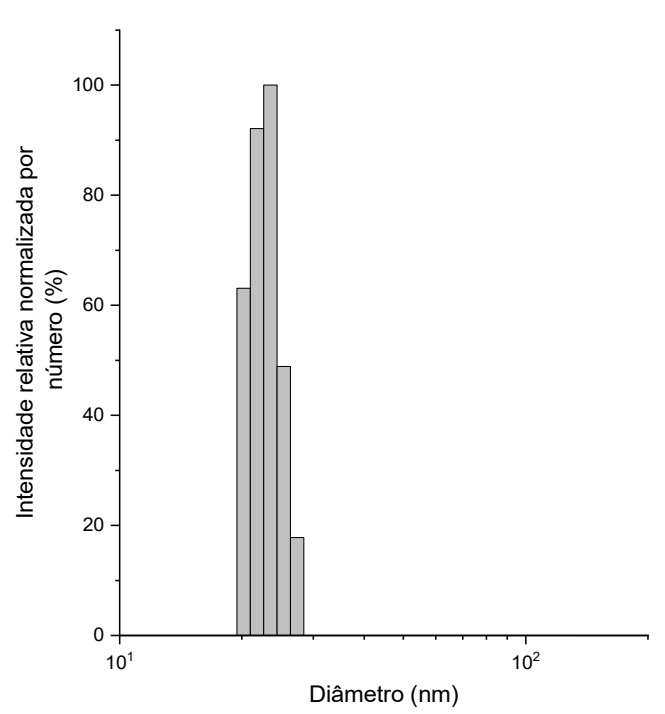

Figura 4.26. (A) Curva de correlação e (B) valores de intensidade relativa, normalizada por número, em função dos valores de diâmetros, para a amostra 1. 
A

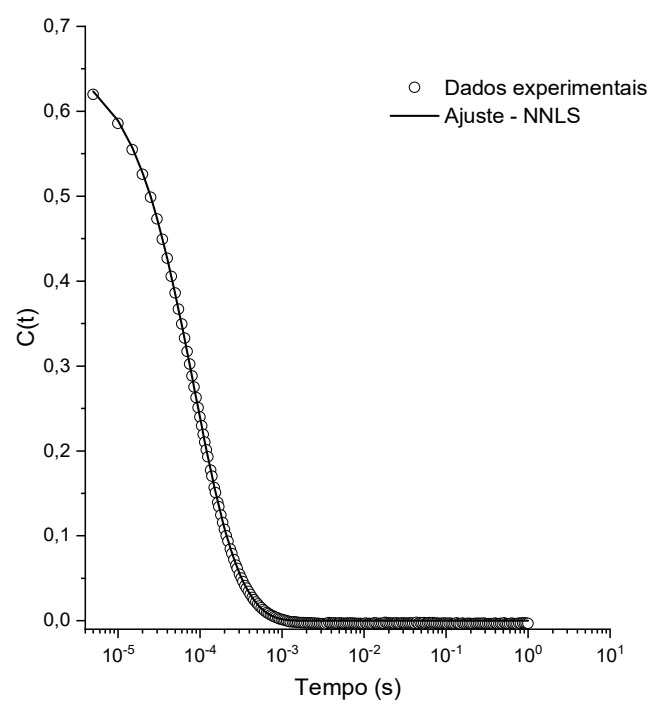

B

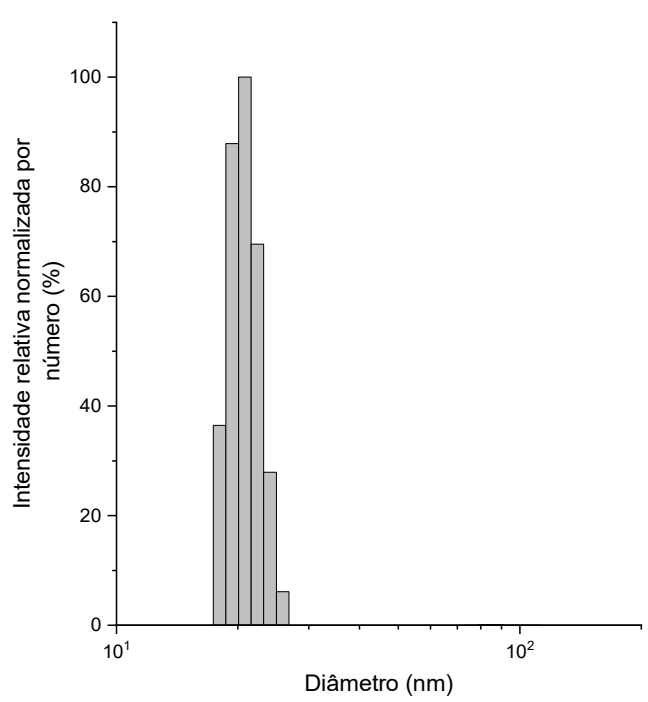

Figura 4.27. (A) Curva de correlação e (B) valores de intensidade relativa, normalizada por número, em função dos valores de diâmetros, para a amostra 2 .

Tabela 4.7. Comparação entre raios médios, determinados pelas análises de DLS, e os valores esperados. *Valores esperados, com base na literatura.

\begin{tabular}{ccc}
\hline Amostra & $\mathrm{R}_{\mathrm{DLS}}(\mathrm{nm})$ & $\mathrm{R}_{\text {esperado }}(\mathrm{nm})^{*}$ \\
\hline Amostra 1 & $11,4 \pm 1,5$ & $9-12,5$ \\
Amostra 2 & $10,4 \pm 1,5$ & $9-12,5$ \\
\hline
\end{tabular}

Os dados de DLS também foram úteis na avaliação da polidispersão das amostras. Isto pode ser observado no histograma das distribuições de diâmetros e, sobretudo, nas curvas de correlação. No caso dos resultados apresentados nas Figuras 4.26 e 4.27, o perfil do decaimento das curvas de correlação, $C(t)$, indicou que não há a presença de populações de diferentes dimensões. Esta avaliação garante que os demais experimentos conduzidos descrevem o comportamento das partículas monoméricas. 


\section{Lente térmica e lente Soret}

Para a determinação do coeficiente Soret foram realizados os experimentos de ZS, nas duas escalas temporais, que permitiram observar os fenômenos de difusão de calor e de matéria. A escolha por realizar os dois experimentos, foi baseada no tempo característico para cada um dos fenômenos. Ao optar pela realização de apenas um experimento, na escala de segundos para observar o fenômeno de difusão de massa, o efeito térmico seria limitado à análise de um pequeno número de pontos experimentais. Por isso, opta-se por realizar dois experimentos independentes, cada um em sua escala temporal adequada.

Considerando que o tempo característico para difusão de calor $\left(\mathrm{t}_{\mathrm{LT}}\right)$ é um parâmetro relacionado a cada meio, e já tendo sido verificado, em nosso grupo, que este parâmetro não se altera significativamente, mesmo entre as amostras de LDL em diferentes níveis de oxidação, este foi mantido como um parâmetro fixo nos ajustes. $\mathrm{O}$ valor adotado $\left(\mathrm{t}_{\mathrm{LT}}=2 \mathrm{~ms}\right)$ foi baseado em uma estimativa considerando a constante de difusividade térmica da água $\left(\mathrm{D}_{\mathrm{T}}\right.$ $=1,45.10^{-7} \mathrm{~m}^{2} / \mathrm{s}$ ), e o valor para o comprimento de Rayleigh, correspondente ao arranjo usado $\left(\mathrm{z}_{0} \simeq 3,8 \mathrm{~mm}\right)$, por meio da equação 2.19. A este valor de $t_{\mathrm{LT}}$ esteve associada a escolha do tempo de irradiação, de $50 \mathrm{~ms}$, para os experimentos de LT. O tempo de irradiação deve ser bastante superior ao $t_{\mathrm{LT}}$, afim de garantir a formação e estabilização do fenômeno físico. Isto se reflete na tendência de estabilização na região final da curva, que descreve a dependência temporal da $T_{N}$, como mostra o resultado apresentado na Figura 4.28. A curva apresentada corresponde a um resultado típico para a $T_{N}$, em função do tempo, para uma amostra de LDL. Note-se um perfil de redução da $T_{N}$, indicando a ocorrência do fenômeno de desfocalização do feixe, para uma posição $z$ positiva. Neste caso, sendo o objetivo apenas destacar o comportamento temporal da $T_{N}$, nenhum ajuste foi realizado, sendo o resultado, mostrado na Figura 4.28, correspondente apenas aos dados experimentais. 


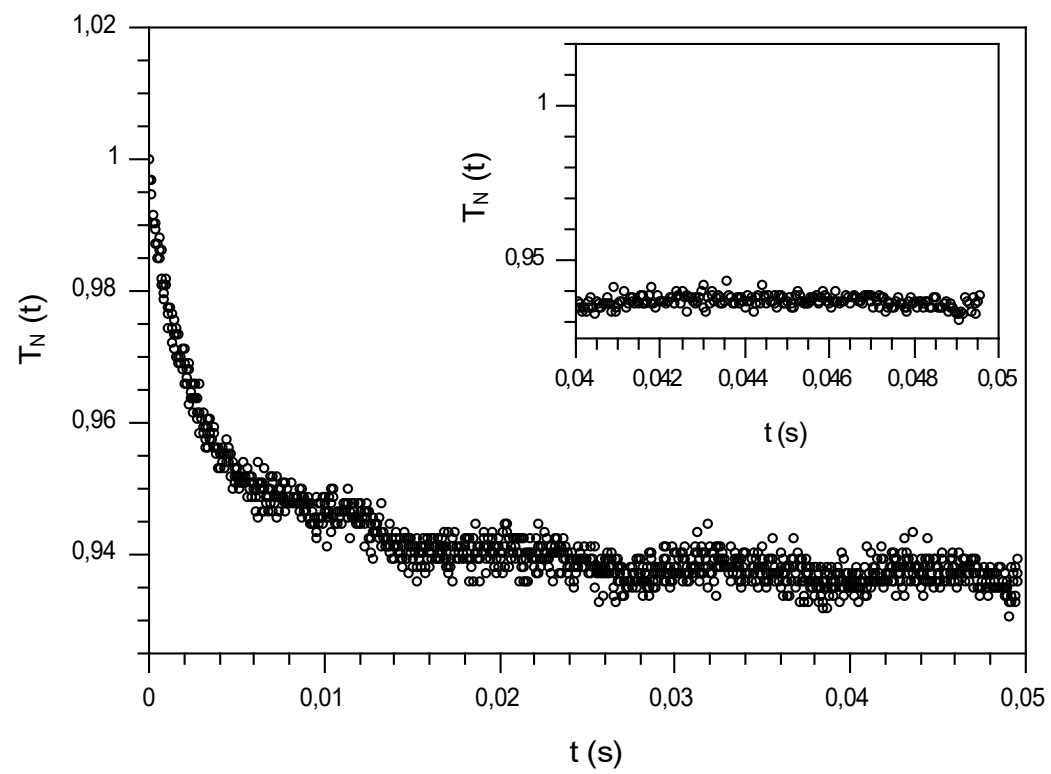

Figura 4.28. Resultado típico para a dependência temporal da $T_{N}$ em um experimento de LT com uma escolha adequada para o tempo de irradiação da amostra. A posição tomada é uma posição após o foco $(z>0)$. Em destaque, o treco da curva entre os instantes de 40 e $50 \mathrm{~ms}$, mostrando a estabilização da curva.

Os resultados obtidos para a evolução espacial da $T_{N}$ foram também característicos, com as curvas apresentando o perfil pico-vale, indicativo da desfocalização do feixe, após sua passagem pela amostra. Isto mostra o comportamento de lente divergente da amostra de LDL, sob efeito de lente térmica. Os resultados são mostrados nas Figuras 4.29 e 4.30, para as amostras 1 e 2 , respectivamente.

Na Tabela 4.8 são apresentados os valores de $A_{484 \mathrm{~nm}}$ (tabela 4.6), para cada uma das amostras, e os correspondentes valores de $\theta_{L T}$, retornados pelos ajustes apresentados na Figuras 4.29 e 4.30 . Os valores para as amplitudes $\theta_{L T}$ das amostras não apresentaram valores muito distintos, uma vez que o sinal térmico das partículas de LDL está diretamente relacionado com a absorção das partículas em $532 \mathrm{~nm}$. Logo, a proximidade entre os valores de $\theta_{L T}$ é coerente com os espectros de absorção, semelhantes neste comprimento de onda. 


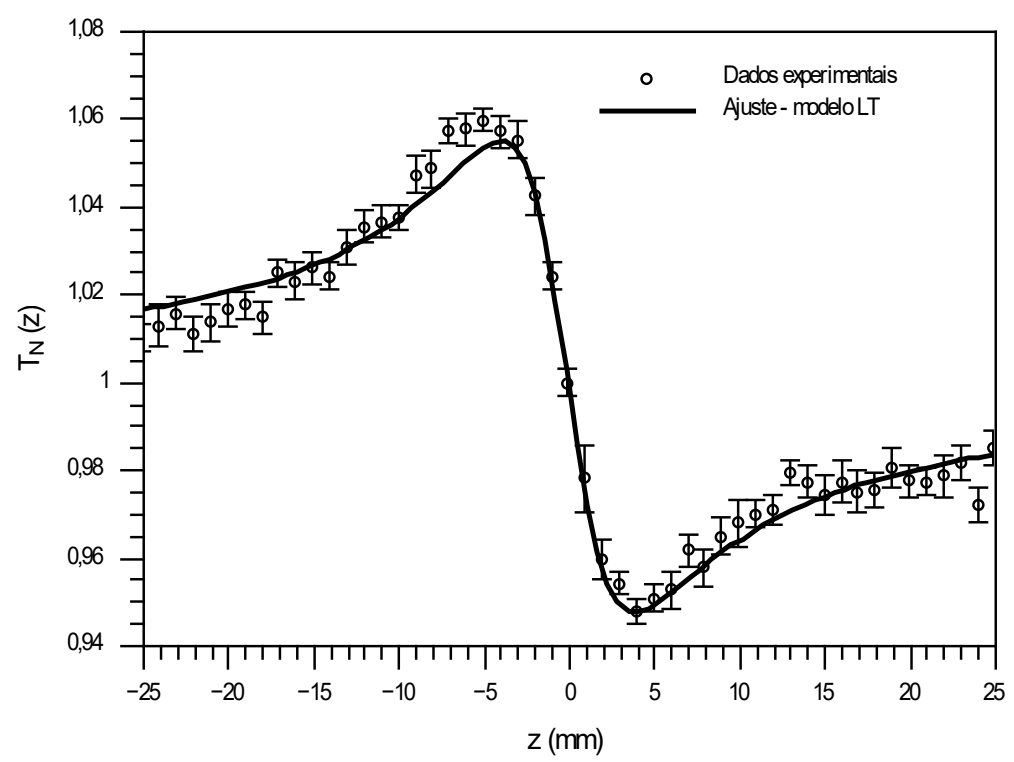

Figura 4.29. Resultado do experimento de LT para a amostra 1. Os símbolos representam os dados experimentais e as linhas são os ajustes teóricos.

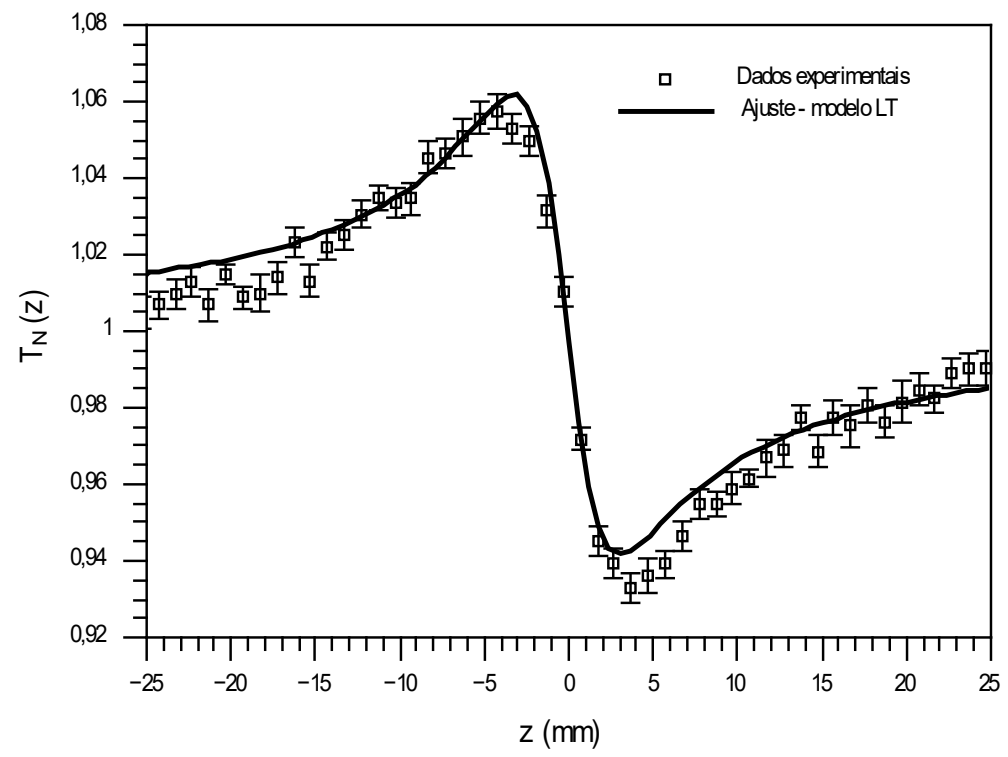

Figura 4.30. Resultado do experimento de LT para a amostra 2. Os símbolos representam os dados experimentais e as linhas são os ajustes teóricos. 
Tabela 4.8. Valores de $A_{484 \mathrm{~nm}}$ e $\theta_{L T}$, para as amostras 1 e 2. Os valores de $A_{484 n m}$ e $\theta_{L T}$ não foram corrigidos por $c$, representando exatamente a concentração das amostras empregadas nos ensaios realizados.

\begin{tabular}{ccc}
\hline Amostra & $A_{484 \mathrm{~nm}}(\mathrm{DO})$ & $\theta_{L T} \pm \sigma_{\theta_{L T}}$ \\
\hline Amostra 1 & $0,330 \pm 0,001$ & $0,055 \pm 0,001^{*}$ \\
Amostra 2 & $0,541 \pm 0,001$ & $0,061 \pm 0,002^{*}$
\end{tabular}

*Incertezas retornadas pelo ajuste dos dados experimentais, do qual se obteve $\theta_{L T}$.

Para os experimentos na escala temporal de segundos, os resultados são mostrados na Figura 4.31. A equação 2.33 foi empregada nos ajustes das curvas experimentais de $T_{N} \mathrm{x} t$, para a determinação da $\theta_{L S}$. A escolha desta abordagem, para a determinação de $\theta_{L S}$, foi baseada em estudos anteriores de nosso grupo de pesquisa [58]. Sua aplicação, neste estudo, tem como vantagem a redução do tempo de execução do experimento, na escala de tempo de segundos, já que a mostra é mantida em uma posição fixa e não realizada uma varredura das posições. Desse modo, é reduzido o tempo total de exposição da amostra à incidência do laser, reduzindo-se o risco de afetar as partículas no decorrer do experimento.

Os valores obtidos, para as amplitudes da LS $\left(\theta_{L S}\right)$, foram empregados para a determinação dos coeficientes Soret, por meio da equação 2.32 ou $S_{T}=\frac{\theta_{L S}}{\theta_{L T} c}\left(\frac{d n}{d c}\right)^{-1}\left(\frac{d n}{d T}\right)$. Uma vantagem desta abordagem está na normalização do $S_{T}$, pela concentração da amostra (c) e pela amplitude da LT $\left(\theta_{L T}\right)$, permitindo um estudo comparativo entre amostras com diferentes concentrações e/ou diferentes contribuições de sinal térmico.

Os valores obtidos para o $S_{T}$ são apresentados na Tabela 4.9, na qual também são mostrados os valores dos parâmetros experimentais adotados e dos parâmetros ajustados com as análises. Os coeficientes termo-ópticos foram $\mathrm{dn} / \mathrm{dT}=(-1,10 \pm 0,01) \times 10^{-4}$, para a amostra 1, e dn/dT $=(-0,85 \pm 0,06) \times 10^{-4}$, para a amostra 2. Para a dependência do índice de refração com a concentração, os coeficientes determinados foram $\mathrm{dn} / \mathrm{dc}=(0,90 \pm 0,05) \times 10^{-3}$, para a amostra $1, \mathrm{e} \mathrm{dn} / \mathrm{dc}=(1,11 \pm 0,02) \times 10^{-3}$, para a amostra 2 . 


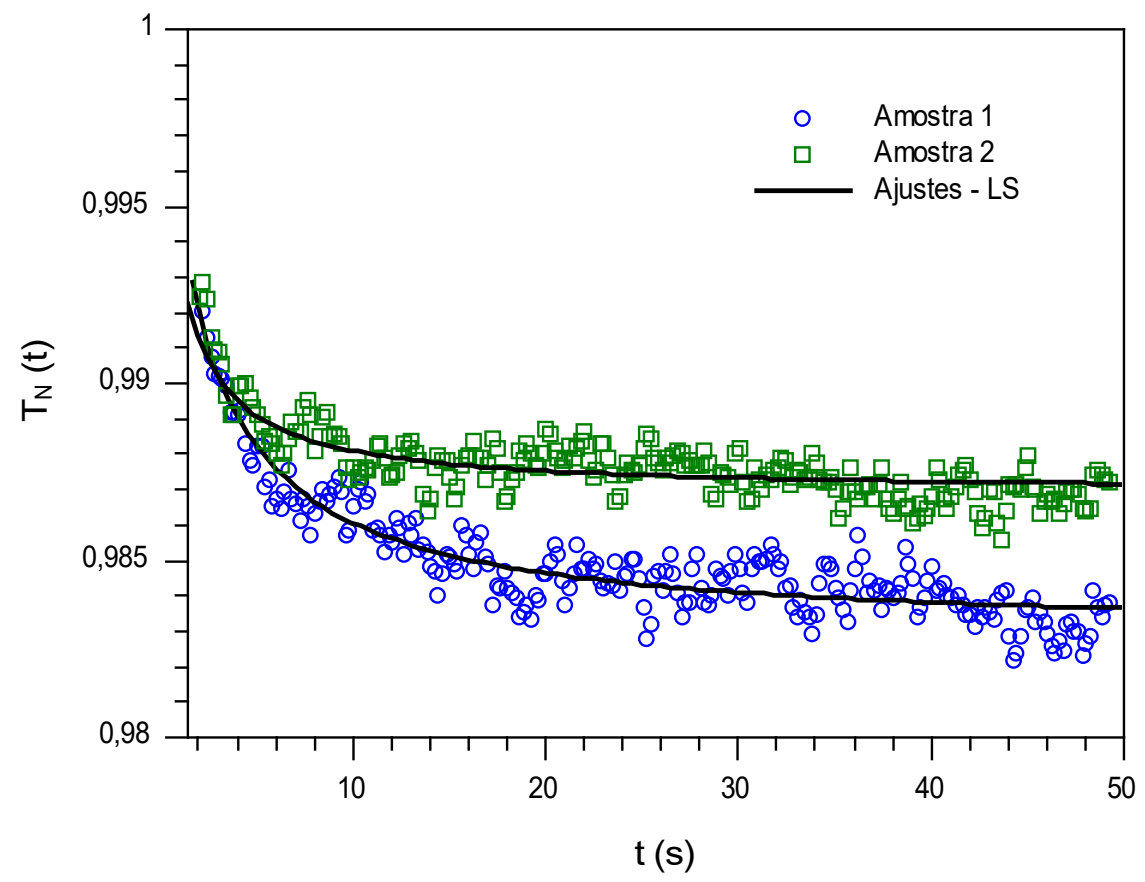

Figura 4.31. Resultados dos experimentos de LS, mostrando o comportamento termofóbico $\left(S_{T}>0\right)$ observado. A posição experimental foi $z=7 \mathrm{~mm}$. Os símbolos representam os dados experimentais e as linhas correspondem aos ajustes teóricos.

Tabela 4.9. Valores de $S_{T}$ determinados e os parâmetros experimentais ou ajustados.

\begin{tabular}{cccccccc}
\hline LDL nativa & $\alpha\left(\mathrm{m}^{-1}\right)$ & $c(\mathrm{mg} / \mathrm{mL})$ & $\theta_{L T}$ & $\theta_{L S}$ & $\sigma_{\theta_{L T}} *$ & $\sigma_{\theta_{L S}} *$ & $S_{T}\left(\mathrm{~K}^{-1}\right)$ \\
\hline Amostra 1 & $19,3 \pm 0,2$ & 1,3 & 0,055 & $-0,020$ & 0,001 & 0,0001 & $0,034 \pm 0,002$ \\
Amostra 2 & $22,1 \pm 0,2$ & 1,4 & 0,061 & $-0,017$ & 0,002 & 0,00009 & $0,016 \pm 0,001$ \\
\hline
\end{tabular}

*Incertezas retornadas pelos ajustes dos dados experimentais.

Esses resultados mostraram uma aplicação da generalização do modelo de LT, possibilitando a determinação de um $S_{T}$ experimental para as partículas de LDL. As partículas exibiram valores de $S_{T}$ positivos, caracterizando um comportamento termofóbico. Isto significa que as partículas de LDL nessas amostras, quando sujeitas a um gradiente de temperatura, migram para as regiões frias do meio.

Uma segunda constatação foi a diferença nos valores de $S_{T}$, para as duas amostras, conduzindo à questão de se esta diferença seria devido a alguma característica específica, que diferencie as amostras 1 e 2.

Com base nos resultados de caracterização, a diferença mais imediata está nos resultados de espectroscopia UV-vis, sendo os espectros de absorção e os valores de $A_{484} \mathrm{~nm}$ 
(Figura 4.25 e Tabela 4.6, respectivamente), diferentes para as amostras 1 e 2. Desse modo, estabelecemos uma primeira hipótese sobre a influência dos níveis de modificação, mais especificamente níveis de oxidação, no efeito Soret da LDL. Sendo assim, consideramos que a amostra 1 estaria mais oxidada que a amostra 2, o que conduz a seu valor de $S_{T}$ mais elevado, caracterizando um comportamento termodifusivo mais termofóbico. Na Tabela 4.10 são apresentados novamente os valores de $A_{484} \quad n m$ e os valores normalizados pela concentração, $A_{c}$, para as amostras 1 e 2 , e os valores de $S_{T}$ correspondentes. Estes mostram valores de $S_{T}$ inversamente relacionados aos valores de $A_{484 \mathrm{~nm}}$, estando de acordo com a ideia inicial.

Tabela 4.10. Valores das absorbâncias a $484 \mathrm{~nm}\left(A_{484 n m}\right.$ e $\left.A_{c}\right)$ e de $S_{T}$, para as amostras 1 e 2.

\begin{tabular}{cccc}
\hline Amostra & $A_{484 n m}(\mathrm{DO})$ & $A_{c}\left(\mathrm{DO} \mathrm{mg}{ }^{-1} \mathrm{~mL}\right)$ & $S_{T}\left(\mathrm{~K}^{-1}\right)$ \\
\hline Amostra 1 & $0,330 \pm 0,001$ & $0,254 \pm 0,001$ & $0,034 \pm 0,002$ \\
Amostra 2 & $0,541 \pm 0,001$ & $0,386 \pm 0,001$ & $0,016 \pm 0,001$ \\
\hline
\end{tabular}

Dadas as considerações e resultados acima, serão apresentados, no tópico a seguir, os mecanismos físicos que sugerimos estarem associados ao efeito Soret nas partículas de LDL, e uma hipótese do que pode estar relacionado aos diferentes valores de $S_{T}$, para as duas amostras analisadas.

\section{Origem do efeito Soret nas partículas de LDL}

Cada partícula de LDL apresenta uma apolipoproteína, a ApoB-100, que é descrita estar disposta ao redor da partícula [16], como já foi mencionado. A ApoB-100 é uma proteína constituída por aminoácidos carregados, como as lisinas, um resíduo carregado positivamente. Em modificações da LDL in vivo, como a oxidação, alterações dessas lisinas têm sido relacionadas a mudanças de cargas desta partícula [84, 85]. Com base nisso, aspectos relacionados à termodifusão de nanopartículas carregadas, podem ser pensados como fatores relacionados ao efeito Soret das partículas de LDL.

Ao final da seção 2.2.2, foi apresentada uma breve descrição das contribuições para o efeito Soret em nanopartículas carregadas. Foi apresentada uma definição para a energia armazenada na dupla camada, e sua relação com a velocidade termoforética. Para assegurar 
que a LDL estivesse em condições análogas às fisiológicas, as amostras foram preparadas na presença de sais, que poderiam, devido ao efeito Seebeck, também descrito na seção 2.2.2, influenciar o $S_{T}$ das partículas de LDL.

No entanto, vários estudos investigaram a influência das diferentes classes de íons no coeficiente Soret de nanopartículas $[61,62,86]$. Vigolo et al mostraram as drásticas mudanças no valor do $S_{T}$, de micelas do surfactante aniônico dodecil sulfato de sódio (SDS), em decorrencia da adição de $\mathrm{NaOH}$. Ao contrário disso, os íons provenientes da adição de $\mathrm{NaCl}$, apresentaram uma contribuição bem menos significativa [86]. Em um trabalho de revisão bibliográfica, Niether e Wiegand concluíram que a contribuição da dupla camada elétrica pode ser o mecanismo predominante, na termodifusão de nanopartículas carregadas, quando estas estão na presença de um único sal ou composição única de tampão [40]. Com base nessas constatações, consideramos que seja baixa a contribuição termoelétrica em soluções constituídas por $\mathrm{NaCl}$, principal sal nas amostras de LDL usadas nesta trabalho. Sendo assim, a contribuição termoforética pode ser considerada como predominante no comportamento termodifusivo observado para as partículas de LDL.

Considerando que o efeito Soret é influenciado por propriedades estruturais e físicoquímicas das partículas, nossa hipótese está relacionada a possíveis diferenças na carga superficial das partículas, constituintes das duas amostras, como consequência de seus estágios de oxidação. Tais mudanças de carga têm impacto na energia da dupla camada que, por sua vez, está relacionada à velocidade termoforética, como já foi mostrado pelas equações 2.34 e 2.35. Esta suposição é coerente com os resultados de absorbância que indicaram uma menor absorbância para a amostra 1, sugerindo que esta pode estar mais oxidada que a amostra 2.

A peroxidação lipídica corresponde à primeira etapa do processo oxidativo na LDL. Esta resulta na degradação de lipídios, gerando produtos aldeídicos, que podem afetar a ApoB-100, como já foi citado. A ligação desses aldeídos, aos grupamentos amino $\left(\mathrm{NH}_{3}{ }^{+}\right)$das lisinas da ApoB-100, leva ao bloqueio desses grupos positivos na superfície das partículas (Anexo II). Estudos mostram que a LDL oxidada é mais negativa que a LDL nativa, como consequência do processo descrito acima [84, 85]. Para explicar nossos resultados, consideramos que o processo de oxidação acarreta, portanto, uma mudança da carga superficial da LDL. Mudanças na carga superficial promovem a chamada deformação da dupla camada elétrica, em partículas carregadas, resultando na alteração da interação 
interfacial partícula-fluido. Isto afetaria o comportamento termodifusivo e, consequentemente, o $S_{T}$, das partículas de LDL.

A fim de investigar mais sobre a influência dos níveis de oxidação da LDL em seus valores de $S_{T}$, um estudo in vitro foi realizado. Os resultados são apresentados na seção seguinte.

\subsection{2 $\mathrm{S}_{\mathrm{T}}$ para a LDL oxidada in vitro: Influência dos níveis de oxidação da LDL}

As amostras foram preparadas seguindo a mesma metodologia que o estudo anterior, mas as diálises foram na ausência de EDTA, para permitir a oxidação da LDL. A partir da LDL nativa, as amostras oxidadas foram obtidas. Uma amostra nativa foi preparada, sendo mantida sem cobre e com adição do EDTA a $1 \mathrm{mM}$, a mesma concentração de EDTA adicionada para interromper as reações de oxidação. $O$ consumo dos antioxidantes nas amostras foi monitorado pelos espectros de absorção, como mostra a Figura 4.32.

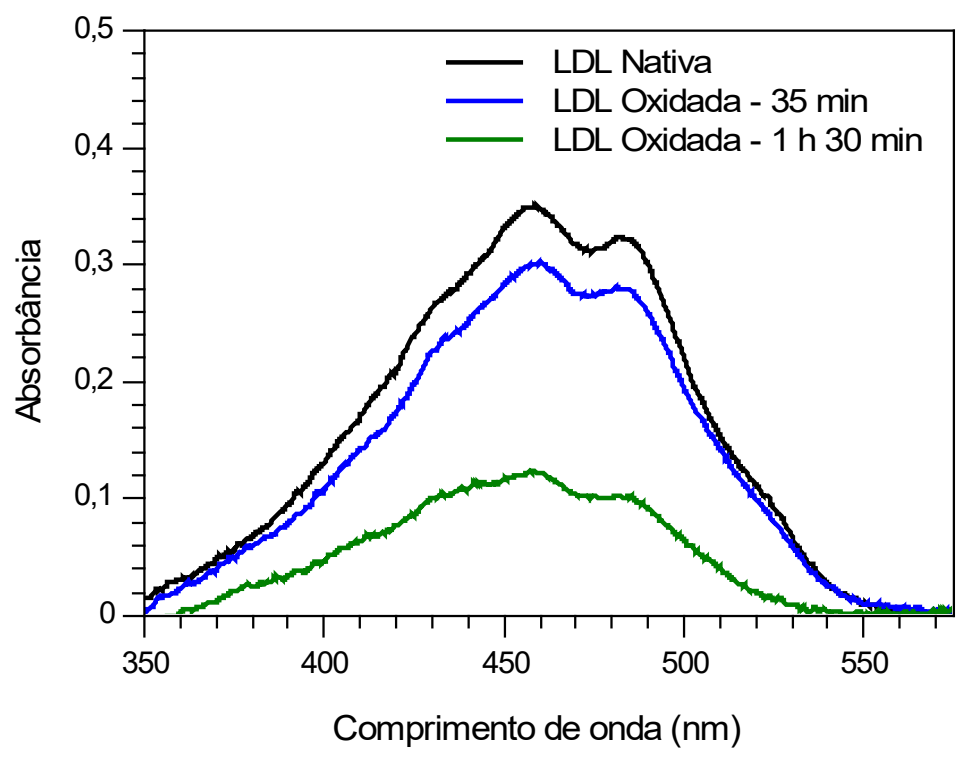

Figura 4.32. Espectros de absorbância para as amostras de LDL nativa e oxidadas, mostrando a redução nos níveis dos antioxidantes carotenoides com o tempo de oxidação.

Os valores de absorbância a $484 \mathrm{~nm}$, para as amostras nativa e oxidadas, são mostrados na Tabela 4.11. Os resultados mostram a redução dos valores desse parâmetro, indicando a redução dos níveis de antioxidantes carotenoides em função da oxidação, 
corroborando a informação da Figura 4.32. Neste caso, as amostras foram todas obtidas de um mesmo processo de separação, apresentando, portanto, a mesma concentração.

Tabela 4.11. Valores das absorbâncias a $484 \mathrm{~nm}$, para as amostras de LDL nativa e oxidadas durante dois tempos de reação distintos. Os valores mostram a redução dos níveis de antioxidantes em função da oxidação.

\begin{tabular}{cc}
\hline Amostra & $A_{\lambda=484 \mathrm{~nm}}(\mathrm{DO})$ \\
\hline Nativa & $0,322 \pm 0,001$ \\
Oxidada 35min & $0,279 \pm 0,001$ \\
Oxidada $1 \mathrm{~h} 30$ & $0,101 \pm 0,001$ \\
\hline
\end{tabular}

Os ajustes dos dados experimentais, obtidos com os experimentos de ZS, forneceram as amplitudes $\theta_{L T}$ e $\theta_{L S}$, empregadas no cálculo dos $S_{T}$. Os resultados são mostrados nas Figuras 4.33 e 4.34 .

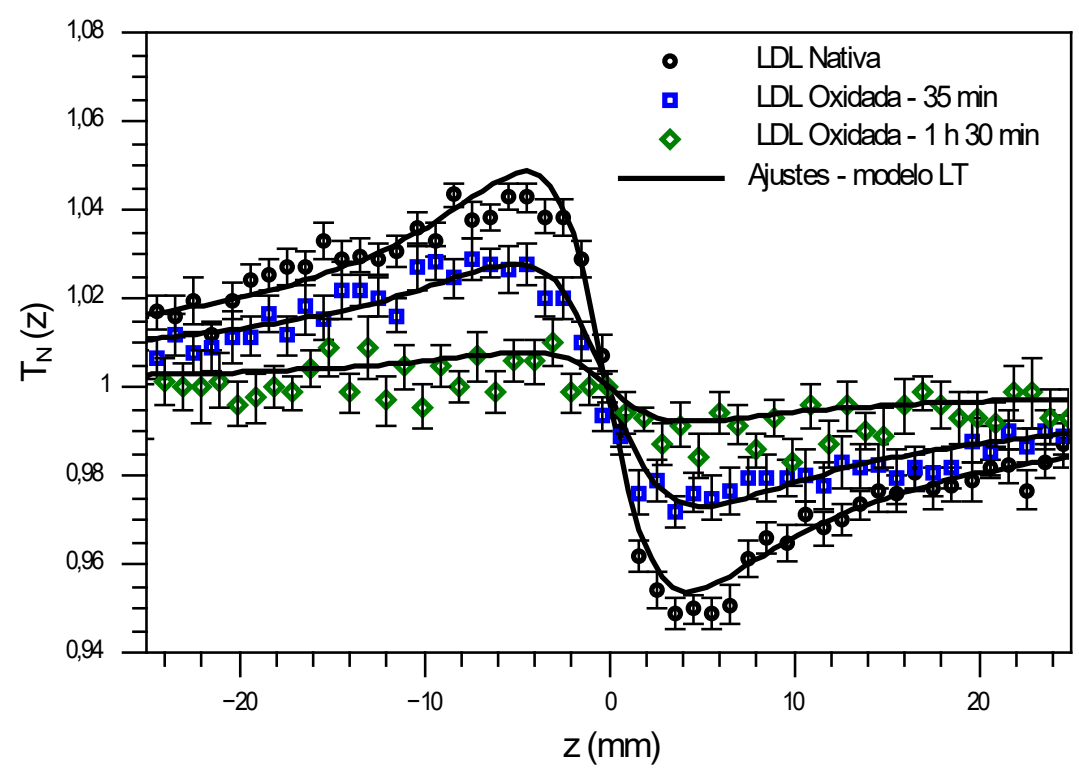

Figura 4.33. Resultados dos experimentos de LT para as amostras nativa e oxidadas. Os dados experimentais são mostrados pelos símbolos e as linhas correspondem aos ajustes teóricos. 


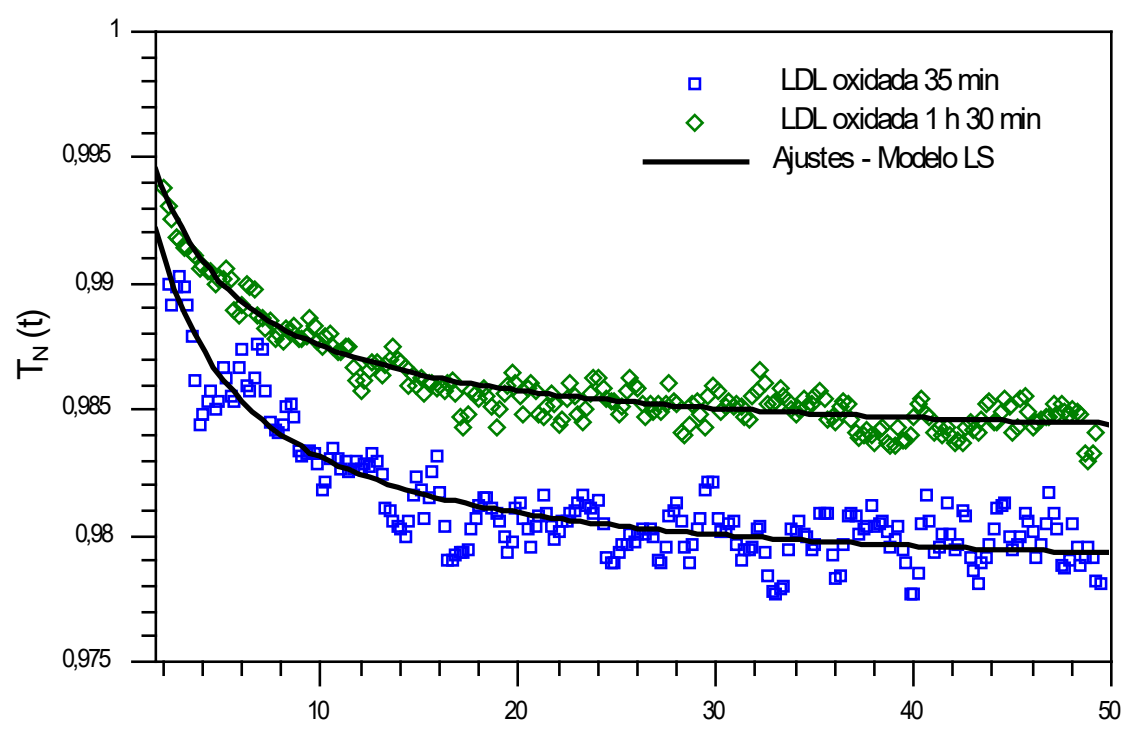

$\mathrm{t}(\mathrm{s})$

Figura 4.34. Resultados dos experimentos de LS para as duas amostras oxidadas. Os dados experimentais são mostrados pelos símbolos e as linhas correspondem aos ajustes teóricos.

Os valores de $S_{T}$ determinados são apresentados na Tabela 4.12, na qual também são mostrados os valores dos parâmetros experimentais adotados e dos parâmetros ajustados com as análises. Os coeficientes termo-ópticos foram $\mathrm{dn} / \mathrm{dT}=(-1,11 \pm 0,02) \times 10^{-4}$ para a amostra nativa, $\mathrm{dn} / \mathrm{dT}=(-1,06 \pm 0,02) \times 10^{-4}$ para a amostra oxidada por $35 \mathrm{~min}$ e $\mathrm{dn} / \mathrm{dT}=(-1,12 \pm$ $0,02) \times 10^{-4}$ para a amostra oxidada por 1 h 30 min. Para a dependência do índice de refração com a concentração, os coeficientes determinados foram $\mathrm{dn} / \mathrm{dc}=(7,47 \pm 0,03) \times 10^{-4}$ para a amostra nativa, $\mathrm{dn} / \mathrm{dc}=(7,8 \pm 0,2) \times 10^{-4}$ para a amostra oxidada por $35 \mathrm{~min}$ e $\mathrm{dn} / \mathrm{dc}=(7,9 \pm$ $0,3) \times 10^{-4}$ para a amostra oxidada por $1 \mathrm{~h} 30 \mathrm{~min}$.

Tabela 4.12. Valores de $S_{T}$, parâmetros experimentais e ajustados, para os dois estudos termodifusivos.

\begin{tabular}{ccccccccc}
\hline Amostra & $\mathrm{P}(\mathrm{W})$ & $\alpha\left(\mathrm{m}^{-1}\right)$ & $c(\mathrm{mg} / \mathrm{mL})$ & $\theta_{L T}$ & $\theta_{L S}$ & $\sigma_{\theta_{L T}} *$ & $\sigma_{\theta_{L S}} *$ & $S_{T}\left(\mathrm{~K}^{-1}\right)$ \\
\hline Nativa & 0,10 & $12,9 \pm 0,2$ & 1,4 & 0,048 & $-0,021$ & 0,001 & 0,0001 & $0,047 \pm 0,002$ \\
Ox-35 min & 0,10 & $12,0 \pm 0,2$ & 1,4 & 0,028 & $-0,022$ & 0,0008 & 0,0001 & $0,079 \pm 0,003$ \\
Ox-1 h 30 min & 0,10 & $1,61 \pm 0,2$ & 1,4 & 0,008 & $-0,020$ & 0,001 & 0,0001 & $0,26 \pm 0,05$ \\
\hline
\end{tabular}

*Incertezas retornadas pelos ajustes dos dados experimentais. 
A Figura 4.35A apresenta os valores de $A_{c}$, isto é, valores de $A_{\lambda}=484 \mathrm{~nm}$ normalizada por concentração. Já na Figura 4.35B, é mostrada a dependência do $S_{T}$ com o tempo de oxidação. Nota-se um aumento nos valores de $S_{T}$, enquanto há um decréscimo do conteúdo antioxidante nas amostras, indicado pelo decréscimo dos valores de $A_{c}$. Logo, os resultados sugerem uma maior termofobicidade das partículas de LDL, em função do seu grau de oxidação. Estes resultados indicaram o mesmo que o observado no estudo com as amostras nativas, ou seja, um aumento dos valores de $S_{T}$, conforme mais oxidada esteja a partícula.
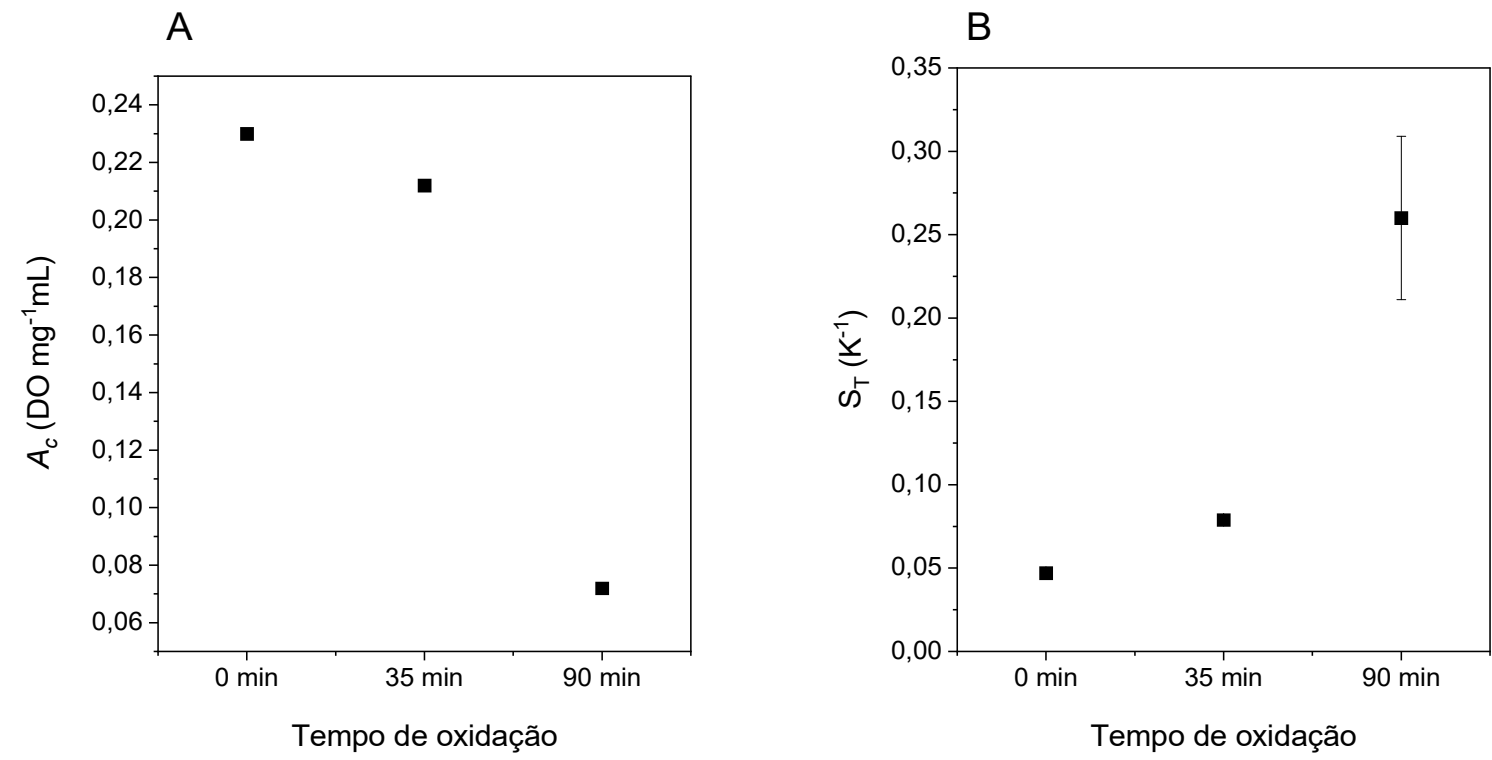

Figura 4.35. Dependência de $A_{c}$ (A) e do $S_{T}$ (B) com o tempo de oxidação, para os ensaio de oxidação in vitro da LDL. Nos dados para os quais as barras de incertezas não são visíveis, estas foram menores que o símbolo representativo do parâmetro.

Vale aqui pontuar que não está sendo proposta uma relação direta entre o consumo de antioxidantes, das partículas de LDL, e a variação do $S_{T}$. O que se sugere é que, o consumo de antioxidantes seja um indicativo do quanto a amostra está oxidada e que, mudanças decorrentes dessa oxidação é que podem acarretar alterações na partícula que, por sua vez, alterem sua migração termoforética. De modo análogo ao que se observa nas discussões dos resultados estruturais, as alterações de densidade eletrônica estão relacionadas aos mecanismos de oxidação em si, e não ao consumo de antioxidantes. 
Como já foi discutido anteriormente, esses resultados podem ter relação com alterações na carga superficial da LDL e, consequentemente, alterações da dupla camada elétrica da partícula. No entanto, um outro parâmetro que é sabido ser influente na difusão de nanopartículas em solução, em resposta a um gradiente térmico, é a dimensão destas. Em partículas esféricas, como a LDL a $37^{\circ} \mathrm{C}$, pode ocorrer uma dependência do $S_{T}$ com o raio. No entanto, no estudo da LDL nativa, não foram observadas diferenças relevantes, considerando a técnica de análise, nos valores de $R_{H}$ das partículas, determinados a partir de experimentos de DLS (Tabela 4.7). Em adição a isto, os resultados de SAXS não indicaram alterações significativas para o raio da LDL, em função do processo oxidativo. Logo, este parâmetro também não explica as variações do $S_{T}$ no estudo da LDL oxidada.

Uma outra contribuição, para a presença do efeito Soret em soluções de nanopartículas, é o já referido efeito Seebeck. Embora tenhamos discutido sobre a possível influência insignificante do efeito Seebeck proveniente dos sais empregados na preparação das amostras, algo a ser considerado seria uma possível contribuição desse efeito devido à presença de produtos da oxidação dos lipídios da LDL no meio. No entanto, esta contribuição seria algo a ser mais bem estudado e avaliado em experimentos futuros, uma vez que só seria possível se os produtos da oxidação lipídica tivessem caráter iônico. 


\section{Conclusões e Perspectivas}

Os estudos estruturais permitiram monitorar as alterações nas partículas de LDL, em função do processo de oxidação, induzido por íons $\mathrm{Cu}^{2+}$. A avaliação da dependência desse modelo de oxidação in vitro, com a concentração do agente oxidante e com o tempo de reação, indicou serem ambos os parâmetros influentes no processo. No entanto, a evolução temporal pareceu ser mais efetiva. Além disso, considerando a literatura disponível para a cinética de oxidação da LDL, em função do tempo, a interpretação dos resultados estruturais em função deste mesmo parâmetro, se torna mais intuitiva. Além de uma maior compreensão sobre as alterações provocadas na partícula, esta proposta pode auxiliar no desenho experimental de ensaios envolvendo a oxidação da LDL.

A interpretação das alterações estruturais, com base nas curvas $p(r)$, foi coerente com a sequência de eventos descritos para a oxidação da LDL. Os resultados sugerem que a oxidação da LDL afeta principalmente a distribuição de densidade eletrônica da partícula, podendo ser isto relacionado aos eventos moleculares, ocorridos na monocamada da LDL. Associamos esses eventos ao aumento da densidade eletrônica na camada externa da LDL.

O modelo adotado para ajuste dos dados, obtidos dos experimentos de SAXS, se mostrou satisfatório ao estudo. A grande aplicabilidade deste foi retornar um parâmetro, $\mu$, relacionado a estas variações de densidade eletrônica. Alterações de densidade eletrônica na LDL oxidada já foram investigadas por outros autores, no entanto, por meio de abordagens que forneceram um perfil de densidade eletrônica, representando uma abordagem apenas qualitativa. A variação dos valores de $\mu$, em função da oxidação das amostras, também se mostrou coerente com a suposição de um aumento da densidade eletrônica na camada externa da LDL. A oxidação, de acordo com os resultados das análises por SAXS e DLS, não altera significativamente o raio $(R)$ das partículas de LDL.

A combinação das informações obtidas pelo método IFT, um método de análise independente da forma e de relativa simplicidade, e pela modelagem de dados, se mostrou uma abordagem bastante informativa, considerando a resolução da técnica de SAXS, podendo ser aplicada a outros estudos.

Ao submeter a LDL à oxidação na temperatura corporal, foi possível avaliar a influência, da organização do colesterol no núcleo da partícula, nas alterações estruturais decorrentes da oxidação. Verificamos que as alterações observadas nos resultados dos experimentos realizados a $25{ }^{\circ} \mathrm{C}$, também parecem ocorrer na partícula oxidada a $37{ }^{\circ} \mathrm{C}$, sugerindo que a estratificação do colesterol, ou a perda desta, não é um fator de inibição das 
alterações de densidade eletrônica na LDL oxidada. No entanto, esta foi uma primeira avaliação, sendo a sequência desses estudos uma perspectiva do presente trabalho. Quanto ao estudo in vivo, a modelagem dos dados permitiu determinar os valores de $R$ e $\mu$, que foram associados aos instantes T0 e T6 do tratamento farmacológico dos pacientes infartados. Observadas as diferenças significativas nesses parâmetros, inferiu-se que os tratamentos mais eficientes incluem o antiplaquetário ticaglelor na terapia combinada.

Os estudos ópticos mostraram a aplicação da técnica de $\mathrm{ZS}$, com a realização de experimentos nas escalas temporais para efeitos térmicos e efeitos de difusão de massa, no estudo do comportamento termodifusivo da LDL, possibilitando a determinação do $S_{T}$ das partículas de LDL. Os valores desse coeficiente se mostraram sensíveis às modificações oxidativas da LDL, e os resultados sugerem ser a oxidação um fator de aumento da termofobicidade da LDL. Esta conclusão foi baseada nos resultados que mostraram um aumento dos valores de $S_{T}$ para amostras com um menor valor de absorbância, referente aos antioxidantes carotenóides. Com base nesses resultados, supõe-se que, variações de carga superficial geram modificações da interação partícula-fluido para a LDL, resultando nas variações dos $S_{T}$ em função dos níveis de oxidação das partículas. A termodifusão pode ser apontada como uma nova abordagem no estudo de lipoproteínas e foi apresentada, neste trabalho, uma metodologia que pode ser empregada em estudos dessa natureza.

Os resultados gerais, tanto dos estudos estruturais como dos ópticos, corroboram a ideia de que as alterações, decorrentes da oxidação da LDL, ocorrem na superfície da partícula. A importância disso está relacionada ao fato de que, alterações da monocamada da LDL são, provavelmente, as envolvidas nos eventos que contribuem para a mudança da dinâmica da partícula no organismo, bem como para seu não reconhecimento por receptores celulares. Logo, podem ser eventos relacionados à atuação da LDL no desenvolvimento de patologias cardiovasculares, sendo a identificação e compreensão destes, fundamentais para entender a atuação aterogênica desta partícula.

A estratégia de análise dos dados de SAXS apresentada nesta tese, que combina o método IFT e a modelagem dependente da forma, se coloca como uma abordagem útil a diferentes estudos da partícula de LDL. A sequência das investigações sobre o impacto da oxidação na estrutura desta partícula em diferentes temperaturas, o que implica em diferentes estados de organização do colesterol no núcleo da LDL, é uma perspectiva ao presente trabalho. Tais investigações podem contribuir para a compreensão do papel da organização lipídica, do núcleo da LDL, para a suscetibilidade desta lipoproteína à oxidação. O modelo 
adotado para a análise de dados de espalhamento, como mostrado no estudo das alterações da LDL como resultado do tratamento dos pacientes infartados, poderá ser adotada em diferentes estudos in vivo.

Os estudos de termodifusão se colocam como um ponto de partida, no que se refere a determinações experimentais, para investigações da difusão da LDL. Podendo também contribuir em estudos do impacto das modificações desta partícula, como oxidação ou glicação, em sua dinâmica de migração. Como perspectiva mais imediata, pode-se adotar uma variação na abordagem experimental, com a determinação da amplitude da lente de matéria de forma análoga à determinação da amplitude da lente térmica. Isto é, por ajuste dos dados de $T_{N}$ em função da posição $z$. No entanto, para isto, é necessário investigar a não alteração da partícula em um experimento com maior tempo de duração. A utilização de outros comprimentos de onda para os experimentos, de modo a explorar a absorção de outros componentes da LDL para promover o gradiente térmico, também é uma possibilidade de estudo futuros. 


\section{Referências Bibliográficas}

1. Schmidt et al. 2011. Chronic non-communicable diseases in Brazil: burden and current challenges. Lancet. 377: 1949-61.

2. Ritchie, H., Roser, M. 2018. Causes of Death. Our World In Data. Disponível em: https://ourworldindata.org/causes-of-death [Online Resource]. Acessado em 08/05/21.

3. Organização mundial da saúde (OMS). Doenças cardiovasculares. Disponível em: https://www.who.int/news-room/fact-sheets/detail/cardiovascular-diseases-(cvds). Acessado em $25 / 06 / 21$.

4. Libby, P. 2006. Inflammation and cardiovascular disease mechanisms. Am J Clin Nutr. 83:. 456-60.

5. Kerenyi et al. 2006. Role of Hyperlipidemia in Atherosclerotic Plaque Formation in the Internal Carotid Artery. Journal of Clinical Ultrasound. 34: 283-88.

6. Sociedade Brasileira de Cardiologia. V Diretriz Brasileira de Dislipidemias e Prevenção da Aterosclerose. v.101, n. 4, 2013.

7. Zárate, A. 2016. Hypercholesterolemia As a Risk Factor for Cardiovascular Disease: Current Controversial Therapeutic Management. Archives of Medical Research. 47:491-95.

8. Lehninger Principles of Biochemistry. David L. Nelson \& Michael M. Cox, 3 ed. W.H. Freeman and Company, New York, 2000.

9. Stocker, R., Keaney, JR J. F. 2004. Role of Oxidative Modifications in Atherosclerosis. Physiol Rev. 84: 1381-478.

10. Berliner, J. A., Heinecke, J. W. 1996. The role of oxidized lipoproteins in atherogenesis. Free Radic Biol Med. 20: 707-27.

11. Hulthe, J. Fagerberg, B. 2002. Circulating Oxidized LDL Is Associated With Subclinical Atherosclerosis Development and Inflammatory Cytokines. Arterioscler Thromb Vasc Biol. 22: $1162-67$.

12. Hansson, G. K. 2005. Inflammation, Atherosclerosis, and Coronary Artery Disease. $N$ Engl J Med. 352: 1685-95.

13. Hevonoja et al. 2000. Structure of low density lipoprotein (LDL) particles: Basis for understanding molecular changes in modified LDL. Biochimica et Biophysica Acta. 1488: 189-210.

14. Prassl, R., Laggner, P. 2008. Molecular structure of low density lipoprotein: current status and future challenges. European Biophysics Journal 38:145.

15. Segrest, J.P., Jones, M.K., De Loof, H., Dashti, N. 2001. Structure of apolipoprotein B100 in low density lipoproteins. Journal of Lipid Research. 42: 1346-66. 
16. Olofsson, O. S., and Bore'n, J. 2005. Apolipoprotein B: a clinically important apolipoprotein which assembles atherogenic lipoproteins and promotes the development of atherosclerosis. Journal of Internal Medicine. 258: 395-410.

17. Esterbauer, H., Ramos, P. 1995. Chemistry and Pathophysiology of Oxidation of LDL Rev. Physiol. Biochem. Pharmacol. 127.

18. Steinberg, D. 2009. The LDL modification hypothesis of atherogenesis: an update. $J$. Lipid Res. 376-81.

19. Moore, K. J., Freeman, M. W.Scavenger. 2006. Receptors in Atherosclerosis Beyond Lipid Uptake. Arterioscler Thromb Vasc Biol. 26: 1702-11.

20. Haberland, M. E., Olch, C. L., Folgelman, A. 1984. Role of Lysines in Mediating Interaction of Modified Low Density Lipoproteins with the Scavenger Receptor of Human Monocyte Macrophages. Journal of biological chemistry. 259: 11305-11.

21 Go, G., Mani, A. 2012. Low-density Lipoprotein receptor (LdLr) Family orchestrates cholesterol Homeostasis. Journal of biology and medicine. 85: 19-28.

22. Haberland, M. E., Folgelman, A, Edwards, P. A. 1982. Specificity of receptor-mediated recognition of malondialdehydemodified low density lipoproteins. Proc. NatL Acad. Sci. Biochemistry. 79: 1712-16.

23. Hoff, H. F, O’Neil, J. 1993. Structural and functional changes in LDL after modification with both 4-hydroxynonenal and malondialdehyde. Journal of Lipid Research. 34

24.Gillotte et al. 2000. Oxidized phospholipid adducts as ligands for macrophage recognition. Journal of Lipid Research. 41

25. Orekhov, A. N. 2018. LDL and foam cell formation as the basis of atherogenesis. Curr Opin Lipidol. 29:279-84.

26. Öörni et al. 2000. Aggregation, fusion, and vesicle formation of modified LDL. Journal of Lipid Research. 41: 1703-14.

27. Öörni, K., Kovanen, P. T. 2021. Aggregation Susceptibility of Low-Density Lipoproteins-A Novel Modifiable Biomarker of Cardiovascular Risk. J. Clin. Med. 10: 1769.

28. Hoff, H. F., O'Neil, J. 1991. Lesion-Derived Low Density Lipoprotein and Oxidized Low Density Lipoprotein Share a Lability for Aggregation, Leading to Enhanced Macrophage Degradation. Arteriosclerosis and Thrombosis. 11: 1209-22.

29. Esterbauer, H., Gebicki, J., Puhl, H., and Jurgens, G. 1992. The role of lipid peroxidation and antioxidants in oxidative modification of LDL. Free Radical Biology \& Medicine. 13: 341-90. 
30. Hevonoja et al. 2000.Structure of low density lipoprotein (LDL) particles: Basis for understanding molecular changes in modified LDL. Biochimica et Biophysica Acta. 1488:189-210.

31. Scanu, A. M. 1972. Structural studies on serum lipoproteins. Biochimica et Biophysica Acta. 265: 471-508.

32. Deckelbaum, R. J., Shipley, G. G., Small, D. M. 1977. Structure And Interactions Of Lipids In Human Plasma Low Density Lipoproteins. J. Biol. Chem. 252: 744-54.

33. Maric, T.K. Lind, J. Lyngsø, M. Cárdenas, J.S. Pedersen. 2017. Modeling small-angle Xray scattering data for low-density lipoproteins: insights into the fatty core packing and phase transition. ACS Nano. 11:1080-90.

34. Kumar,V., Butcher, S. J., Oorni, K.; Engelhardt, P., Heikkonen, J., Kaski, K., AlaKorpela, M., Kovanen, P. T. 2011. Three-Dimensional Cryoem Reconstruction Of Native LDL Particles To 16A Resolution At Physiological Body Temperature. PLoS One. 6, e18841.

35. Schuster, B., Prass1, R., Nigon, F., Chapman, M. J., Laggner, P. 1995.Core Lipid Structure Is a Major Determinant of the Oxidative Resistance of Low-Density-Lipoprotein. Proc. Natl. Acad. Sci. 92: 2509-13.

36. Chung, S., Vafai, K. 2012. Effect of the fluid-structure interactions on low-density lipoprotein transport within a multi-layered arterial wall. Journal of Biomechanics. 45: 37181.

37. Iasiello, M., Vafai, K., Andreozzi, A., Bianco, N. 2016. Low-density lipoprotein transport through an arterial wall under hyperthermia and hypertensionconditions - An analytical solution. Journal of Biomechanics. 49:193-204.

38. Chung, S., and K. Vafai, 2014. Mechanobiology of low-density lipoprotein transport within an arterial wall-Impact of hyperthermia and coupling effects. Journal of Biomechanics 47:137-47.

39. Alves, S., Bourdon, A. and Neto, A. M. F., 2003. Generalization of the thermal lens model formalism to account for thermodiffusion in a single-beam Z-scan experiment: determination of the Soret coefficient. J. Opt. Soc. Am. B. 20:713-18.

40. Niether, D., Wiegand, S. 2019. Thermophoresis of biological and biocompatible compounds in aqueous solution J. Phys.: Condens. Matter. 31: 503003.

41. Gómez, S. L. et al. 2004. Characterization of native and oxidized human low-density lipoproteins by the Z-scan technique. Chemistry and Physics of Lipids. 132:185-95.

42. Gómez, S. L. et al. 2010. $\mathrm{Cu}$ and Fe metallic ions-mediated oxidation of low-density lipoproteins studied by NMR, TEM and Z-scan technique. Chemistry and Physics of Lipids. 163: 545-51.

43. Santos, P. R. et al. 2012. Behavior of the thermal diffusivity of native and oxidized human 
low-density lipoprotein solutions studied by the Z-scan technique. Journal of biomedical optics. 17: 3825-34.

44. Freitas et al. 2016. Z-Scan Analysis: a New Method to Determine the Oxidative State of Low-Density Lipoprotein and Its Association with Multiple Cardiometabolic Biomarkers. Braz J Phys. 46: 163-69.

45. Oliveira, C. L. P., Santos, P. R., Monteiro, A. M., Figueiredo Neto, A. M. 2014a. Effect of oxidation on the structure of human low- and high-density lipoproteins. Biophysical journal. 106: 2595-605.

46. Mello, A.P.Q., Albattarni, G., Espinosa, D. H. G., Reis, D., Neto, A. M. F. 2018. Structural and Nonlinear Optical Characteristics of In Vitro Glycation of Human Low-Density Lipoprotein, as a Function of Time. Brazilian Journal of Physics. 48: 560-70.

47. Monteiro et al. 2012. Measurement of the nonlinear optical response of low-density lipoprotein solutions from patients with periodontitis before and after periodontal treatment: evaluation of cardiovascular risk markers. Journal of Biomedical Optics. 17:115004.

48. Pedroso, J. F., Lotfollahi , Z., Albattarni, G., Schulz, M.A., Monteiro, A. M., Sehnem, A. L., Gidlund, M. A., Neto, A. M. F., Jardini, M. A. N. 2019. Influence of Periodontal Disease on cardiovascular markers in Diabetes Mellitus patients. Scientific Reports. 9:16138.

49. Lotfollahi, Z., Mello, A.P.Q., Costa, E.S. et al. 2020. Green-banana biomass consumption by diabetic patients improves plasma low-density lipoprotein particle functionality. Scientific Reports. 10: 12269.

50. Lotfollahi, Z., Mello, A.P.Q., Fonseca, F. A. H., Machado, L.O., Mathias, A. F., Izar, M. C., Damasceno, N. R. T., Oliveira, C. L. P., Neto, A. M. F. 2021. Changes in lipoproteins after pharmacological therapies. PLoS One. (em submissão).

51. Oliveira, C. L. P. 2011. Investigating Macromolecular Complexes in Solution by Small Angle X-Ray Scattering. In Current Trends in X-Ray Crystallography.

52. O. Glatter and O. Kratky (editors). Small Angle X-Ray Scattering. Academic Press, London, 1982.

53. Santos, Priscila Ribeiro dos. Caracterização estrutural e óptica de lipoproteínas humanas nativas e oxidadas. Tese (Doutorado). São Paulo, 2013.

54. Gómez, S. L. et al. 2004. Characterization of native and oxidized human low-density lipoproteins by the Z-scan technique. Chemistry and Physics of Lipids. 132: 185-95.

55. Rusconi, R., Isa, L., and Piazza, R., 2004 Thermal-lensing measurement of particle thermophoresis in aqueous dispersions. J. Opt. Soc. Am. B. 21: 605-15.

56. Gordon, J. P., R. C. C. Leite, R. S. Moore, S. P. S. Porto, and J. R. Whinnery, 1965. LongTransient Effects in Lasers with Inserted Liquid Samples. Journal of Applied Physics. 36:3-8. 
57. Sehnem, A. L., Aquino, R., Campos, A. F. C., Tourinho, F. A., Depeyrot, J., and Figueiredo Neto, A. M., 2014. Thermodiffusion in positively charged magnetic colloids: Influence of the particle diameter. Physical Review E. 89: 032308.

58. Sehnem, André Luiz. Investigação da influência do tamanho de partícula na termodifusão de colóides magnéticos positivamente carregados. Dissertação (Mestrado). São Paulo, 2014.

59. Ghofraniha, N., Ruocco, G., Conti, C. 2009. Collective Thermal Diffusion of Silica Colloids Studied by Nonlinear Optics. Langmuir. 25: 12495-500.

60. Sehnem, A. L., Neto, A. M. F., Aquino, R., Campos, A. F. C., Tourinho, F. A., Depeyrot J. 2015. Temperature dependence of the Soret coefficient of ionic colloids. Phys. Rev. E 92:042311.

61. Ruckenstein, E., 1981. Can Phoretic Motions Be Treated as Interfacial Tension Gradient Driven Phenomena? Journal of Colloid and Interface Science. 83: 77-81.

62. Eslahian, K. A., A. Majee, M. Maskos, and A. Wurger, 2014. Specific salt effects on thermophoresis of charged colloids. Soft Matter. 10:1931-36.

63. Sehnem, A. L., Figueiredo Neto, A. M., Niether, D. and Wiegand, S. 2018. Diffusiophoresis as ruling effect: Influence of organic salts on thermodiffusion of iron oxide nanoparticles. Physical Review E. 98: 062615.

64. Cartolano, F. C., Dias, G. D., Freitas, M.C.P., Neto, a. M. F., Damasceno, N. R. T. Insulin Resistance Predicts Atherogenic Lipoprotein Profile in Nondiabetic Subjects. 2017. Journal of Diabetes Research.

65. Havel, R. J., Eder, H. A., Bragdon, J. H. 1955. The distribution and chemical composition of ultracentrifugally separated lipoproteins in human serum. J Clin Invest. 34: 1345-53.

66. Lopes-Virella, M. F., Koskinen, S., Mironova, M., Horne, D., Klein, R., Chassereau, C., Enockson, C., Virella, G. The preparation of copper-oxidized LDL for the measurement of oxidized LDL antibodies by EIA. 2000. Atherosclerosis. 152: 107-15.

67. Vieira, 0. V., Laranjinha, J. A. N., Madeira, V. M. C., Almeida, L. M,. 1996. Rapid isolation of low density lipoproteins in a concentrated fraction free from water-soluble plasma antioxidants. J. Lipid Res. 37: 2715-21.

68. Jayaraman, S., Gantz, D. L., Gursky, O. Effects of phospholipase A 2 and its prod-ucts on structural stability of human LDL : relevance to formation of LDL-derived lipid droplets. 2011. Journal of Lipid Research. 52: 549-57.

69. GieBauf, A., van Wickernb, B., Simatb, T., Steinhartb, H., Esterbauer, H. Formation of IV-formylkynurenine suggests the involvement of apolipoprotein B-100 centered tryptophan radicals in the initiation of LDL lipid peroxidation. 1996. Gielhuf et al.IFEBS Letters. 389: $136-40$.

70. Pecora, R. 2000. Dynamic light scattering measurement of nanometer particles in liquids. Journal of Nanoparticle Research. 2: 123-31. 
71. Semenyuk, A. V.; Svergun, D. I. 1991. GNOM - A Program Package for Small-Angle Scattering Data-Processing. Journal of Applied Crystallography. 24: 537-40.

72. Glatter, O. 1981. Convolution square root of band-limited symmetrical functions ans its application to small-angle scattering data. J. Appl. Crystallogr. 14:101-08.

73. Glatter, O., Hainisch, B. 1984. Improvements in real-space deconvolution of small-angle scattering data. J. Appl. Crystallogr. 17:435-441.

74. Oliveira, C.L.P., Behrens, M.A., Pedersen J.S., et al. 2009. A SAXS study of glucagon fi-brillation. J. Mol. Biol. 387: 147-61.

75. Oliveira C. L. P., Monteiro A. M., Figueiredo Neto A. M. 2014b. Structural Modifications and Clustering of Low-Density Lipoproteins in Solution Induced by Heating. Brazilian Journal of Physics. 44: 753-64

76. D.I. Svergun. 1999. Restoring low resolution structure of biological macromolecules from solution scattering using simulated annealing. Biophys. J. 76: 2879-28.

77. Moosmüller, H., Arnott, W. P. 2009. Particle Optics in the Rayleigh Regime. Journal of the Air \& Waste Management Association. 59:1028-31.

78. Quintem, M. Optical properties of nanoparticle systems: Mie and beyond (Wiley-VCH, Weinheim, 2010).

79. Müller, K., Laggner, P., Glatter, O., Kostner, G. 1978. The structure of human plasma low-density lipoprotein B. An X-ray small-angle scattering study. Eur. J. Biochem. 82: 73-90.

80. Meyer, D. F., Nealis, A. S., MacPhee, C. H., Groot, P. H. E., Suckling, K. E., Bruckdorfer, K. R., and Perkins, S. J. 1996. Time-course studies by synchrotron X-ray scattering of the structure of human low-density lipoprotein during $\mathrm{Cu}^{2+}$-induced oxidation in relation to changes in lipid composition. Biochem. J. 319: 217-27.

81. Lehofer, B., Golub, M., Kornmueller, K., Kriechbaum, M., Martinez, N., Nagy, G., Kohlbrecher, J., Amenitsch, H., Peters, J., Prassl, H. 2018. High Hydrostatic Pressure Induces a Lipid Phase Transition and Molecular Rearrangements in Low-Density Lipoprotein Nanoparticles. Part. Part. Syst. Charact. 35: 1800149.

82. Spickett, C. M. 2020. Formation of Oxidatively Modified Lipids as the Basis for a Cellular Epilipidome. Frontiers in Endocrinology. 11: 602771.

83. Rader, D. J; Hobbs, H. H. 2005. Disorders of lipoprotein metabolism. In Harrisons principles of internal medicine. 18: 333-53.

84. Mello, A. P. Q., da Silva, I .T., Abdalla, D. S. P., Damasceno, N. R. T., 2011. Electronegative low-density lipoprotein: Origin and impact on health and disease. Atherosclerosis 215: 257-265.

85. Avogaro, P., Bon, G. B., and Cazzolato G., 1988. Presence of a modified low density lipoprotein in humans. Arterioscler Thromb Vasc Biol. 8:79-87. doi: 10.1161/01.ATV.8.1.79. 
86. Vigolo D., Buzzaccaro, S. and Piazza, R., 2010. Thermophoresis and thermoelectricity in surfactant solutions. Langmuir 26: 7792-7801. 


\section{Anexos}

\section{Anexo I - Resultados complementares referentes à seção 4.1.1}

Neste anexo são apresentados os resultados das análises dos dados de SAXS, empregando o método IFT, para os conjuntos que não foram discutidos no corpo da tese. Os valores de concentração de $\mathrm{CuSO}_{4}$ e dos tempos de reação, empregados na oxidação das amostras LDL, são indicados para cada um dos conjuntos. Todos os valores, para esses parâmetros, podem ser verificados na Tabela 4.1 (seção 4.1.1). Para a apresentação dos dados experimentais das intensidades espalhadas, as curvas correspondentes a cada uma das amostras, foram deslocadas por multiplicação dos valores por um dado fator. O mesmo foi realizado para os ajustes pelo método IFT.

Considerando que as análises dos dados de SAXS, nesse estudo, envolveram o método IFT e a interpretação das curvas $p(r)$ obtidas, será também apresentada, neste anexo, uma descrição mais detalhada desse método, complementar ao que foi apresentado na fundamentação teórica (seção 2.1.1).

Avaliação da relação "tempo de reação x concentração do agente oxidante" na oxidação da $L D L$

\section{Conjunto 1}

Resultados apresentados e discutidos no corpo da tese. 


\section{Conjunto 2}

A Figura I1-A mostra os resultados da evolução temporal, das curvas de espalhamento $(I(q) x q)$, obtidas com a análise das amostras oxidadas a $50 \mu \mathrm{M}$ de $\mathrm{CuSO}_{4}\left(\mathrm{C}_{2}\right)$. Já a Figura I1-B, apresenta as variações das curvas $I(q) \times q$, em função da concentração de $\mathrm{CuSO}_{4}$, para o tempo de reação de $2 \mathrm{~h} 20 \mathrm{~min}\left(\mathrm{t}_{2}\right)$.

A

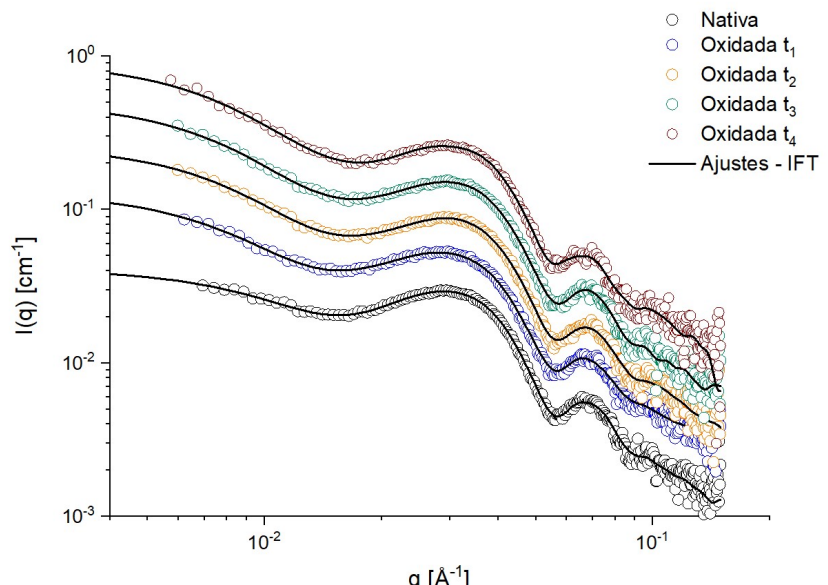

B

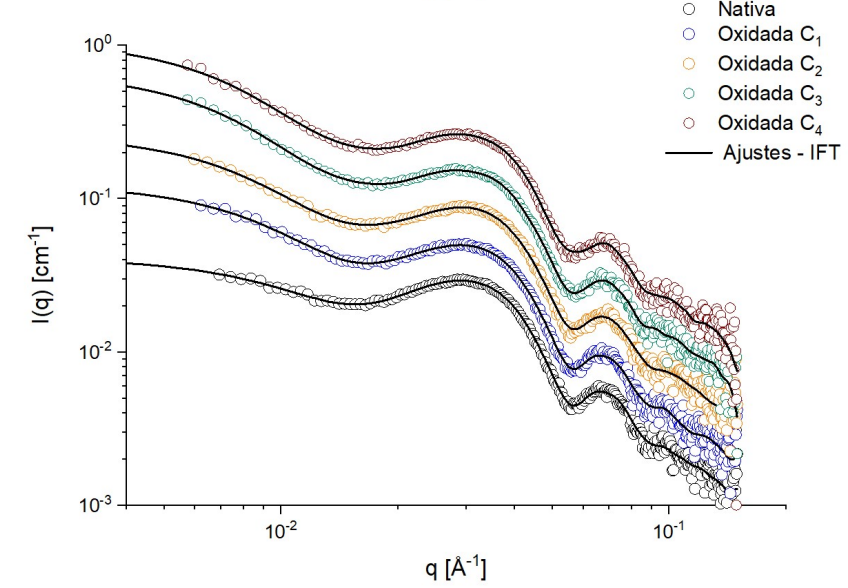

Figura I1. Curvas de espalhamento para as amostras de LDL nativa e oxidadas, nas condições que combinaram $\mathrm{C}_{2}$ e $\mathrm{t}_{2}$. Em (A) é apresentada a evolução temporal das curvas $I(q) \times q$ e em (B) a evolução destas curvas em função da concentração de $\mathrm{Cu}^{2+}$. Os símbolos correspondem aos dados experimentais e, as linhas contínuas, aos ajustes pelo método IFT. 
Quanto às curvas $p(r)$, a Figura I2-A mostra os resultados da evolução temporal das curvas obtidas com a análise das amostras oxidadas a $50 \mu \mathrm{M}$ de $\mathrm{CuSO}_{4}\left(\mathrm{C}_{2}\right)$. A Figura I2-B, apresenta as variações das funções $p(r)$, em função da concentração de $\mathrm{CuSO}_{4}$, para o tempo de reação de 2 h 20 min ( $\left.t_{2}\right)$.

A

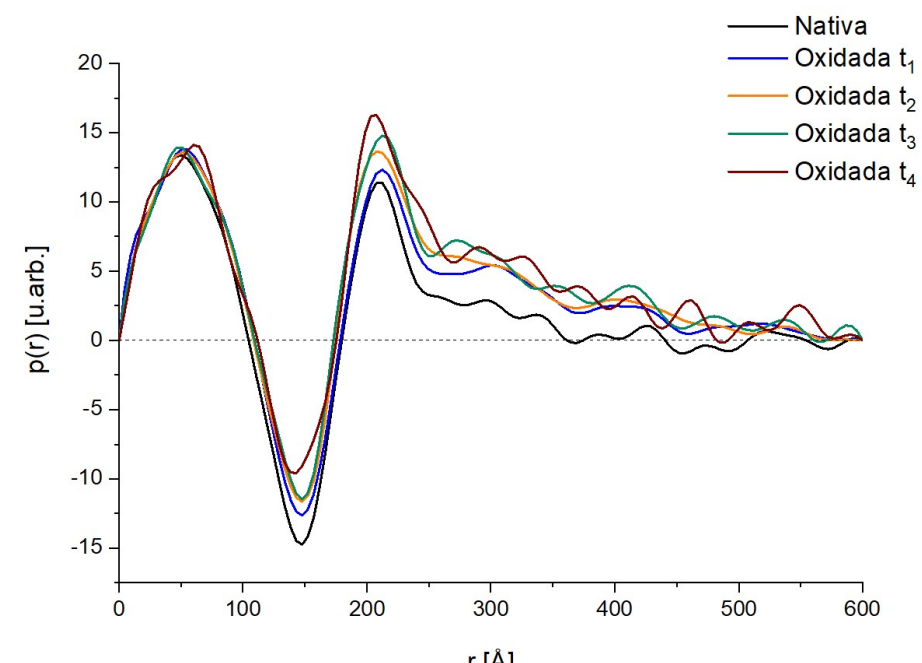

B

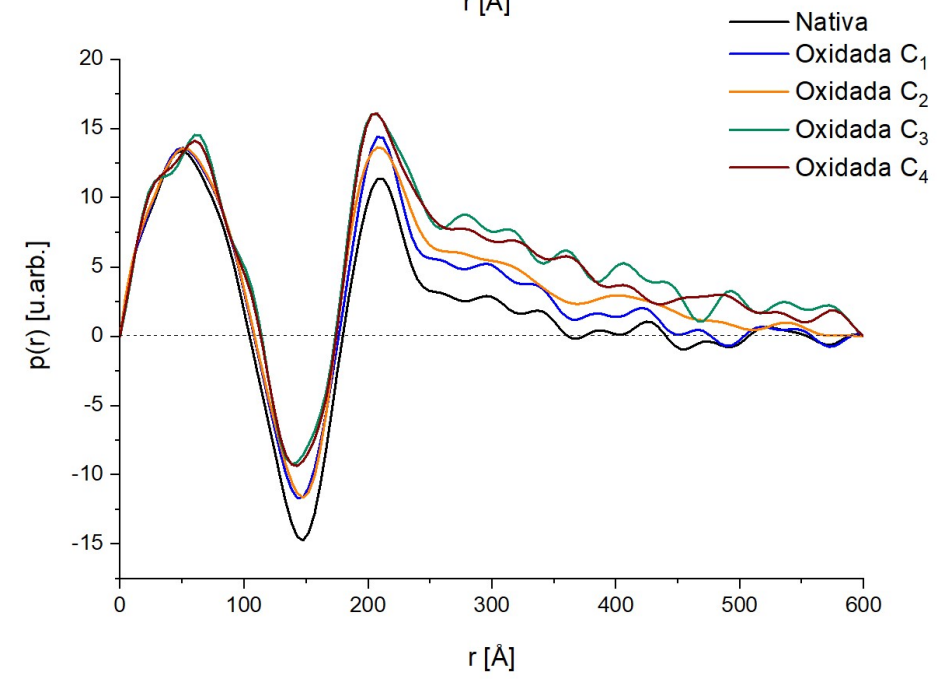

Figura I2. Curvas das funções $p(r)$ para as amostras de LDL nativa e oxidadas, nas condições que combinaram $\mathrm{C}_{2}$ e $t_{2}$. Em (A) é apresentada a evolução temporal das curvas $p(r)$ e em (B) a evolução destas curvas em função da concentração de $\mathrm{Cu}^{2+}$. 


\section{Conjunto 3}

Para o terceiro conjunto de dados, os resultados são apresentados nas Figuras I3 e I4. A Figura I3-A mostra a evolução temporal, das curvas $I(q)$ x $q$, obtidas com a análise das amostras oxidadas a $90 \mu \mathrm{M}$ de $\mathrm{CuSO}_{4}\left(\mathrm{C}_{3}\right)$. Já a Figura $\mathrm{I} 3-\mathrm{B}$, apresenta as variações das curvas $I(q)$ x $q$, em função da concentração de $\mathrm{CuSO}_{4}$, para o tempo de reação de $3 \mathrm{~h} 40$ min $\left(t_{3}\right)$.
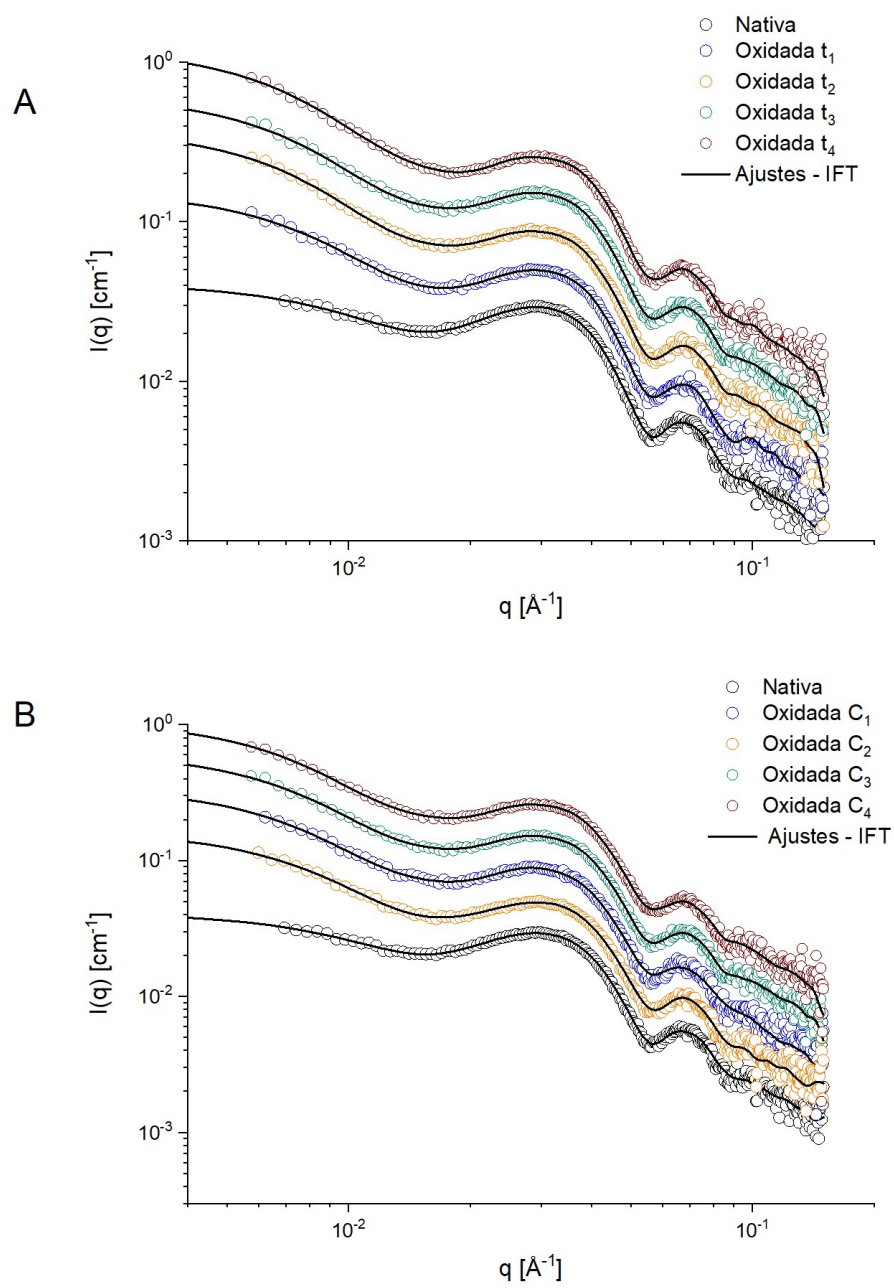

Figura I3. Curvas de espalhamento para as amostras de LDL nativa e oxidadas, nas condições

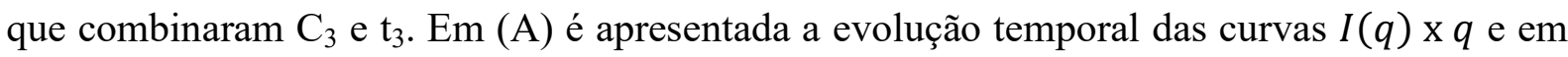
(B) a evolução destas curvas em função da concentração de $\mathrm{Cu}^{2+}$. Os símbolos correspondem aos dados experimentais e, as linhas contínuas, aos ajustes pelo método IFT. 
A Figura I4-A mostra os resultados da evolução temporal das curvas $p(r)$, obtidas com a análise das amostras oxidadas a $90 \mu \mathrm{M}$ de $\mathrm{CuSO}_{4}\left(\mathrm{C}_{3}\right)$. Já a Figura I4-B, apresenta as variações das funções $p(r)$, em função da concentração de $\mathrm{CuSO}_{4}$, para o tempo de reação de $3 \mathrm{~h} 40 \min \left(\mathrm{t}_{3}\right)$.

A

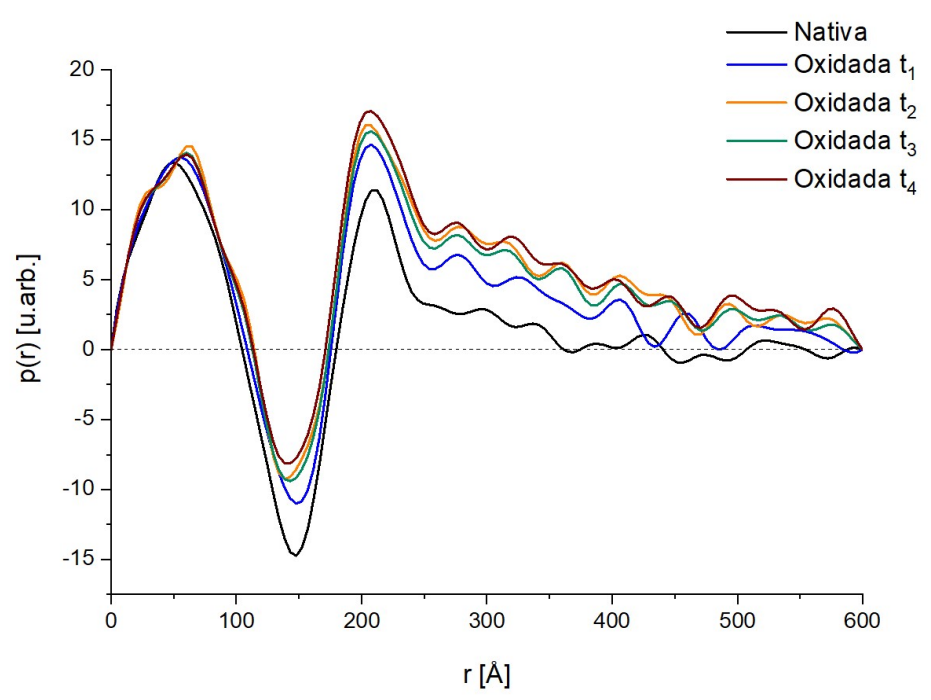

B

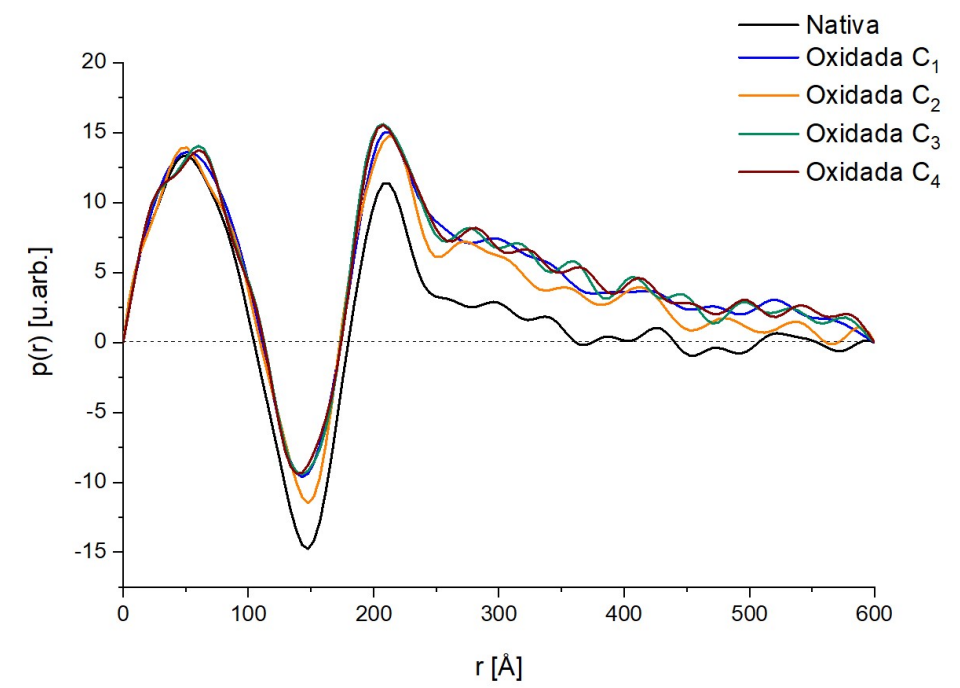

Figura I4. Curvas das funções $p(r)$ para as amostras de LDL nativa e oxidadas, nas condições que combinaram $\mathrm{C}_{3}$ e $\mathrm{t}_{3}$. Em (A) é apresentada a evolução temporal das curvas $p(r)$ e em (B) a evolução destas curvas em função da concentração de $\mathrm{Cu}^{2+}$. 


\section{Conjunto 4}

O quarto conjunto de dados, do ensaio de oxidação, envolveu as condições mais drásticas de reações. Os resultados, mostrados na Figura I5-A, correspondem à evolução temporal das curvas de intensidades espalhadas, obtidas com as análises das amostras oxidadas a $160 \mu \mathrm{M}$ de $\mathrm{CuSO}_{4}\left(\mathrm{C}_{4}\right)$. Já a Figura I5-B, apresenta as variações das curvas $I(q) \times q$, em função da concentração de $\mathrm{CuSO}_{4}$, para o tempo de reação de $6 \mathrm{~h} 45$ min $\left(\mathrm{t}_{4}\right)$.
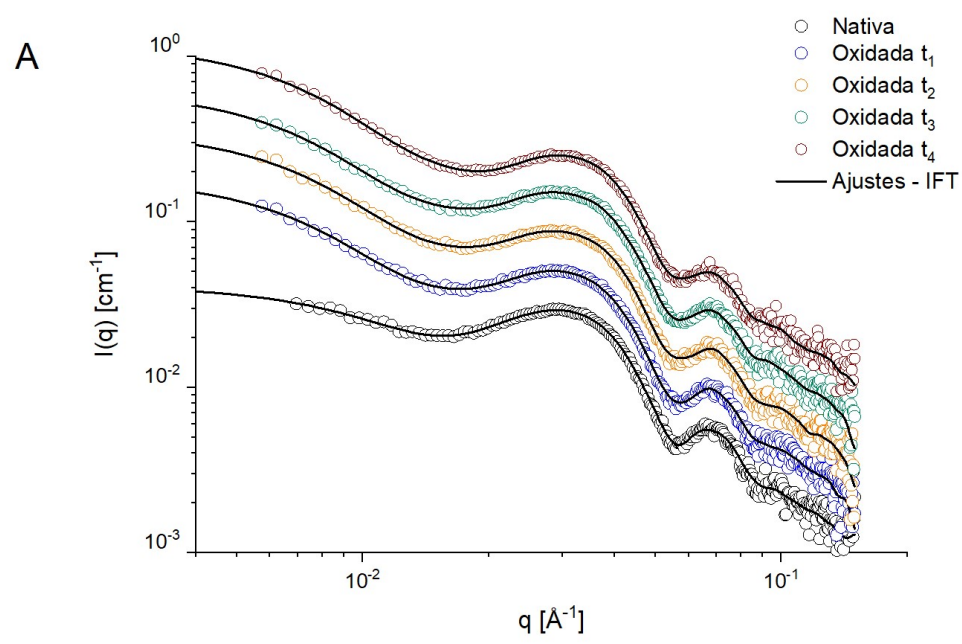

B

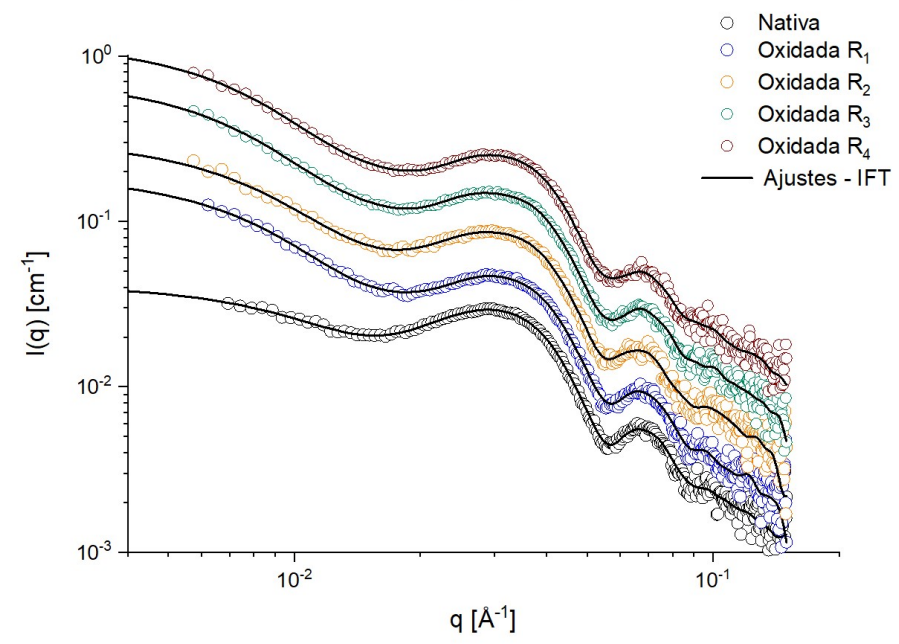

Figura I5. Curvas de espalhamento para as amostras de LDL nativa e oxidadas, nas condições que combinaram $\mathrm{C}_{4}$ e $\mathrm{t}_{4}$. Em (A) é apresentada a evolução temporal das curvas $I(q) \times q$ e em (B) a evolução destas curvas em função da concentração de $\mathrm{Cu}^{2+}$. Os símbolos correspondem aos dados experimentais e, as linhas contínuas, aos ajustes pelo método IFT. 
A Figura I6-A mostra os resultados da evolução temporal das curvas das funções $p(r)$, obtidas com a análise das amostras oxidadas a $160 \mu \mathrm{M}$ de $\mathrm{CuSO}_{4}\left(\mathrm{C}_{4}\right)$. Já a Figura I6-B, apresenta as variações das funções $p(r)$, em função da concentração de $\mathrm{CuSO}_{4}$, para o tempo de reação de6 h 45 min $\left(t_{4}\right)$.

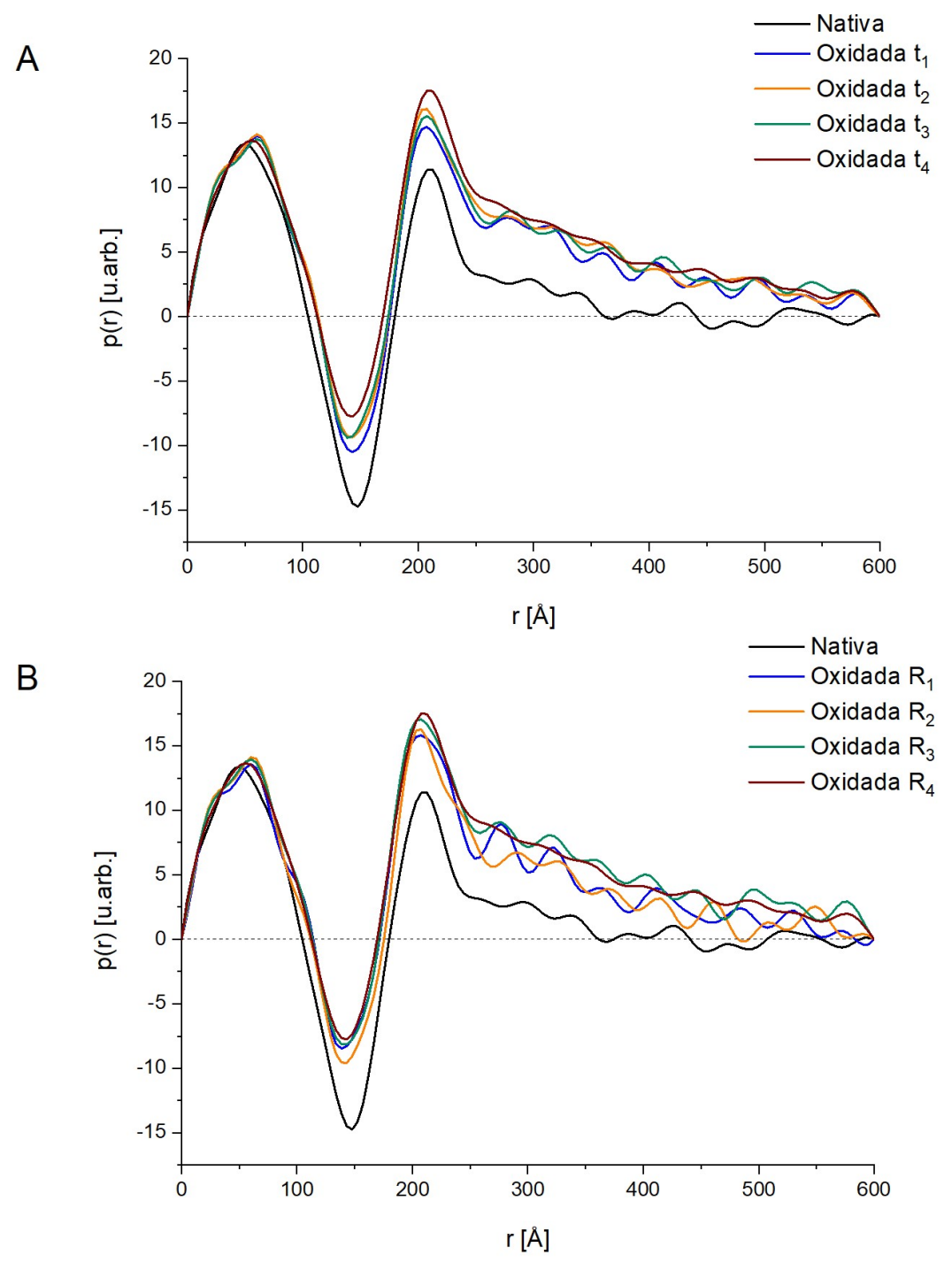

Figura I6. Curvas das funções $p(r)$ para as amostras de LDL nativa e oxidadas, nas condições que combinaram $\mathrm{C}_{4}$ e $\mathrm{t}_{4}$. Em (A) é apresentada a evolução temporal das curvas $p(r)$ e em (B) a evolução destas curvas em função da concentração de $\mathrm{Cu}^{2+}$. 


\section{Método da Transformada de Fourier Indireta (IFT)}

A determinação direta da $p(r)$, pela transformada de Fourier da intensidade espalhada $\mathrm{I}(q)$, possui limitações intrínsecas. Isso porque esta determinação envolve, como visto na equação 2.4 (seção 2.1), uma integração até infinito, enquanto os dados experimentais compõem um intervalo finito. Uma alternativa é a obtenção da $p(r)$ de forma indireta, como no método da transformada de Fourier indireta (IFT).

No método IFT, a $p(r)$ é representada como uma combinação de funções (funções ortogonais $\left.\varphi_{k}\right)$, em um intervalo de $\left[0, \mathrm{D}_{\mathrm{MÁx}}\right]$ :

$$
p(r)=\sum_{n=1}^{K} c_{k} \varphi_{k}\left(q_{i}\right)
$$

Os ajustes dos dados experimentais, nessa abordagem, envolvem a minimização da função

$$
\phi=\chi^{2}+\alpha P(p)
$$

onde

$$
\chi^{2}=\frac{1}{N-1} \sum_{j=1}^{N}\left[\frac{I_{\exp }\left(q_{j}\right)-c I_{\text {calc }}\left(q_{j}\right)}{\sigma\left(q_{j}\right)}\right]^{2}
$$

corresponde à discrepância entre os dados experimentais e os valores calculados pelo modelo e

$$
P(p)=\int_{0}^{D_{M} A X} \frac{d p(r)}{d r} d r
$$

é o termo de suavidade da $p(r)$. O multiplicador de regularização $(\alpha)$ é termo que garante o balanço entre a qualidade do ajuste - primeiro temo da função $\phi$ - e a suavidade da $p(r)$ - segundo temo da função $\phi$. Na equação (5), que define o $\chi^{2}, \mathrm{~N}$ é o número de pontos experimentais, $\sigma$, o desvio padrão e $\mathrm{c}$ o fator de escala.

Em termos da função a $p(r)$, o raio de giro pode ser definido como:

$$
R_{g}=\frac{\int_{0}^{D_{\max }} r^{2} p(r) d r}{2 \int_{0}^{D_{\max x}} p(r) d r}(\mathrm{I} .5)
$$




\section{Anexo II - Aspectos relacionados à oxidação da LDL}

\section{II.1. Peroxidação lipídica}

Como já foi mencionado, estudos mostram que a forma oxidada da LDL é mais aterogênica que sua forma nativa. Embora o mecanismo de oxidação da LDL em organismos vivos não seja totalmente conhecido, sabe-se que esse mecanismo envolve a peroxidação lipídica [1], afetando a porção de lipídios da LDL. A peroxidação lipídica se dá em três etapas: iniciação, propagação e terminação.

Iniciação. Espécies reativas atacam os ácidos graxos poli-insaturados constituintes dos lipídios. Um próton $\left(\mathrm{H}^{+}\right)$é retirado de um grupo metileno do ácido graxo poli-insaturado, formando um radical lipídico $\left(\mathrm{L}^{\bullet}\right)$ que, ao passar por um rearranjo eletrônico, dá origem um dieno conjugado [1].

Propagação. O radical alquila, por combinação com o oxigênio, dá origem a um radical peroxila que reage com um hidrogênio alílico de outro ácido graxo. Nesta reação é formado um radical hidroperóxido lipídico [1].

Terminação. Ocorre a aniquilação dos radicais formados [1]. A Figura II1 mostra um esquema das etapas de iniciação e de propagação da peroxidação lipídica.

\section{II.2. Interiorização do colesterol nas células e o papel da ApoB-100}

A entrada do colesterol nas células se inicia pelo reconhecimento, por partes dos receptores de LDL (LDLr), da apoB-100 constituinte das LDLs circulantes no plasma. Após a ligação da ApoB-100 ao receptor, ocorre um processo de endocitose que engloba a LDL e o seu receptor. O endossomo formado se funde a um lisossomo, cujas enzimas hidrolisam os ésteres de colesterol, resultando na liberação de colesterol e de ácidos graxos para o citosol das células. A ApoB-100 também é degradada nesse processo, liberando o receptor de LDL que retorna para a superfície celular apto a atuar novamente. Quando esse processo supre as necessidades celulares de colesterol, a síntese é reduzida, regulando assim os níveis intracelulares de colesterol [2]. 
Já é consenso que as modificações da LDL são fatores relacionados ao surgimento e à progressão de doenças cardiovasculares [3]. Considerando o papel da ApoB-100, mudanças nessa apolipoproteína impedem o reconhecimento da LDL pelos receptores LDLr [4]. Quando a LDL não é reconhecida pelos LDLr, sua interação se dá com os receptores scavenger, essencialmente localizados nos macrófagos, desencadeando o processo inflamatório relacionado à manifestação da aterosclerose [5]. Além disso, com a ligação da LDL a esse segundo grupo de receptores, não ocorre a regulação dos níveis de colesterol intracelulares [6]. O acúmulo do colesterol intracelular tem sido apontado como um dos fatores de risco para doenças cardiovasculares [7].

Estudos já mostraram que os aldeídos formados na peroxidação lipídica, em decorrência do ataque aos ácidos graxos poli-insaturados da LDL, modificam os resíduos de lisina da ApoB-100 [6]. Haberland et al mostraram que, acima de um determinado nível de modificação desses aminoácidos, a LDL não mais é reconhecida pelos LDLr, e o seu reconhecimento se dá pelos receptores scavenger [8]. A Figura II2 mostra a estrutura de uma molécula do malondialdeído (MDA), apontado como o principal aldeído formado com a oxidação dos lipídios da LDL, e um esquema de sua interação com as lisinas da ApoB-100, resultando na formação de uma base de Shiff $[9,10]$.
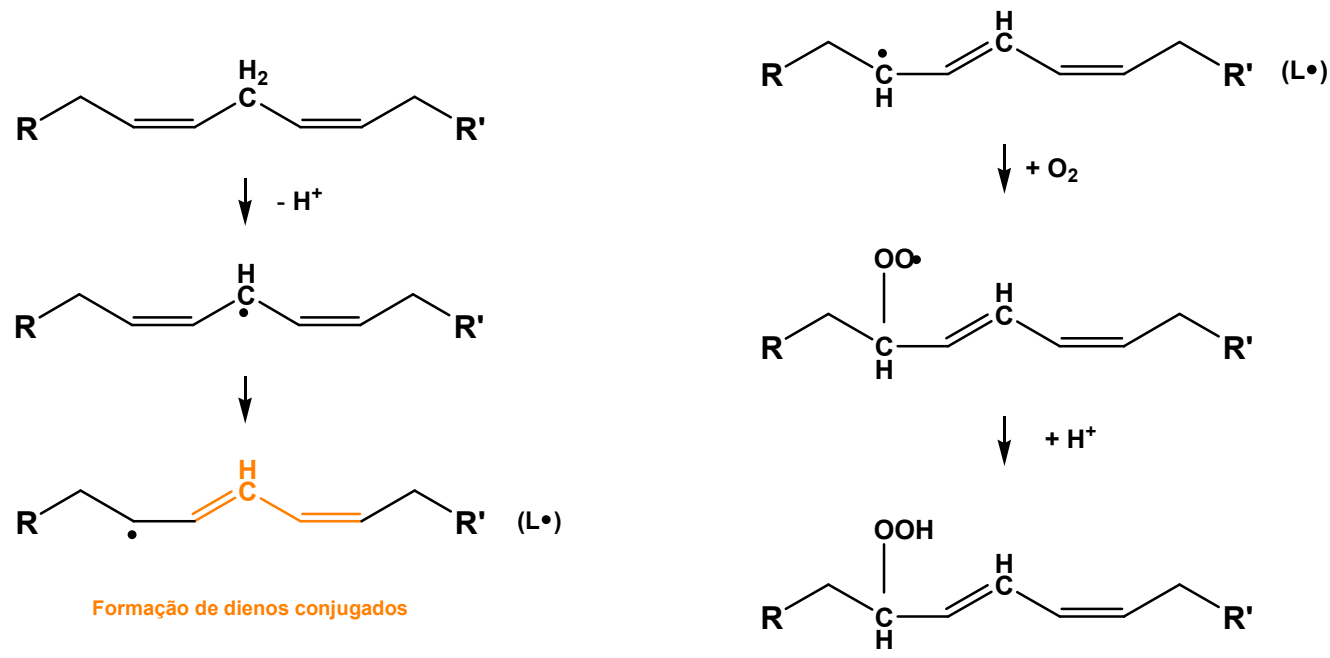

Figura II1. Esquema das etapas de iniciação e de propagação da peroxidação lipídica. 


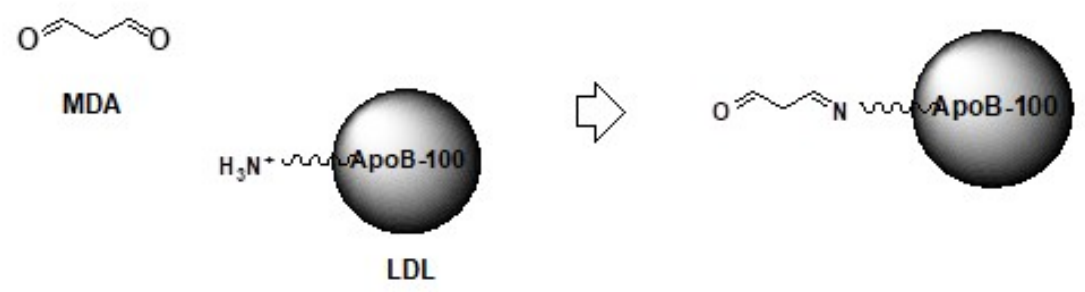

Figura II2. Estrutura de uma molécula do malondialdeído (MDA), $\mathrm{CH}_{2}(\mathrm{CHO})_{2}$, produto da peroxidação lipídica da LDL, e um esquema ilustrativo da formação de uma base de Shiff, entre um grupo aldeído (CHO) do MDA, e um grupamento amina $\left(\mathrm{H}_{3} \mathrm{~N}^{+}\right)$de uma lisina da ApoB-100. Esquema meramente ilustrativo, no qual as representações da LDL e da ApoB-100 não refletem aspectos conformacionais.

1. Lima, E. S., Abdalla, D. S. P. 2001. Peroxidação lipídica: mecanismos e avaliação em amostras biológicas. Brazilian Journal of Pharmaceutical Sciences. 37: 293-303.

2. Lehninger Principles of Biochemistry. David L. Nelson \& Michael M. Cox, 3 ed. W.H. Freeman and Company, New York, 2000.

3. Steinberg, D. 2009. The LDL modification hypothesis of atherogenesis: an update. J. Lipid Res. 376-81.

4. Alique, m., Luna, C., Carracedo, J., Ramírez, R. 2015. LDL biochemical modifications: a link between atherosclerosis and aging. Food \& Nutrition Research, 59: 29240.

5. Moore, K. J., Freeman, M. W.Scavenger. 2006. Receptors in Atherosclerosis Beyond Lipid Uptake. Arterioscler Thromb Vasc Biol. 26: 1702-11.

6. Haberland, M. E., Olch, C. L., Folgelman, A. 1984. Role of Lysines in Mediating Interaction of Modified Low Density Lipoproteins with the Scavenger Receptor of Human Monocyte Macrophages. Journal of biological chemistry. 259: 11305-11.

7. Go, G., Mani, A. 2012. Low-density Lipoprotein receptor (LdLr) Family orchestrates cholesterol Homeostasis. Journal of biology and medicine. 85: 19-28.

8. Haberland, M. E., Folgelman, A, Edwards, P. A. 1982. Specificity of receptor-mediated recognition of malondialdehydemodified low density lipoproteins. Proc. NatL Acad. Sci. Biochemistry. 79: 1712-16.

9. Hoff, H. F, O’Neil, J. 1993. Structural and functional changes in LDL after modification with both 4-hydroxynonenal and malondialdehyde. Journal of Lipid Research. 34

10. Gillotte et al. 2000. Oxidized phospholipid adducts as ligands for macrophage recognition. Journal of Lipid Research. 41 


\section{Anexo III - Controles para os experimentos ópticos}

Considerando o princípio dos experimentos ópticos realizados no presente trabalho, algumas avaliações foram realizadas a fim de confirmar a não interferência, das soluções e dos processos de diálise e filtração, em tais experimentos. Inicialmente foram adquiridos os dados de espectroscopia UV-vis para as soluções empregadas nas diálises. Os espectros para soluções de diálise sem EDTA e com EDTA são mostrados na Figura III-1.
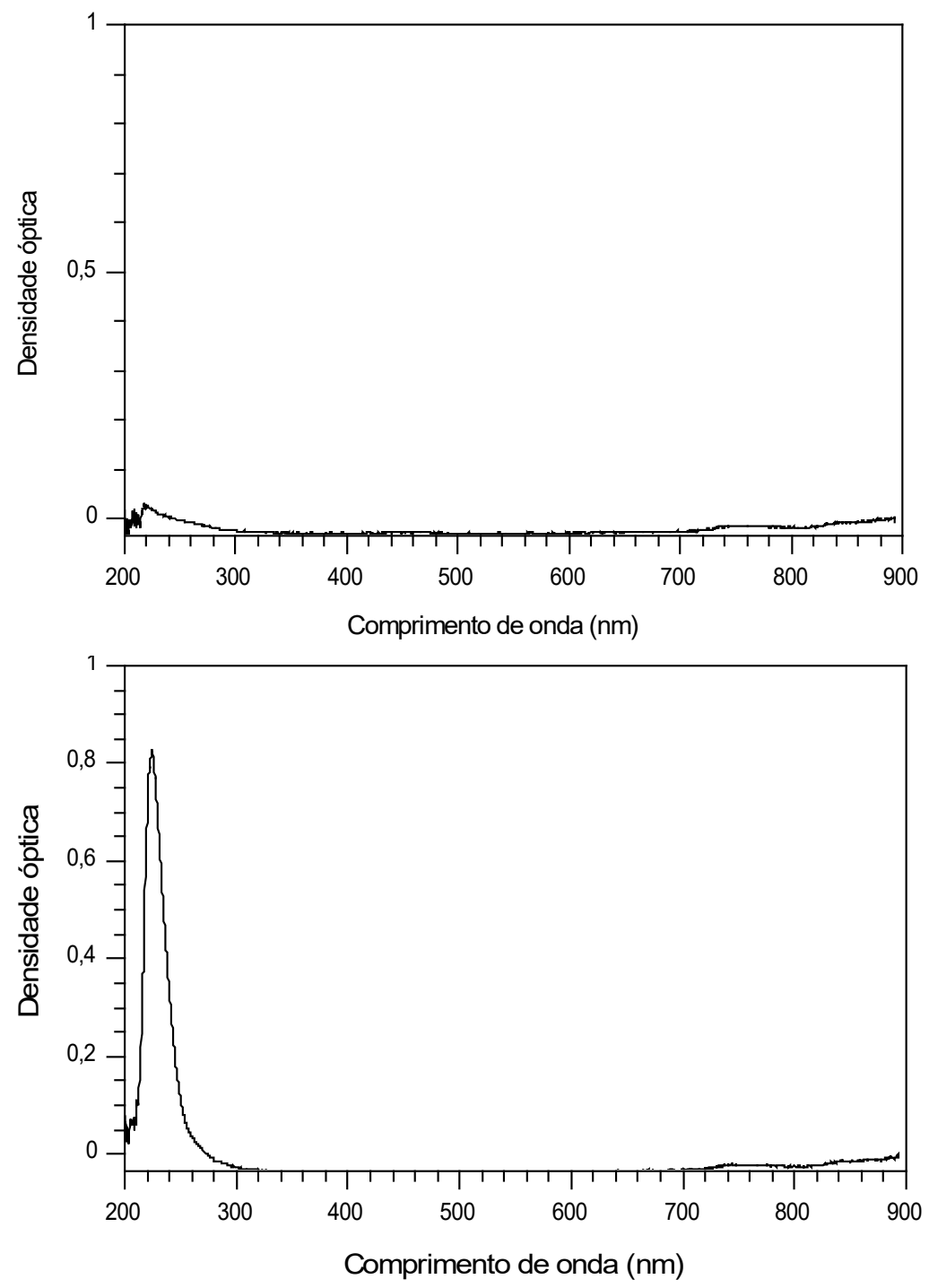

Figura III-1. Resultados da espectroscopia UV-vis para uma amostra de solução fosfato-salina sem EDTA em sua composição (A) e uma solução contendo EDTA a $1 \mathrm{mM}$ (B), sugerindo um pico de absorção devido a este componente. 
Os espectros mostram que não há contribuição proveniente dos sais, no entanto, a presença do EDTA parece gerar um pico de absorção na região de 230-240 nm, como mostram os resultados na Figura III-1. Com base nisso, para confirmar a contribuição associada ao EDTA, foi adquirido o espectro apenas da solução de EDTA, mostrado na Figura III-2. Esses resultados comprovam que não há nenhuma absorção nas amostras, além da das partículas de LDL, no comprimento de onda do laser utilizado nos experimentos ópticos.

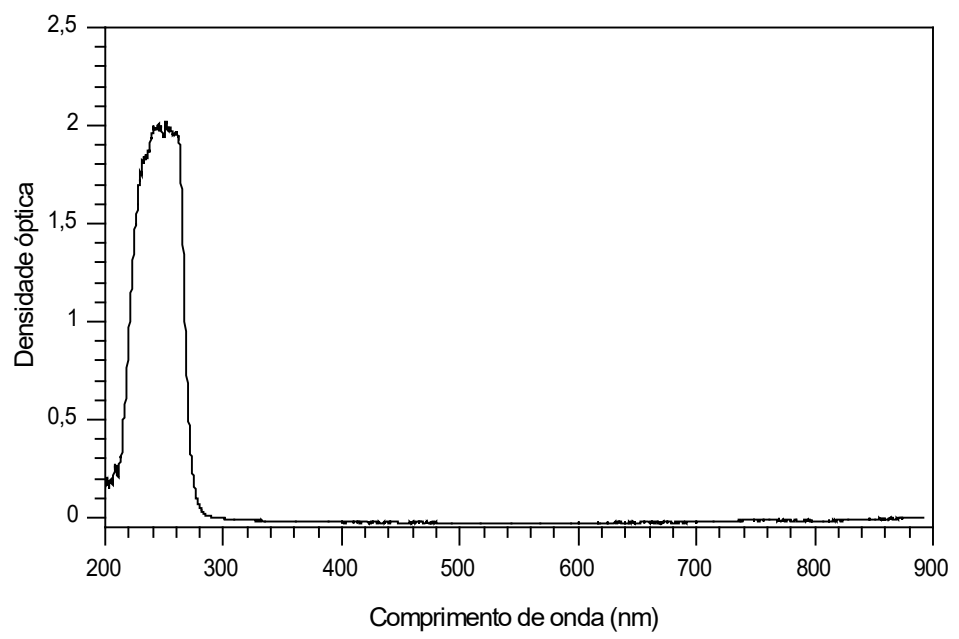

Figura III-2. Resultados da espectroscopia UV-vis para a solução de EDTA a 500 mM.

Outro controle realizado esteve voltado às etapas de diálise e filtração das amostras de LDL. Embora tais processos sejam usuais no preparo de amostras, inclusive de lipoproteínas, foi realizada uma avaliação do impacto destas etapas, sobretudo no perfil do espectro de absorção dessas amostras. Foram adquiridos os espectros para uma mesma amostra de LDL obtida pela ultracentrifugação sequencial (US), antes e após esta ser dialisada e filtrada. Os resultados são apresentados na Figura III-3. 


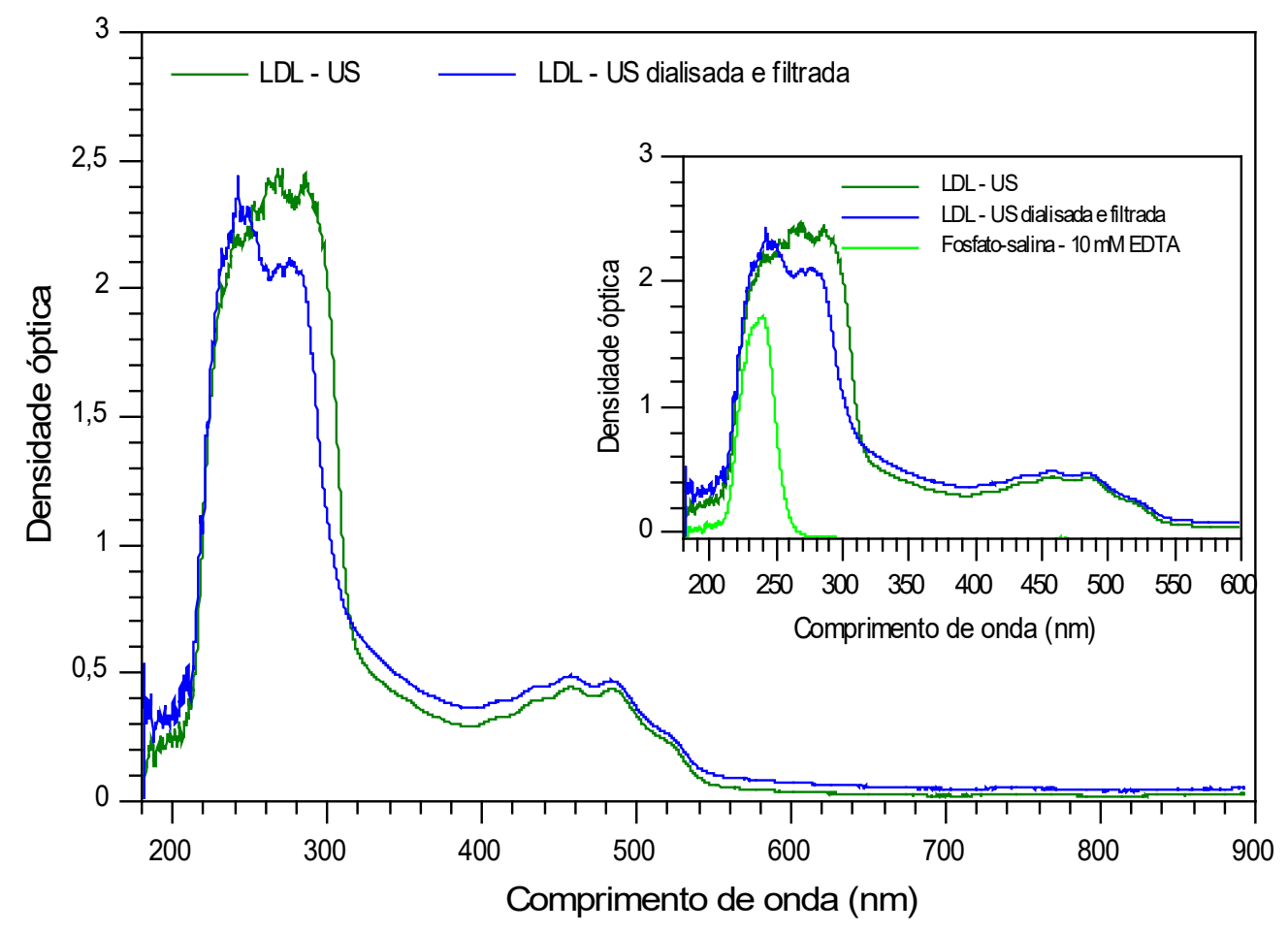

Figura III-3. Resultados da espectroscopia UV-vis para a amostra de LDL separada por ultacentrifugação sequencial, antes dos processos de diálise e filtração (LDL - US) e após diálise e filtração (LDL - US dialisada e filtrada). O inset mostra os resultados em comparação ao tampão fosfato-salina com EDTA a 10mM.

Os resultados mostraram espectros semelhantes para as amostras antes e após diálise e filtração. Parece haver uma redução dos valores de absorbância na região inicial do espectro, indicando uma possível redução de tocoferóis nas partículas de LDL. Além disso, ainda nesta região de menores comprimentos de onda, é visível um pico que parece ser correspondente à presença do EDTA utilizado na diálise, como mostra o inset da Figura III-3. Já a partir de 320 $\mathrm{nm}$ a diferença entre os resultados parece estar associada a um maior espalhamento gerado pelas partículas na amostra dialisada e filtrada. Removendo-se a contribuição do espalhamento, como mostrado no espectro de absorção da Figura III-4, os espectros são muito semelhantes para a faixa de 350 a $600 \mathrm{~nm}$, que é usualmente considerada nos trabalhos do nosso grupo, por ser referente aos antioxidantes carotenoides e por englobar o comprimento de onda do laser utilizado nos experimentos ópticos, $532 \mathrm{~nm}$. 


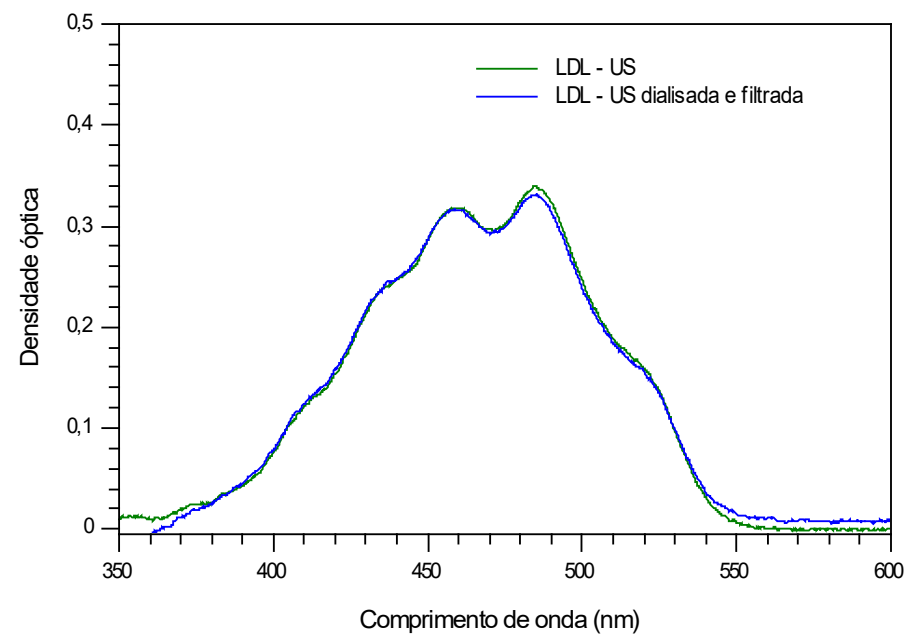

Figura III-4. Espectros de absorção para a amostra de LDL separada por ultacentrifugação sequencial (US), antes dos processos de diálise e filtração (LDL - US) e após diálise e filtração (LDL - US dialisada e filtrada).

Esses resultados estão em conformidade com um trabalho de Chopra et al [1] no qual os autores mostraram que, em condições semelhantes as adotadas para nosso trabalho, não há grandes decréscimos no conteúdo de antioxidantes tocoferóis e carotenóides da LDL, em decorrência da diálise dessas amostras. Embora haja diferenças entre as metodologias adotadas no presente trabalho e no referido artigo, ambas incluem a diálise em solução contendo o EDTA, para agir como antioxidante.

1. Chopra, M., Fitzsimons, P., Hopkins, M., Thurnham, D. I. Dialysis and Gel Filtration of Isolated Low Density Lipoproteins Do Not Cause a Significant Loss of Low Density Lipoprotein Tocopherol and Carotenoid Concentration Lipids, Vol. 36, no. 2 (2001) 205209. 